Supporting information for

\title{
Multiresponsive Cyclometalated Crown Ether Bearing a Platinum(II) Metal Center
}

Miguel A. Soto, ${ }^{a}$ Veronica Carta, ${ }^{a}$ Maria T. Cano, ${ }^{a}$ Ryan J. Andrews, ${ }^{a}$ Brian O. Patrick, ${ }^{a}$ and Mark J. MacLachlanabc*

a Department of Chemistry, University of British Columbia, 2036 Main Mall, Vancouver, British Columbia V6T 1Z1, Canada

${ }^{b}$ Quantum Matter Institute, University of British Columbia, 2355 East Mall, Vancouver, BC, V6T 1Z4 Canada c WPI Nano Life Science Institute, Kanazawa University, Kanazawa, 920-1192 Japan 


\section{Table of contents}

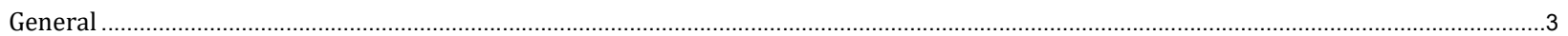

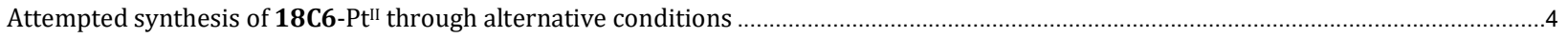

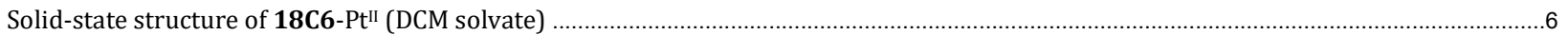

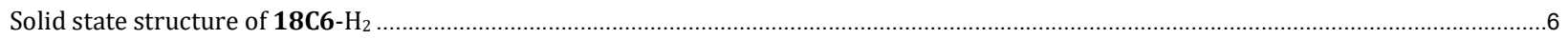

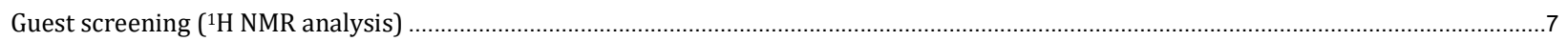

Affinity analyses

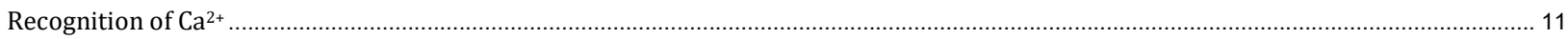

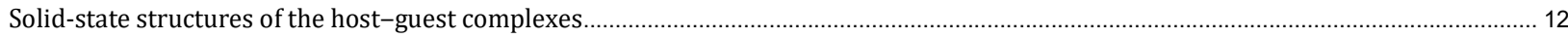

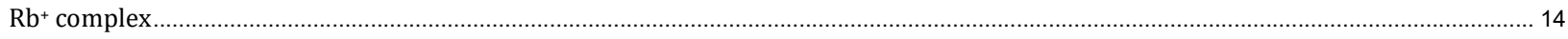

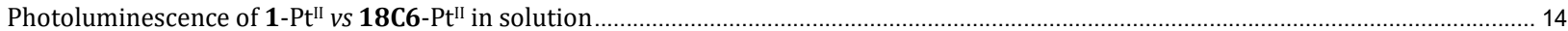

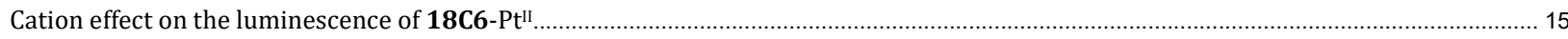

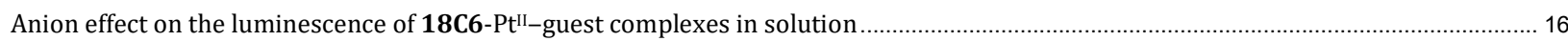

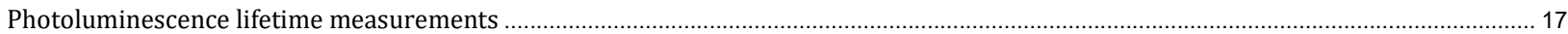

Packing of 18C6-PtII dimers in the solid state

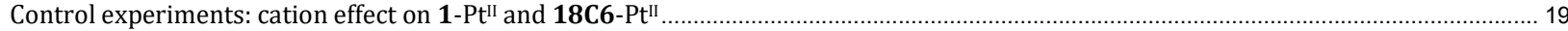

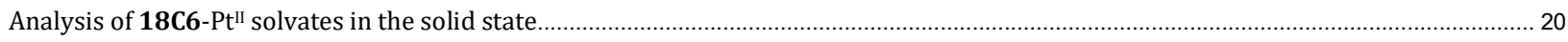

18C6-PtII and its interaction with $\mathrm{AcOH}$

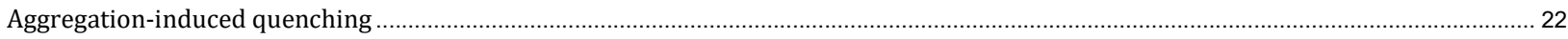

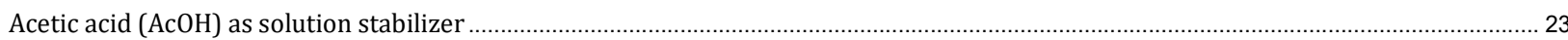

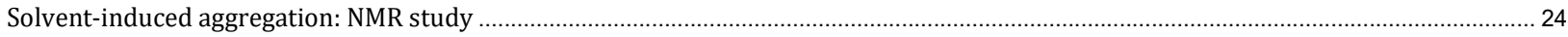

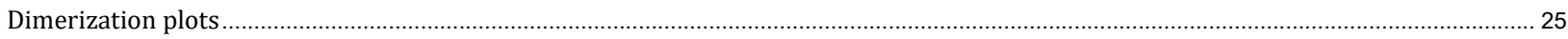

Cation-prevented aggregation ………

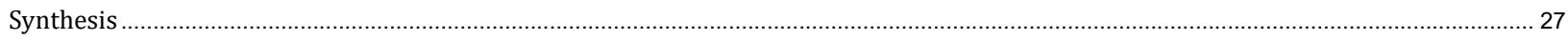

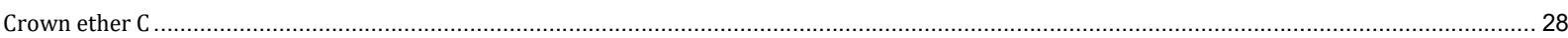

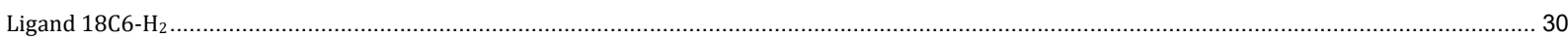

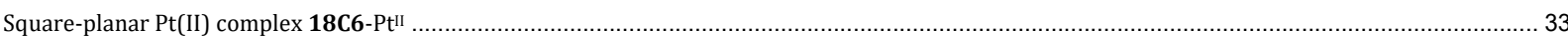

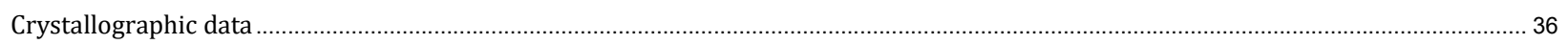

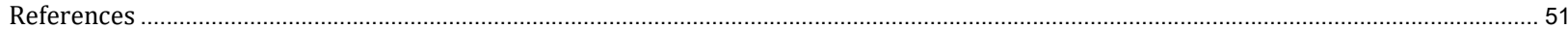




\section{General}

All commercially available chemicals were used without further purification (purchased from Oakwood Chemical and Sigma-Aldrich). Dry tetrahydrofuran (THF) was collected from an Inert PureSolv MD5 purification system. Deuterated solvents (DCM- $d_{2}$, chloroform- $d$, water- $d_{2}$ and MeCN$d_{3}$ ) were purchased from Sigma-Aldrich and Cambridge Isotope Laboratories. Flash column chromatography was conducted using SiliCycle (230-400 mesh) silica gel as the stationary phase. Nuclear magnetic resonance (NMR) experiments were recorded on Bruker AVIII HD $400 \mathrm{MHz}$ and Bruker Avance $400 \mathrm{MHz}$ spectrometers; ${ }^{1} \mathrm{H}$ and ${ }^{13} \mathrm{C}$ NMR chemical shifts $(\delta)$ are given in parts per million (ppm) relative to TMS, using the residual solvent signal for calibration. $J$ values are reported in $\mathrm{Hz}$, signal multiplicity is denoted as s (singlet), $\mathrm{d}$ (doublet), $\mathrm{t}$ (triplet), $\mathrm{m}$ (multiplet) and br (broad signal). All UV-vis data were collected on a Cary 5000 UV-vis-NIR spectrophotometer, using $10 \mathrm{~mm}$ pathlength quartz cuvettes. Photoluminescence spectra were collected on a Photon Technology International (PTI) QuantaMaster 50 fluorimeter fitted with a double excitation monochromator and utilizing a $75 \mathrm{~W}$ Xe arc lamp as the light source. Solution and solid-state measurements were conducted using $10 \mathrm{~mm}$ pathlength quartz cuvettes and glass slides, respectively. High-resolution mass spectra (HRMS) were recorded on an ESI-TOF Waters Micromass LCT spectrometer. Luminescence life-time measurements were conducted on a PTI/Horiba QuantaMaster 400, using a $350 \mathrm{~nm}$ nanosecond LED excitation laser. All samples were prepared in previously degassed MeCN. Powder X-ray diffraction data (PXRD) were collected on a General Area Detector Diffraction System (GADDS).

Compounds A, ${ }^{1} \mathbf{B},{ }^{1}$ 1-PtII, ${ }^{1}$ and tetraethylene glycol ditosylate ${ }^{2}$ were synthesized according to previous methodologies. The collected spectroscopic data ( ${ }^{1} \mathrm{H}$ NMR and MS) matched well with those reported. 


\section{Attempted synthesis of 18C6-PtII through alternative conditions}

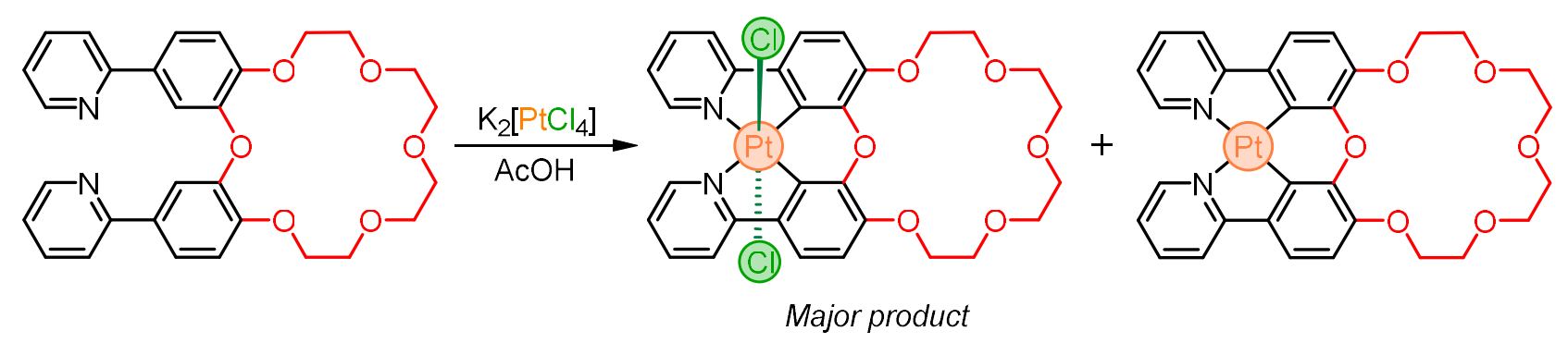

Scheme S1. Alternative synthesis of complex 18C6-PtII.

A flask containing ligand 18C6- $\mathrm{H}_{2}(26.3 \mathrm{mg}, 0.04 \mathrm{mmol}), \mathrm{K}_{2}\left[\mathrm{PtCl}_{4}\right](14.9 \mathrm{mg}, 0.04 \mathrm{mmol})$ and $\mathrm{Bu}_{4} \mathrm{NBr}$ (1.3 mg, $0.004 \mathrm{mmol}$ ) was evacuated and backfilled with $\mathrm{N}_{2}$ three times, followed by the addition of previously sparged $\left(\mathrm{N}_{2}\right) \mathrm{AcOH}(5 \mathrm{~mL})$. The obtained suspension was further degassed under vacuum, backfilled with $\mathrm{N}_{2}$ (three times), and heated at $110{ }^{\circ} \mathrm{C}$ for $24 \mathrm{~h}$ under a $\mathrm{N}_{2}$ atmosphere. After cooling the system to room temperature, water $(10 \mathrm{~mL})$ was added, and the solution was extracted with DCM $(3 \times 15 \mathrm{~mL})$. All combined organic layers were dried $\left(\mathrm{Na}_{2} \mathrm{SO}_{4}\right)$ and evaporated under vacuum to yield a dark yellow solid that was washed with MeCN (15 mL). ${ }^{1} \mathrm{H}$ NMR analysis (Figure S1a) of the crude material revealed full conversion of the ligand into 18C6-Pt $\mathrm{t}^{\mathrm{II}}(23 \%)$ and $18 \mathrm{C6}-\mathrm{Pt}^{\mathrm{IV}}(77 \%)$. Crystals of 18C6- $\mathrm{Pt}^{\mathrm{IV}}$ suitable for SCXRD analysis were obtained through slow vapor diffusion of hexanes into a solution of 18C6- $\mathrm{Pt}^{\mathrm{IV}}$ in DCM; the corresponding solid-state structure is shown in Figure S1b,c. 
a

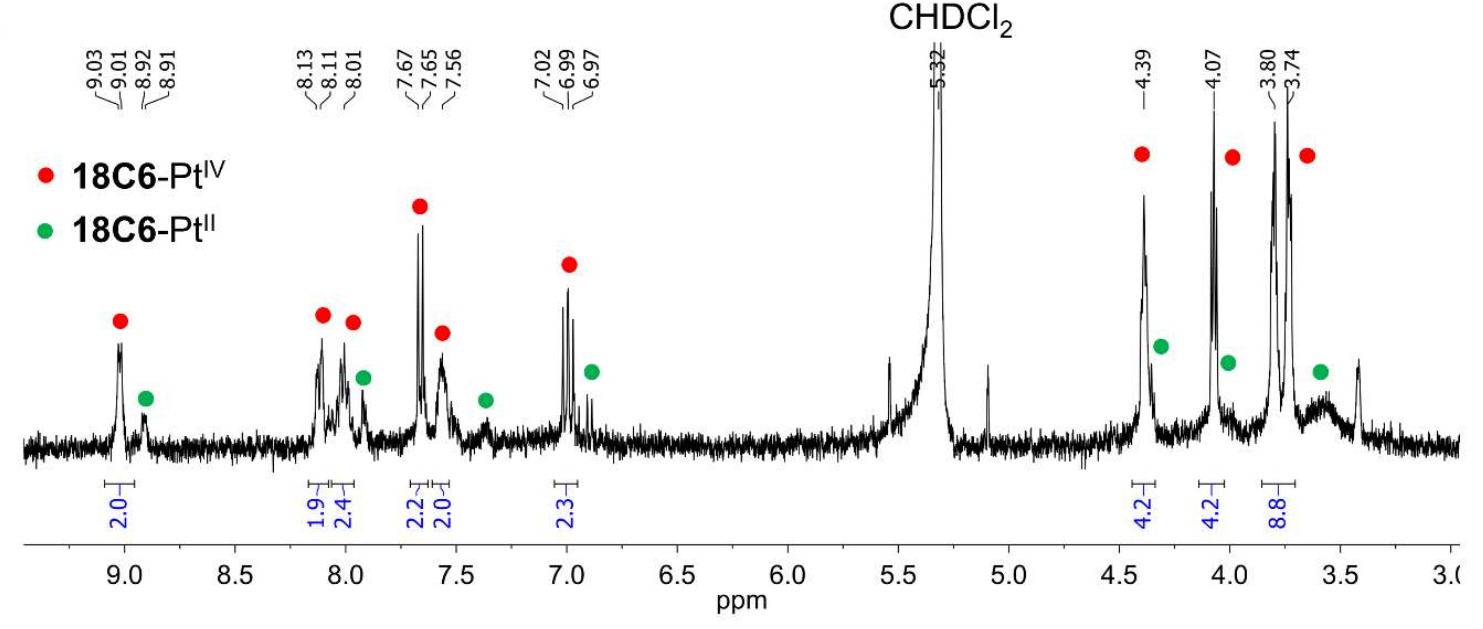

b
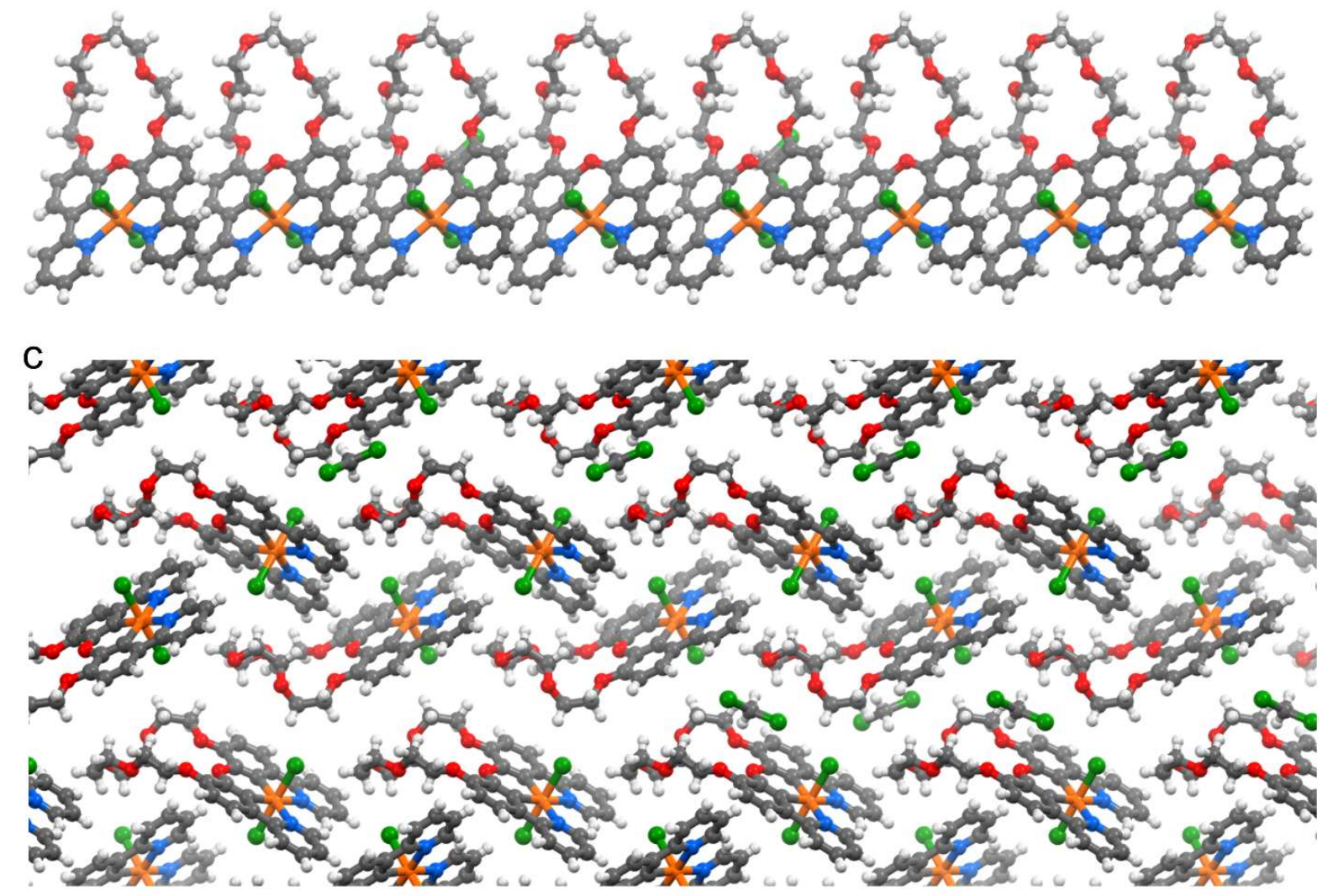

Figure S1. ${ }^{1} \mathrm{H}$ NMR spectrum ( $400 \mathrm{MHz}$, DCM- $d_{2}$ ) of a crude reaction mixture containing complexes 18C6-Pt $\mathrm{t}^{\mathrm{II}}$ and $18 \mathrm{C6}$ $\mathrm{Pt}^{\mathrm{IV}}$. Crystal structure of 18C6-PtIV visualized along the crystallographic axis (b) $a$, and (c) $b$. 


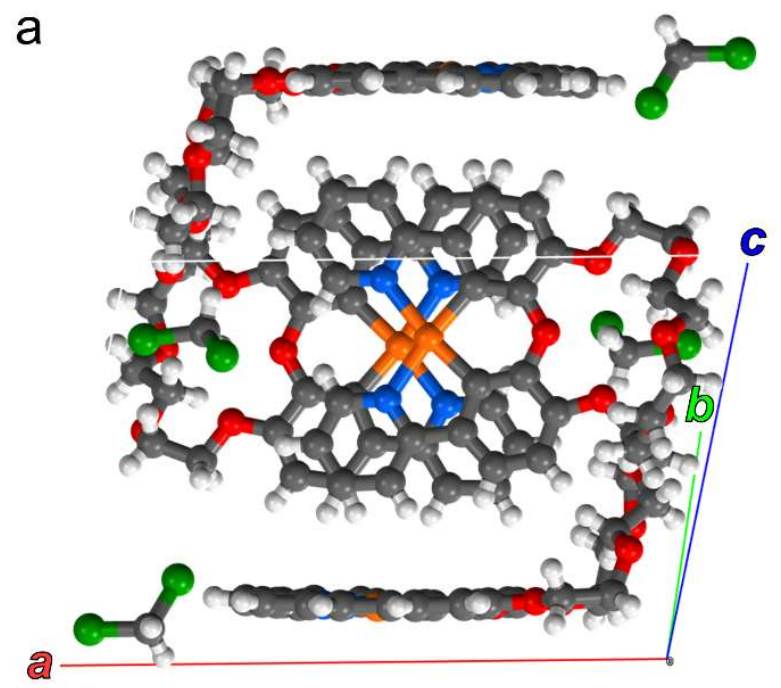

b

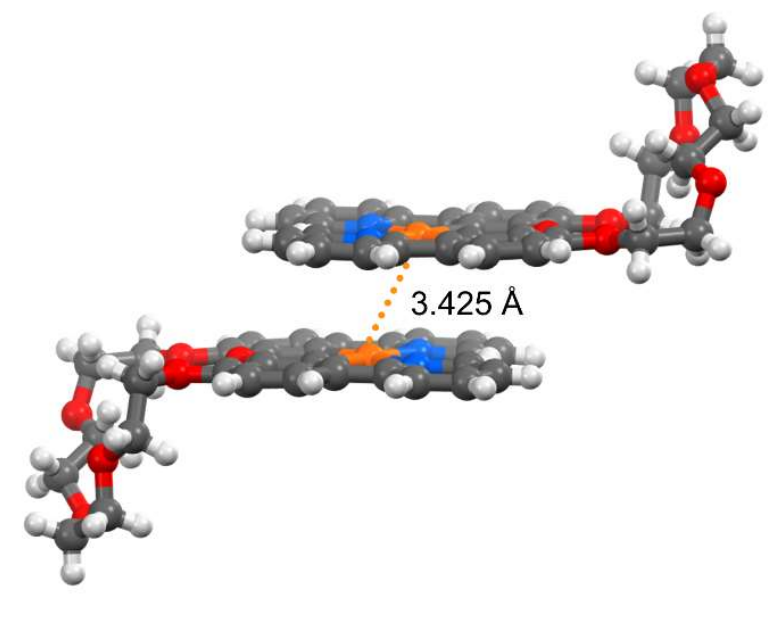

Figure S2. Solid-state structure of complex 18C6- $\mathrm{Pt}^{\mathrm{II}}$. (a) Packing (b) dimeric structure within the unit cell.

\section{Solid state structure of $18 \mathrm{C} 6-\mathrm{H}_{2}$}

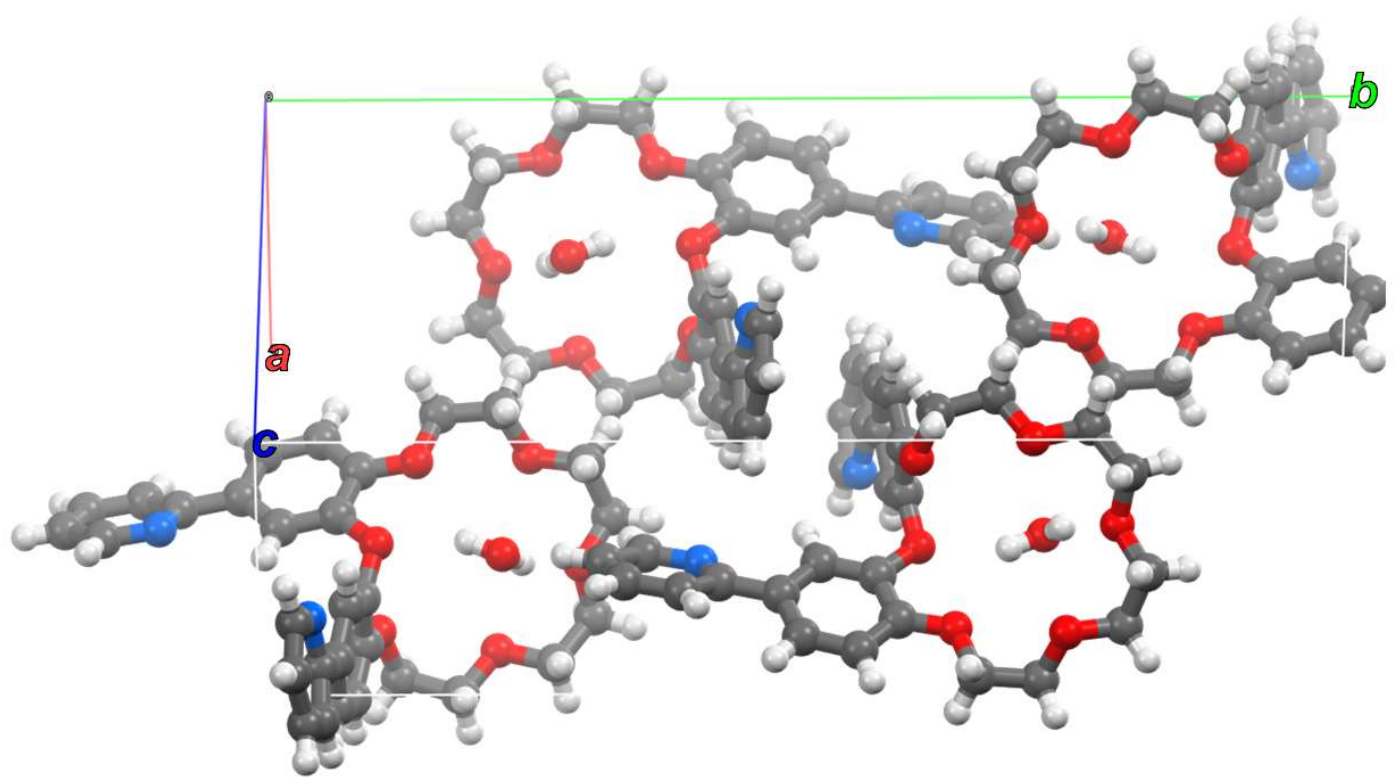

Figure S3. Solid-state structure of ligand 18C6- $\mathrm{H}_{2}$. 


\section{Guest screening ( ${ }^{1} \mathrm{H}$ NMR analysis)}
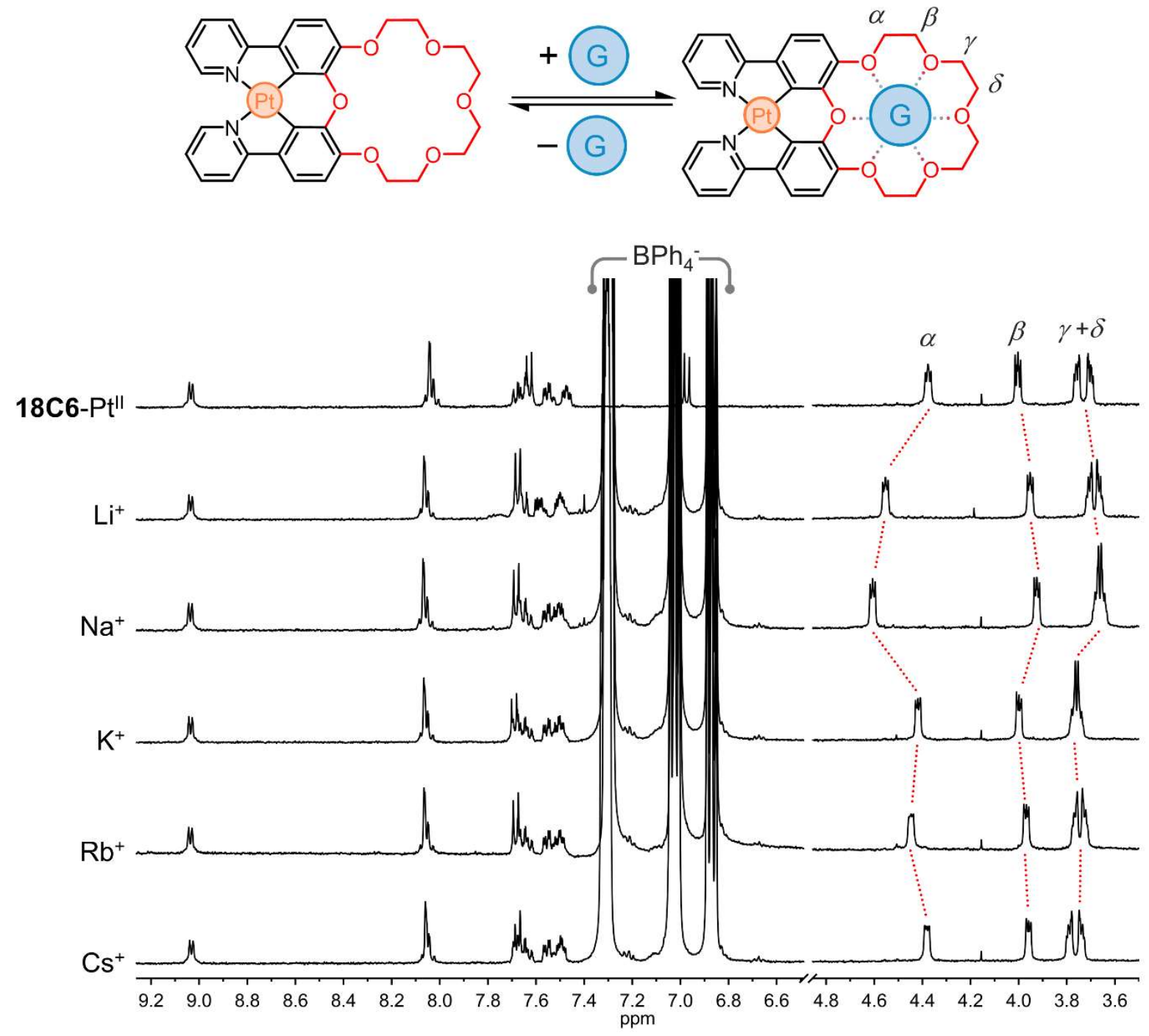

Figure S4. ${ }^{1} \mathrm{H}$ NMR spectra $\left(\mathrm{MeCN}-d_{3}, 400 \mathrm{MHz}\right)$ of host $18 \mathrm{C6}-\mathrm{Pt}{ }^{\mathrm{II}}\left(1.5 \times 10^{-3} \mathrm{M}\right)$ and its mixtures with alkali cations $(10$ equiv) as tetrafluoroborate salts $\left(\mathrm{BPh}_{4}^{-}\right)$. 


\section{Affinity analyses}

Complex 18C6-PtII was titrated with solutions of $\mathrm{LiPF}_{6}, \mathrm{NaPF}_{6}$, and $\mathrm{KPF}_{6}$. All experiments were performed at $\left[18 \mathrm{C} 6-\mathrm{Pt}^{\mathrm{II}}\right]=9.5 \times 10^{-5} \mathrm{M}$ and [guest $]=2.0 \times 10^{-2} \mathrm{M}$. For $\mathrm{Ca}^{2+}$, the concentrations were $9.5 \times 10^{-5} \mathrm{M}$ and $1.0 \times 10^{-3} \mathrm{M}$ for $18 \mathrm{C6}-\mathrm{PtII}^{\mathrm{II}}$ and $\mathrm{Ca}(\mathrm{OTf})_{2}$, respectively. Titrations were performed in MeCN at $25{ }^{\circ} \mathrm{C}$, in triplicate, and monitored through UV-vis spectroscopy. Representative data are shown in Figure S5 to Figure S8. The resulting isotherms (monitored at $380 \mathrm{~nm}$ ) were then fit by a nonlinear least-squares method with the BindFit platform (supramolecular.org) and using a 1:1 global fitting model (Nelder-Mead method) to estimate the corresponding affinity constants $\left(K_{\mathrm{a}}\right)$. Values of $K_{\mathrm{a}}$ and $\Delta G_{\mathrm{a}}$ (obtained through Eq. 1.) are summarized in Table S1. In all cases, we observed a concomitant decrease in the intensity of the monitored band (380 nm) upon the addition of salts. For $\mathrm{Na}^{+}, \mathrm{K}^{+}$, and $\mathrm{Ca}^{2+}$, we also detected a hypsochromic shift (ca. $5 \mathrm{~nm}$ ); suggesting a slight decrease in the electro-donating character of the crown ether after complexation. These changes occur near to two isosbestic points, which implies interconversion between two species in solution (free and complex).

Eq. $1 \Delta G_{\mathrm{a}}=-R T \ln K_{\mathrm{a}}$
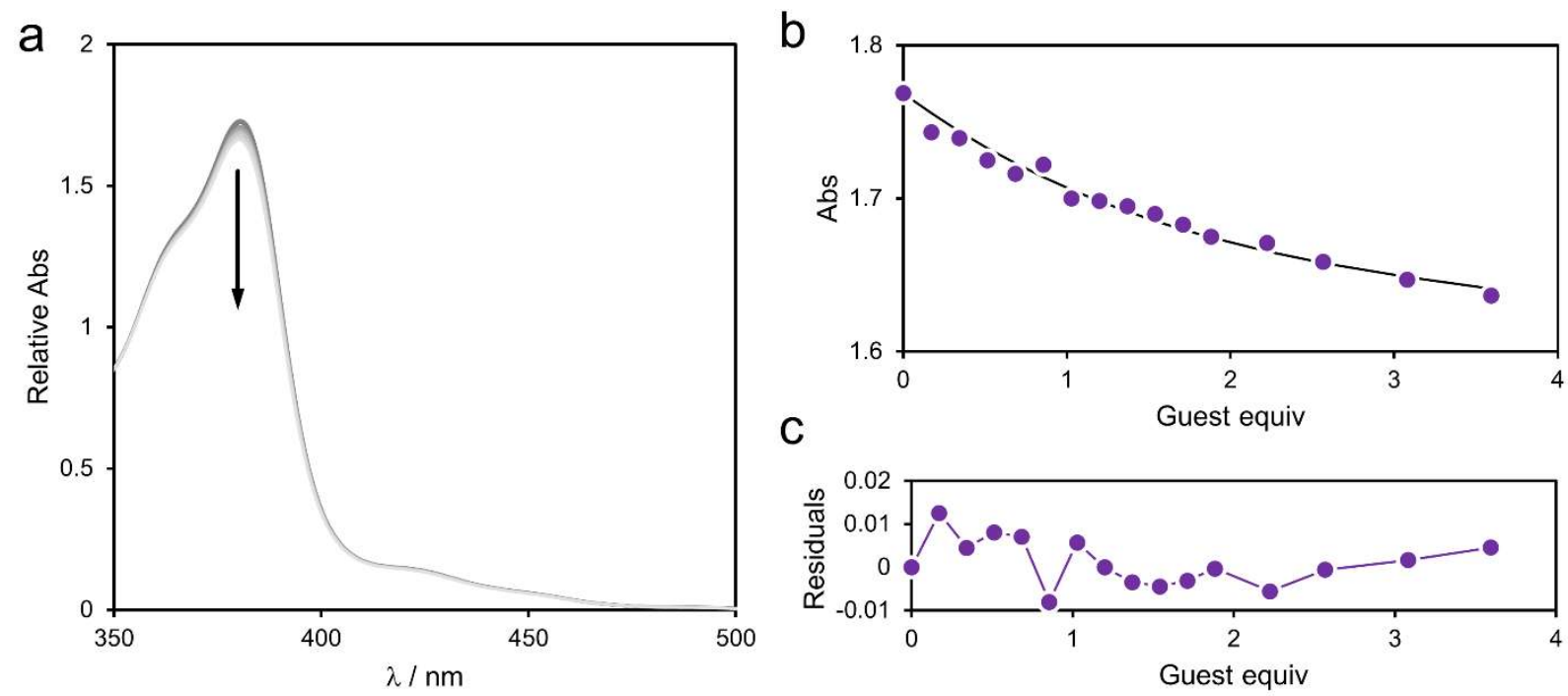

Figure S5. (a) UV-vis titration of 18C6-PtII $\left(9.5 \times 10^{-5} \mathrm{M}\right)$ with $\mathrm{LiPF}_{6}\left(2.0 \times 10^{-2} \mathrm{M}\right)$ in $\mathrm{MeCN}$ at $25^{\circ} \mathrm{C}$. (b) Titration isotherm (monitored at $380 \mathrm{~nm}$ ) and (c) residuals plot derived from a non-linear least-squares fitting. 

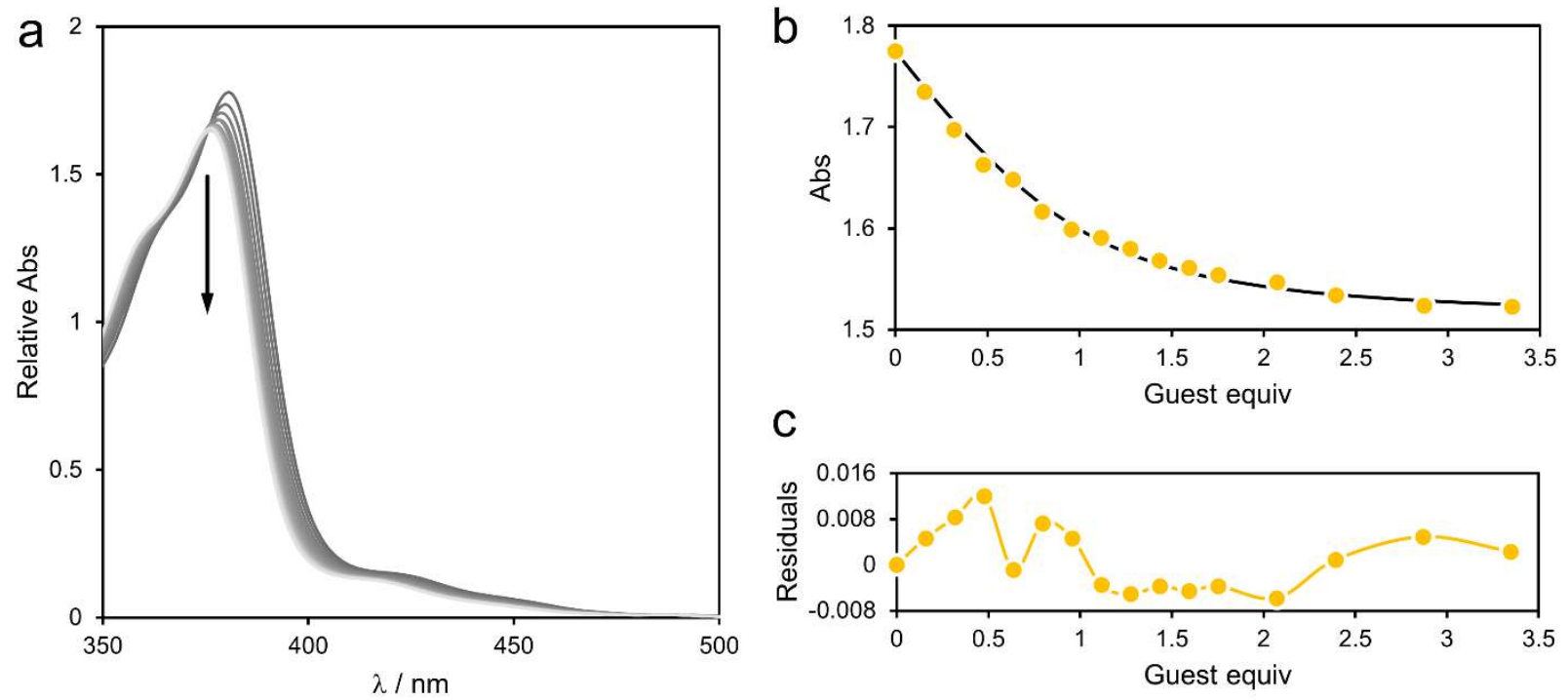

Figure S6. (a) UV-vis titration of 18C6-PtII $\left(9.5 \times 10^{-5} \mathrm{M}\right)$ with $\mathrm{NaPF}_{6}\left(2.0 \times 10^{-2} \mathrm{M}\right)$ in $\mathrm{MeCN}$ at $25^{\circ} \mathrm{C}$. (b) Titration isotherm (monitored at $380 \mathrm{~nm}$ ) and (c) residuals plot derived from a non-linear least-squares fitting.
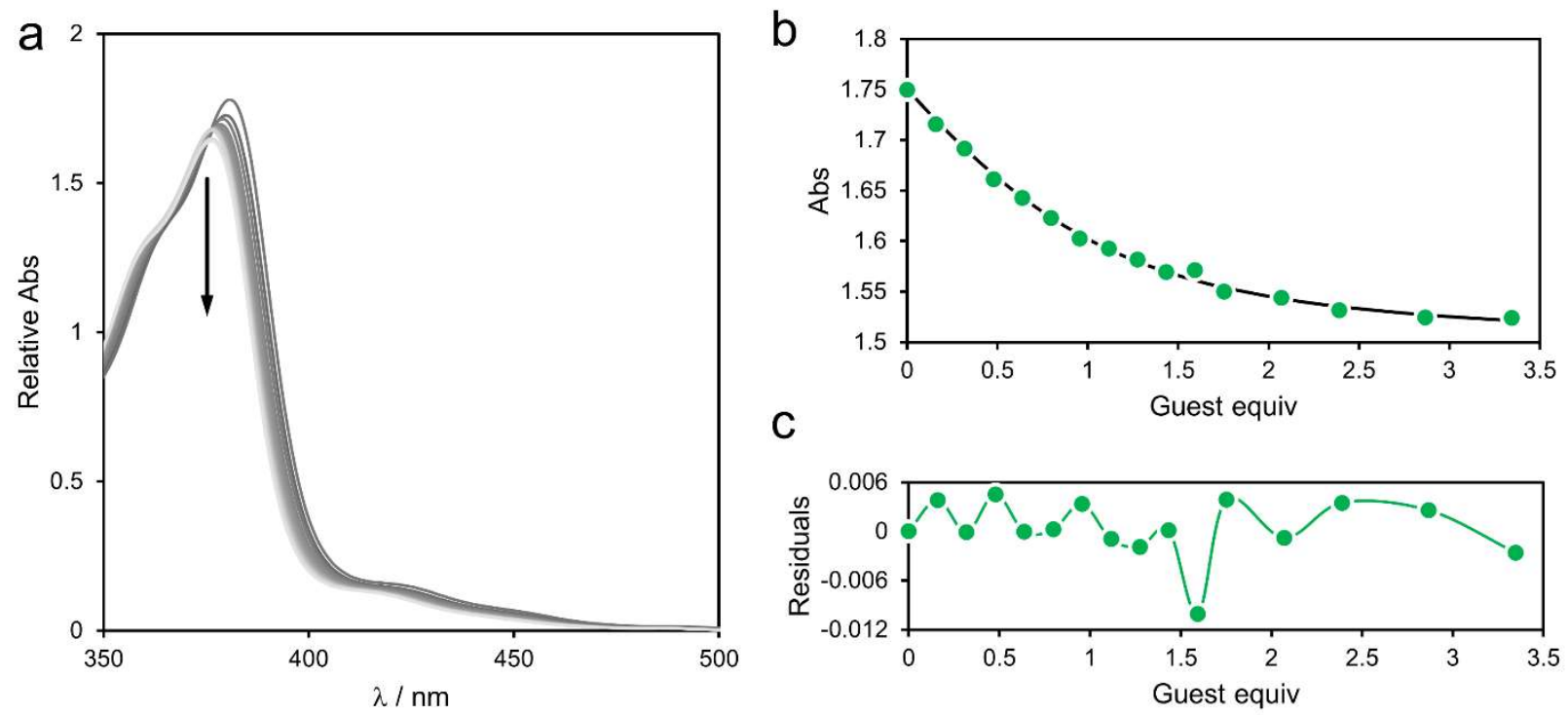

C

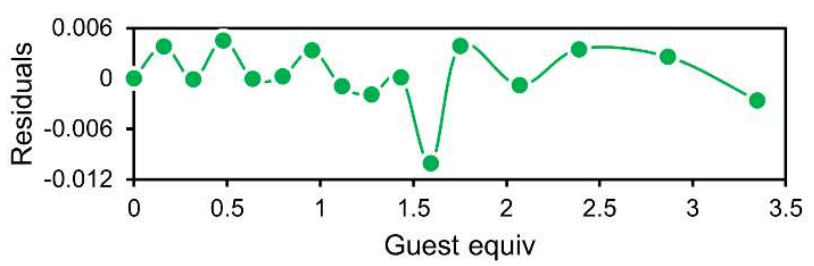

Figure S7. (a) UV-vis titration of $18 \mathrm{C6}-\mathrm{Pt}^{\mathrm{II}}\left(9.5 \times 10^{-5} \mathrm{M}\right)$ with $\mathrm{KPF}_{6}\left(2.0 \times 10^{-2} \mathrm{M}\right)$ in $\mathrm{MeCN}$ at $25^{\circ} \mathrm{C}$. (b) Titration isotherm (monitored at $380 \mathrm{~nm}$ ) and (c) residuals plot derived from a non-linear least-squares fitting. 

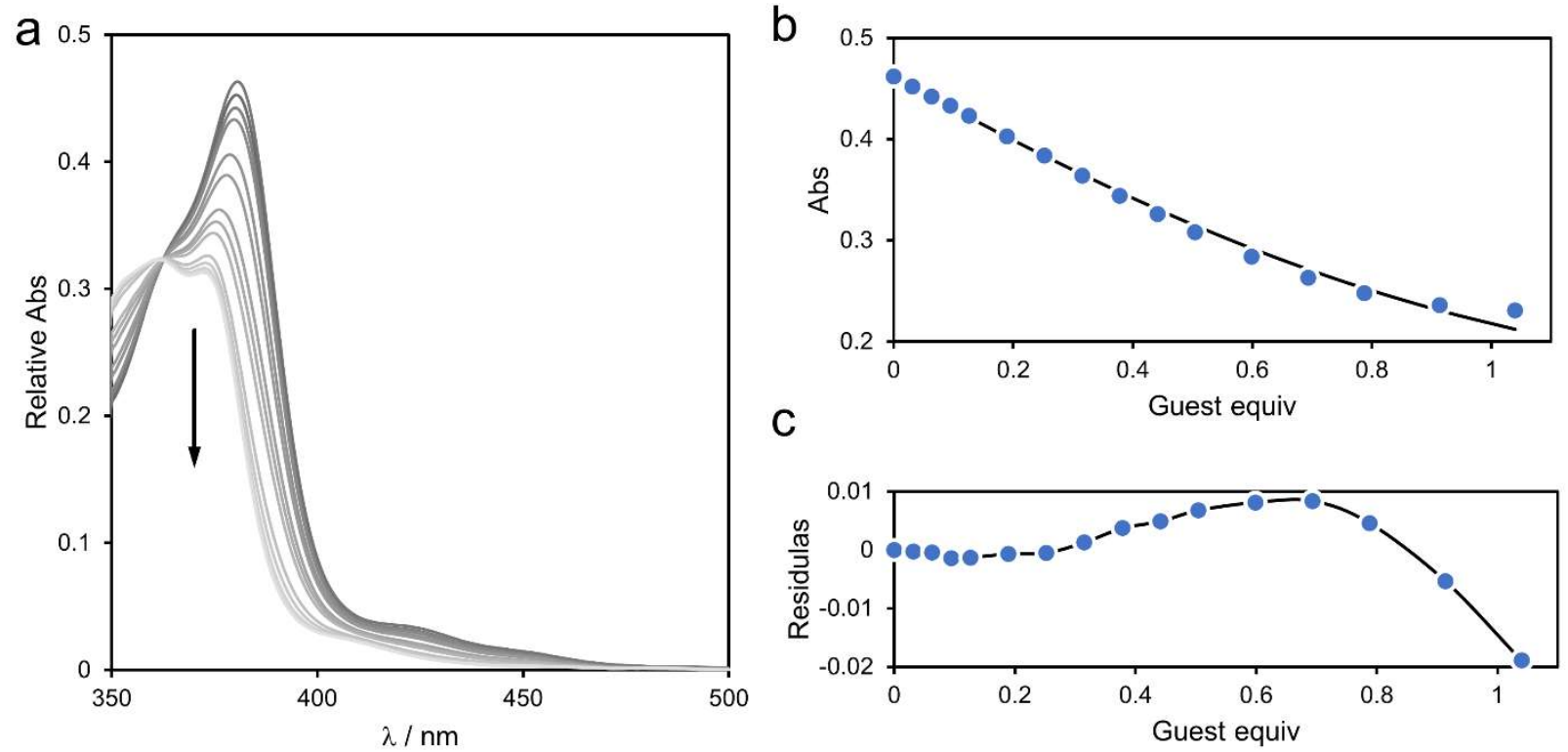

C

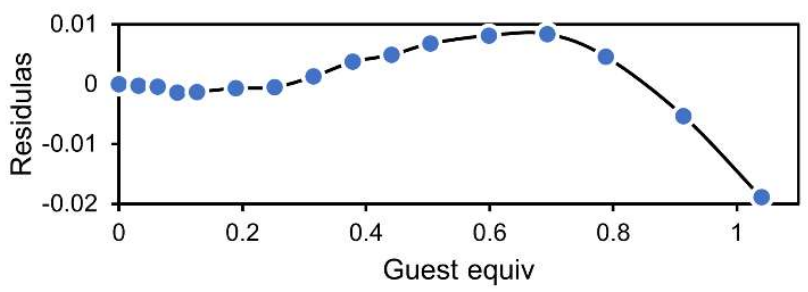

Figure S8. (a) UV-vis titration of 18C6-PtII $\left(2.4 \times 10^{-5} \mathrm{M}\right)$ with $\mathrm{Ca}(\mathrm{OTf})_{2}\left(1.0 \times 10^{-3} \mathrm{M}\right)$ in $\mathrm{MeCN}$ at $25^{\circ} \mathrm{C}$. (b) Titration isotherm (monitored at $380 \mathrm{~nm}$ ) and (c) residuals plot derived from a non-linear least-squares fitting.

Table S1. Thermodynamic parameters corresponding to the host-guest complexes in MeCN at $25^{\circ} \mathrm{C}$. Standard deviations were calculated from three independent experiments.

\begin{tabular}{|l|c|c|}
\hline Cation & $\boldsymbol{K}_{\mathbf{a}} / \mathrm{M}^{-1}$ & $\Delta \boldsymbol{G}_{\mathbf{a}} / \mathrm{kJ} \mathrm{mol}^{-1}$ \\
\hline $\mathrm{Li}^{+}$ & $(7.15 \pm 0.07) \times 10^{3}$ & $-22.0 \pm 0.2$ \\
\hline $\mathrm{Na}^{+}$ & $(4.30 \pm 0.76) \times 10^{4}$ & $-26.4 \pm 4.7$ \\
\hline $\mathrm{K}^{+}$ & $(2.73 \pm 0.30) \times 10^{4}$ & $-24.9 \pm 2.7$ \\
\hline $\mathrm{Ca}^{2+}$ & $(2.74 \pm 0.24) \times 10^{5}$ & $-31.0 \pm 2.7$ \\
\hline
\end{tabular}




\section{Recognition of $\mathrm{Ca}^{2+}$}

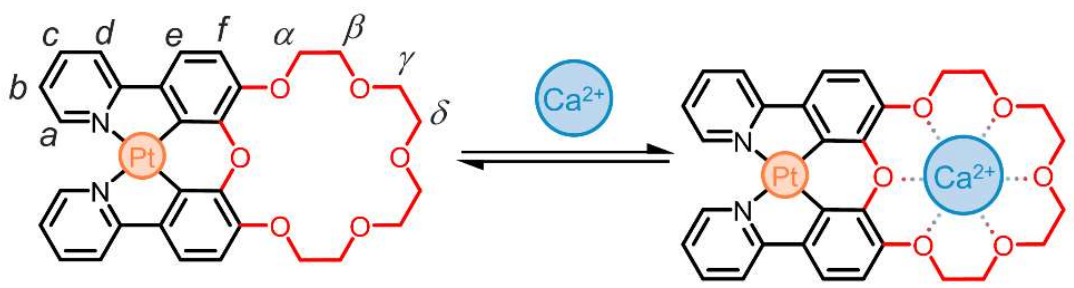

a

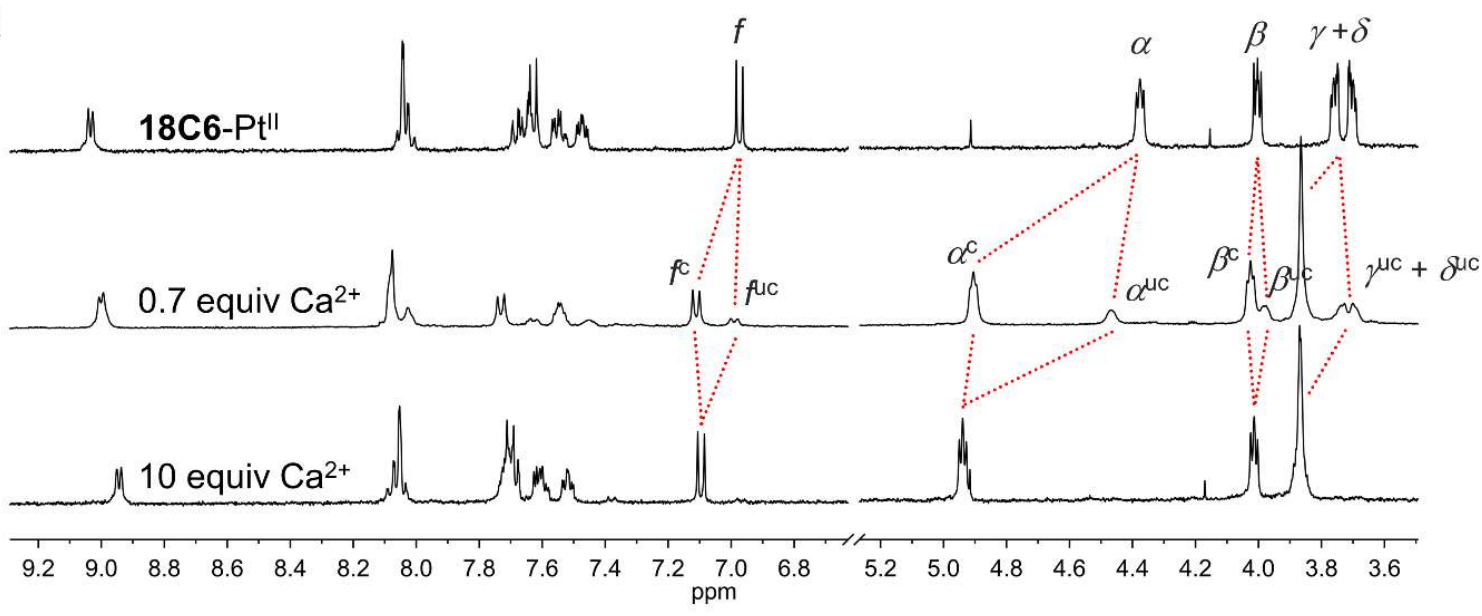

b

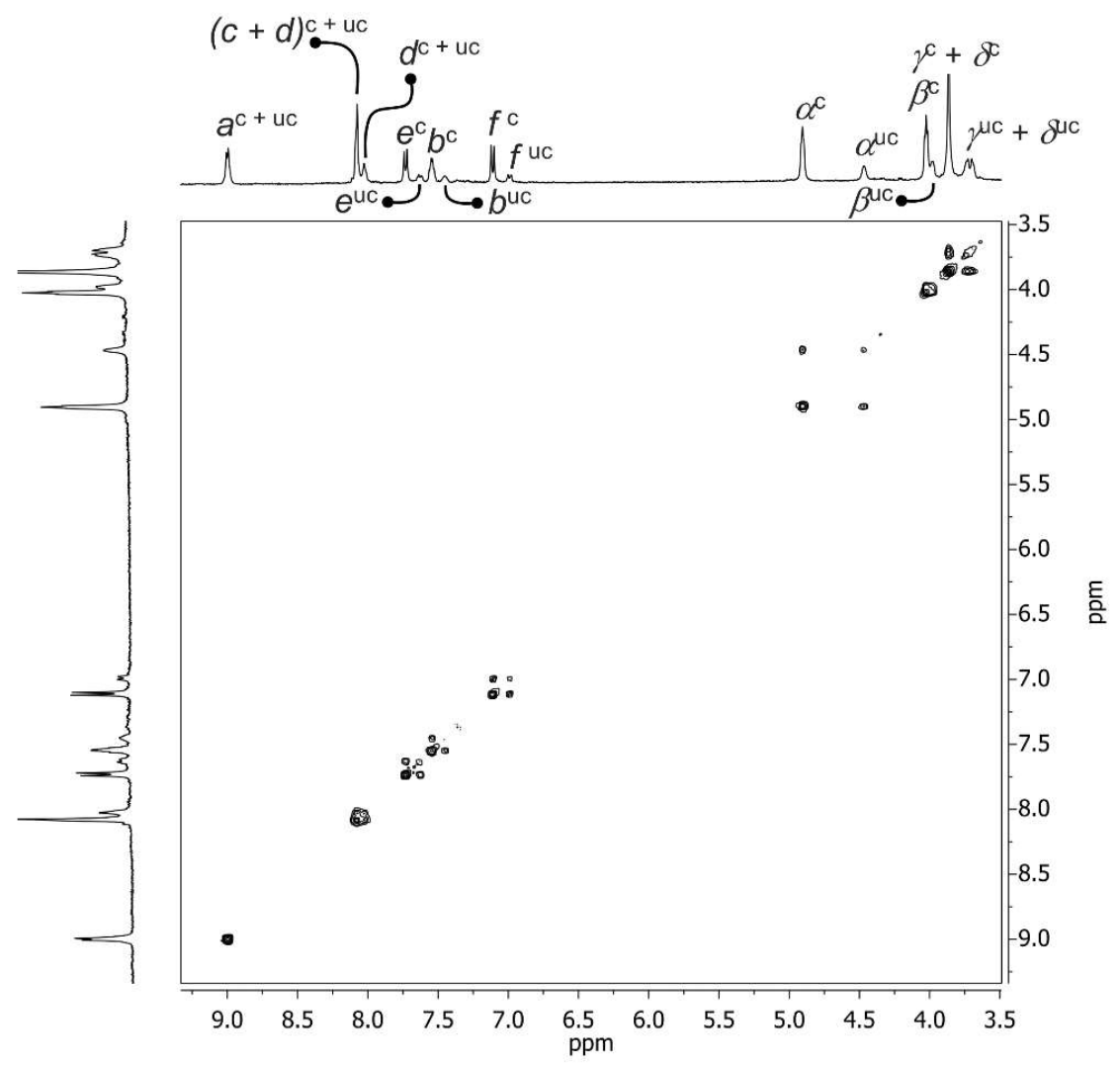

Figure S9. (a) ${ }^{1} \mathrm{H}$ NMR spectrum $\left(400 \mathrm{MHz}, \mathrm{MeCN}-d_{3}\right)$ of $18 \mathrm{C6}-\mathrm{Pt}^{\mathrm{II}}\left(1.5 \times 10^{-3} \mathrm{M}\right)$ and its mixtures with 0.7 and 10 equiv of $\mathrm{Ca}(\mathrm{OTf})_{2}$. (b) ${ }^{1} \mathrm{H}^{-1} \mathrm{H}$ COSY NMR spectrum of a solution of $18 \mathrm{C} 6-\mathrm{Pt}^{\mathrm{II}}\left(1.5 \times 10^{-3} \mathrm{M}\right)$ and 0.7 equiv of $\mathrm{Ca}(\mathrm{OTf})_{2}$. 


\section{Solid-state structures of the host-guest complexes}

a

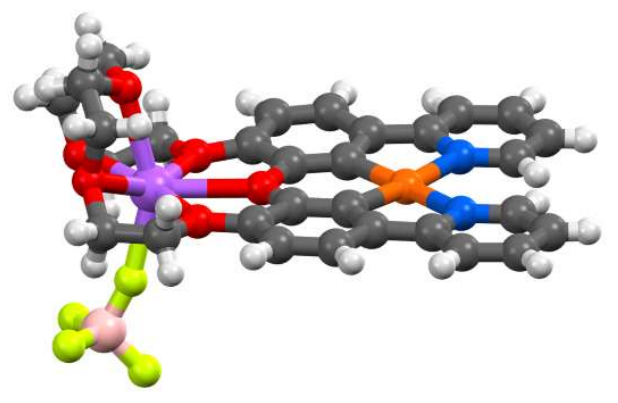

b

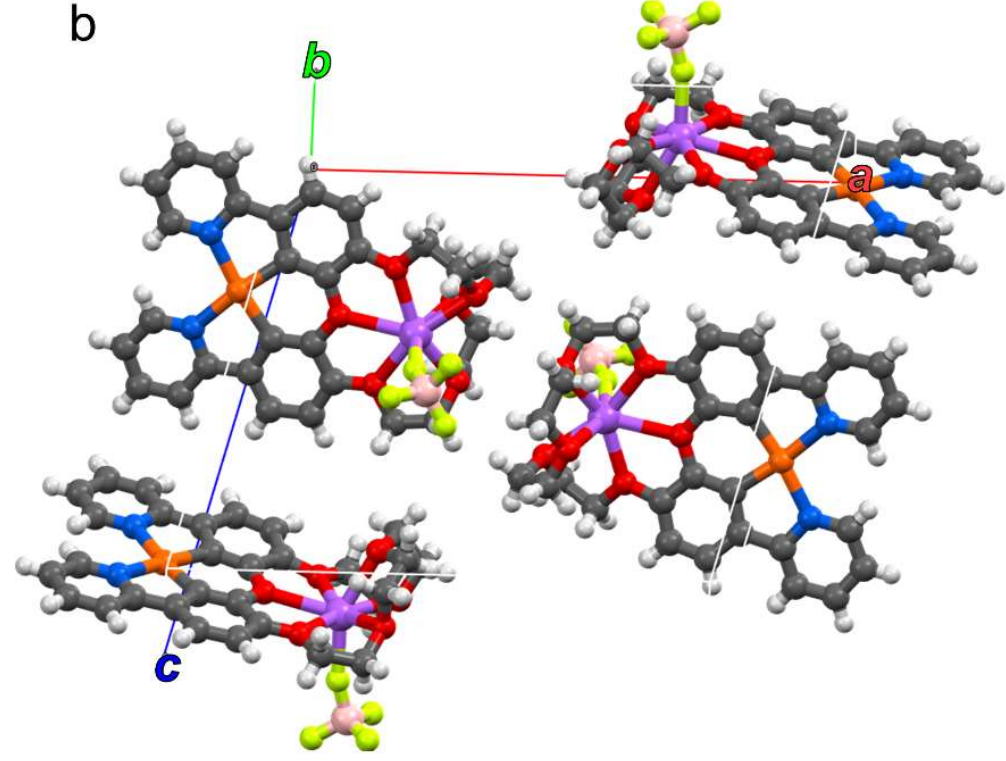

Figure S10. Solid-state structure of (a) 18C6- $\mathrm{Pt}^{\mathrm{II}} \supset \mathrm{NaBF}_{4}$ and (b) its packing within the unit cell.

a

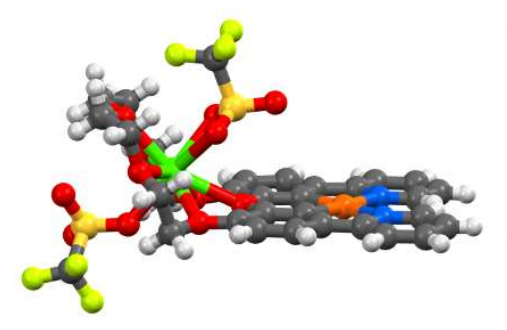

b

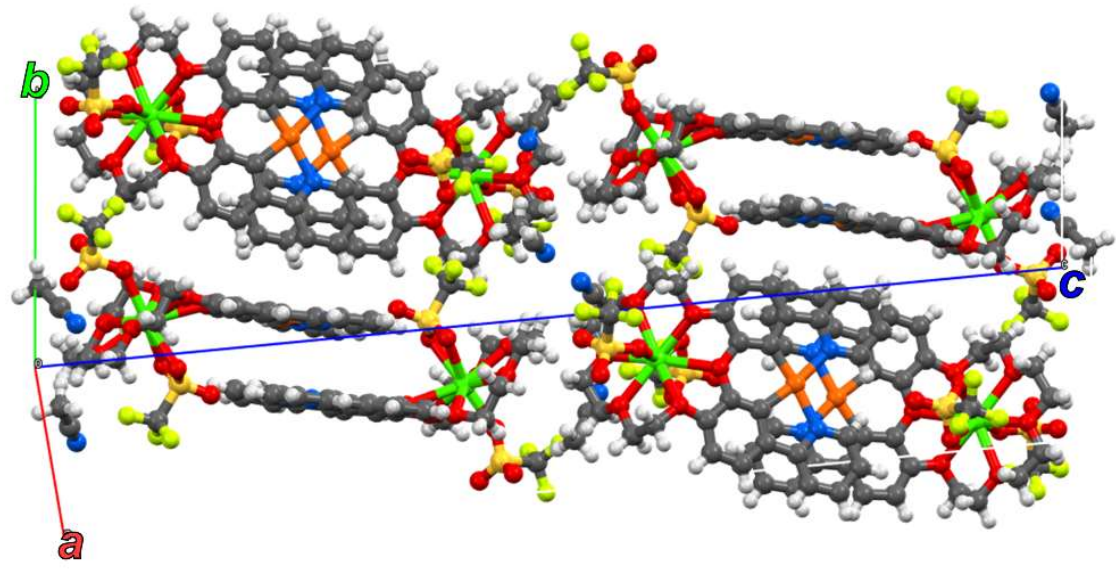

Figure S11. Solid-state structure of (a) 18C6-PtII $\supset \mathrm{Ca}(\mathrm{OTf})_{2}$ and (b) its packing within the unit cell. 

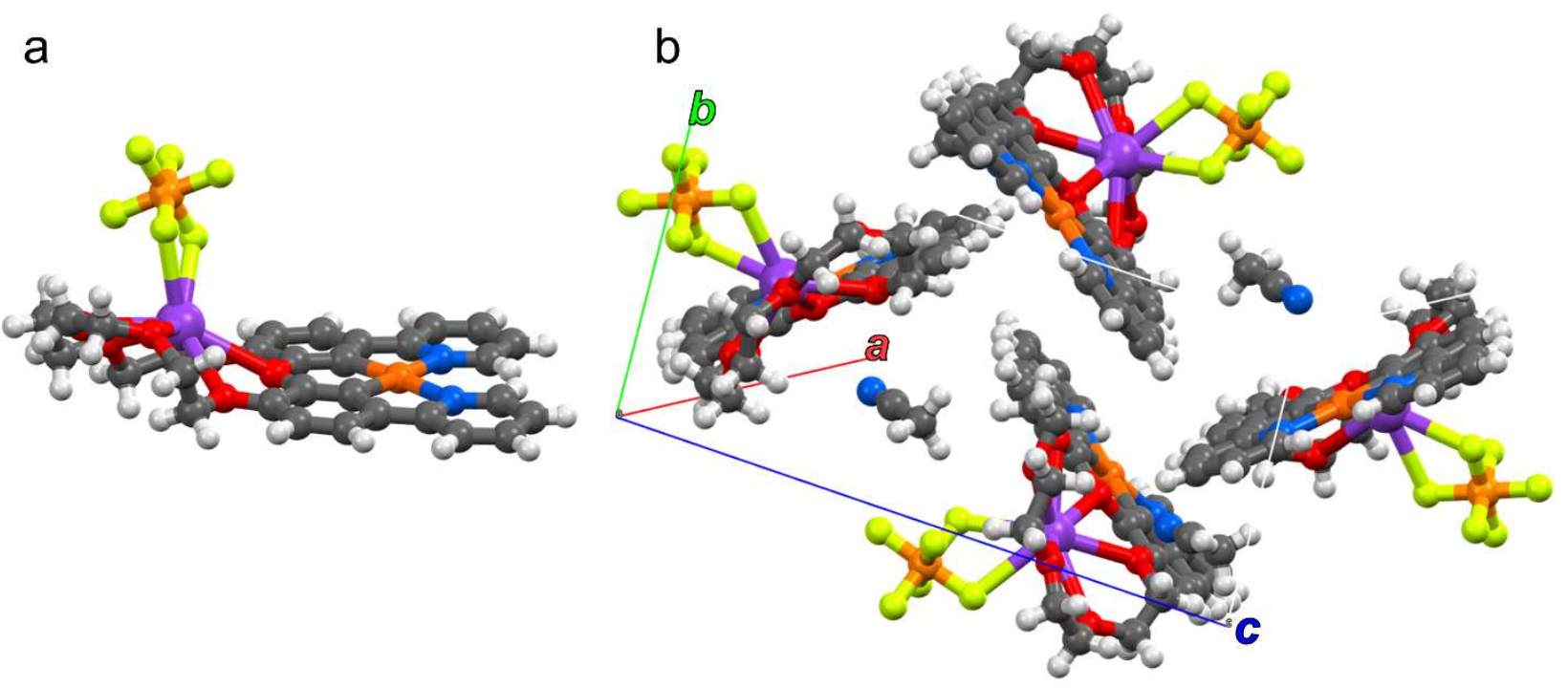

Figure S12. Solid-state structure of (a) 18C6-PtII $\supset \mathrm{KPF}_{6}$ and (b) its packing within the unit cell.

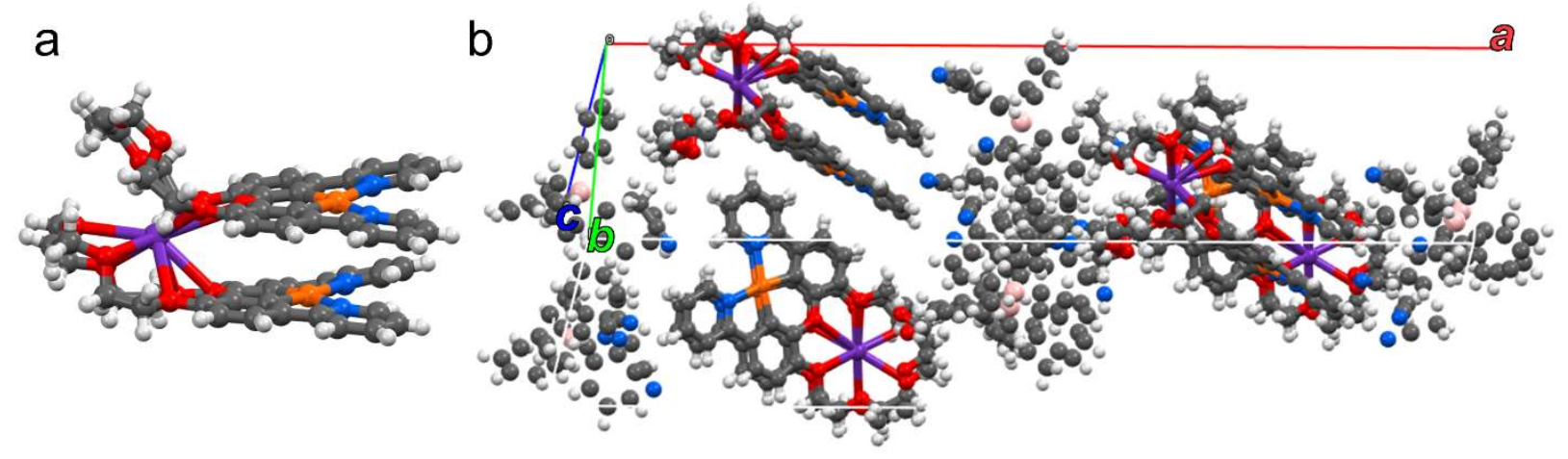

Figure S13. Solid-state structure of (a) 18C6-PtII $\supset \mathrm{RbBPh}_{4}$ and (b) its packing within the unit cell. 


\section{$\mathbf{R b}^{+}$complex}
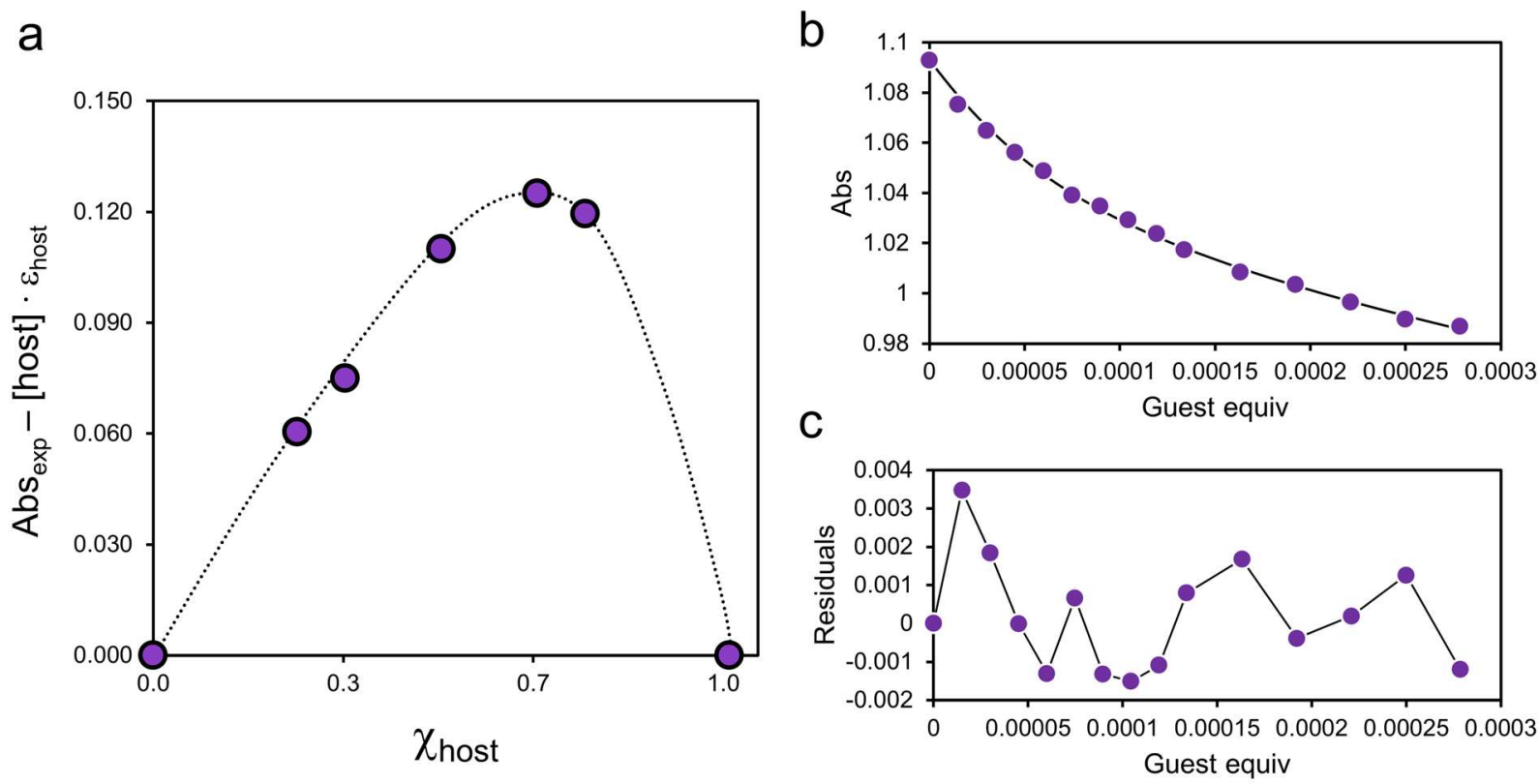

Figure S14. (a) Job plot for the complex formed in solution between $\mathrm{RbBF}_{4}$ and 18C6-PtII. Data extracted from a series of UV-vis spectra in MeCN at $25^{\circ} \mathrm{C}(\lambda=380 \mathrm{~nm})$. The global concentration of the system (host + guest) was kept constant at $5 \times 10^{-5} \mathrm{M}$. The seven data points represent $\chi_{\text {host }}=0.0,0.25,0.33,0.5,0.66,0.75$ and 1.0. (b) Titration isotherm (monitored at $380 \mathrm{~nm}$ ) and (c) residuals plot derived from a non-linear least-squares fitting.

\section{Photoluminescence of 1-PtII vs 18C6-PtII in solution}
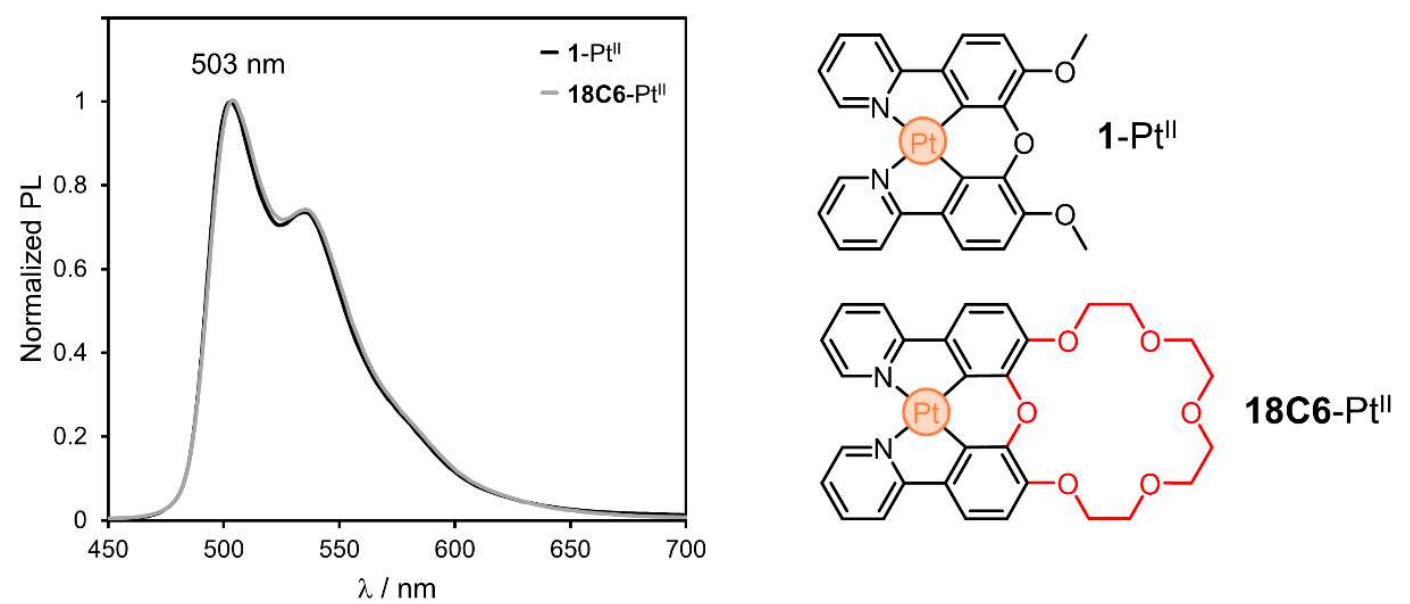

Figure S15. Normalized photoluminescence spectra $\left(\lambda_{\mathrm{ex}}=360 \mathrm{~nm}\right)$ of $1-\mathrm{Pt} \mathrm{tII}^{\mathrm{II}}$ and $18 \mathrm{C6}-\mathrm{Pt}^{\mathrm{II}}$ in $\mathrm{MeCN}$. 


\section{Cation effect on the luminescence of 18C6-PtII}

a

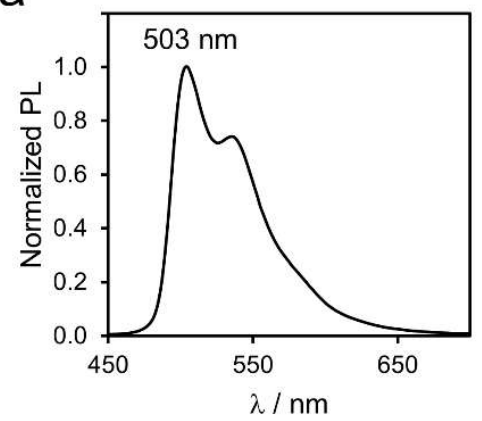

d

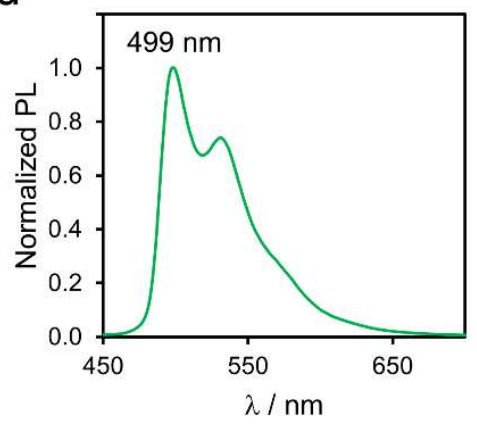

g

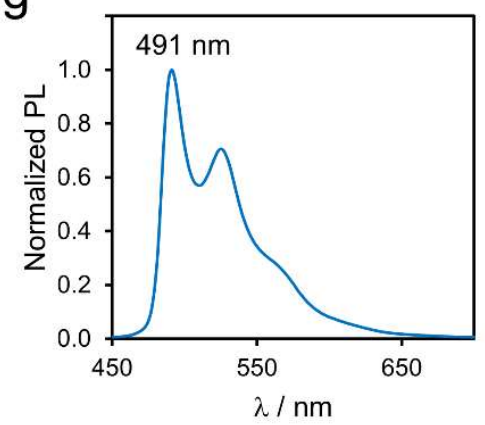

b

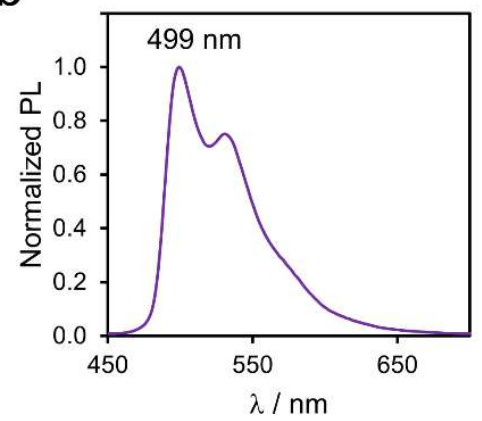

e

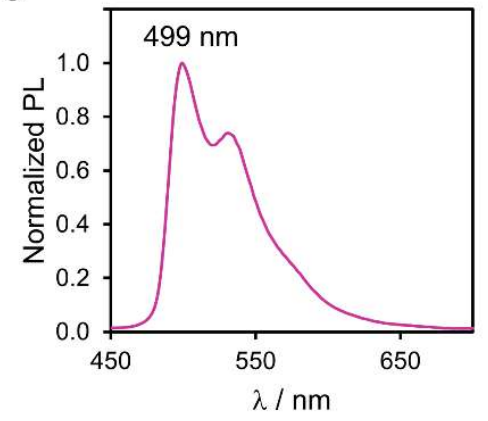

$\mathrm{h}$

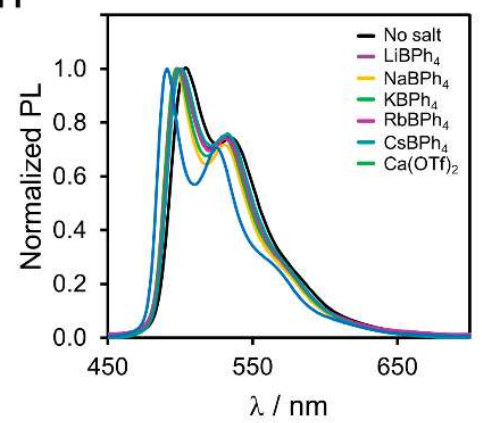

C

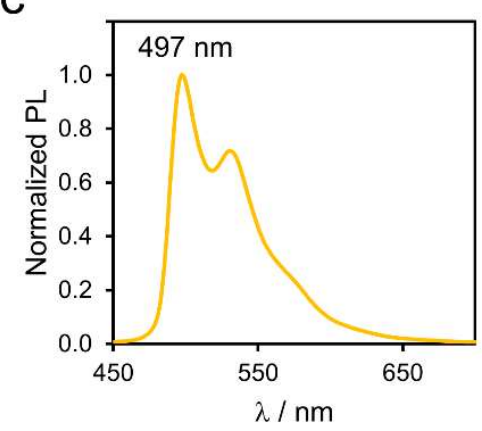

$f$

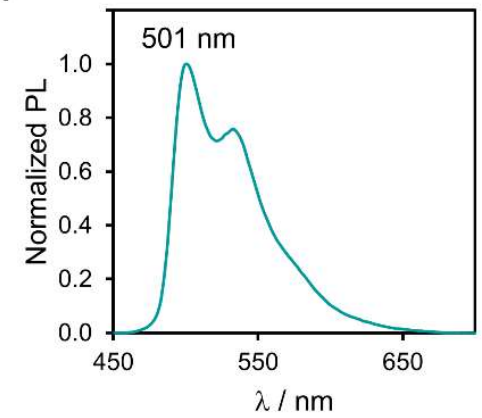

Figure S16. Normalized photoluminescence spectra $\left(\lambda_{\mathrm{ex}}=360 \mathrm{~nm}\right.$ ) of (a) 18C6-PtII and its mixture with 10 equiv of (b) $\mathrm{LiBPh}_{4} \cdot \mathrm{Et}_{2} \mathrm{O}$, (c) $\mathrm{NaBPh}_{4}$, (d) $\mathrm{KBPh}_{4}$, (e) $\mathrm{RbBPh}_{4}$, (f) $\mathrm{CsBPh}_{4}$, and (g) Ca(OTf) 2 . All experiments conducted in $\mathrm{MeCN}$. (h) Overlay of spectra (a) to (g). 

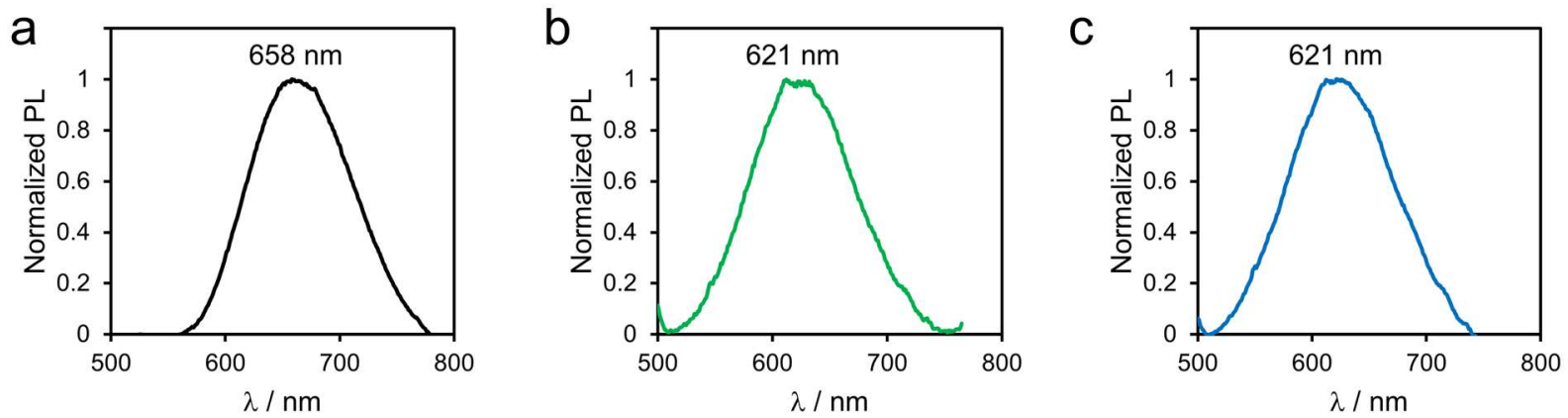

Figure S17. Normalized solid-state photoluminescence spectra $\left(\lambda_{\mathrm{ex}}=450 \mathrm{~nm}\right)$ of (a) 18C6-PtII and its mixture with 1 equiv of (b) $\mathrm{KPF}_{6}$, and (c) $\mathrm{Ca}(\mathrm{OTf})_{2}$. Samples prepared through drop casting onto glass slides, using solution of host and guest in a 1:1 mol ratio.

\section{Anion effect on the luminescence of 18C6-Pt ${ }^{\mathrm{II}}$-guest complexes in solution}

a

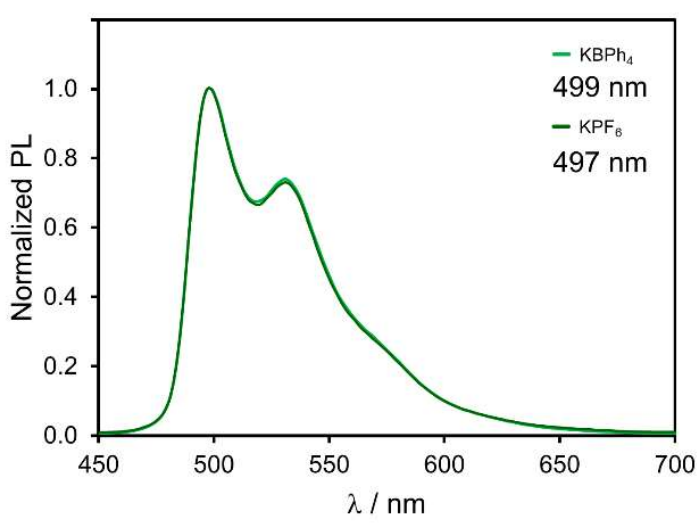

b

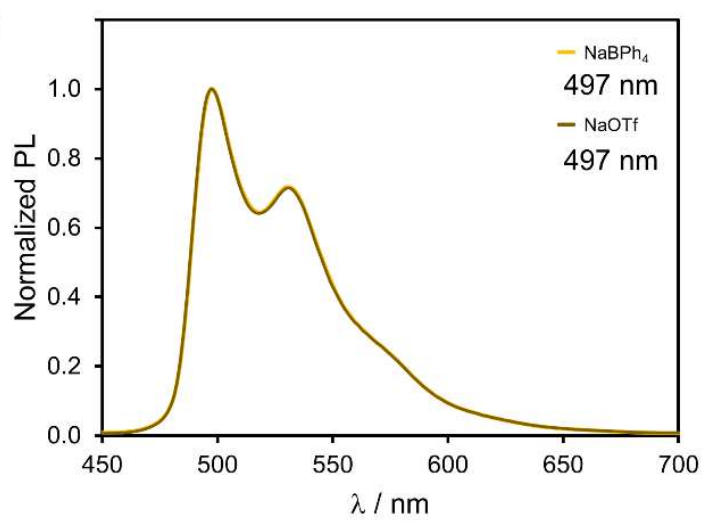

Figure S18. Normalized photoluminescence spectra $\left(\lambda_{\text {ex }}=360 \mathrm{~nm}\right)$ of complexes 18C6-PtII $\supset \mathrm{K}^{+}$and 18C6-PtII $\supset$ Na+ in MeCN, showing no effect when swapping non-coordinating anions: (a) KBPh 4 vs $\mathrm{KPF}_{6}$ and (b) $\mathrm{NaBPh}_{4}$ vs $\mathrm{NaOTf}$ 


\section{Photoluminescence lifetime measurements}

Three solutions of $\mathbf{1 8 C 6}-\mathrm{Pt}^{\mathrm{II}}\left(1.0 \times 10^{-4} \mathrm{M}\right)$ were prepared inside a $\mathrm{N}_{2}$ glovebox using dry and degassed MeCN. Two of the solutions were independently mixed with $\mathrm{KPF}_{6}\left(10\right.$ equiv) and $\mathrm{Ca}(\mathrm{OTf})_{2}$ (10 equiv). All samples were transferred into $10 \mathrm{~mm}$ quartz cuvettes (four polished windows), sealed with septa, and analyzed through lifetime fluorimetry. The results are shown in Figure S19.

a

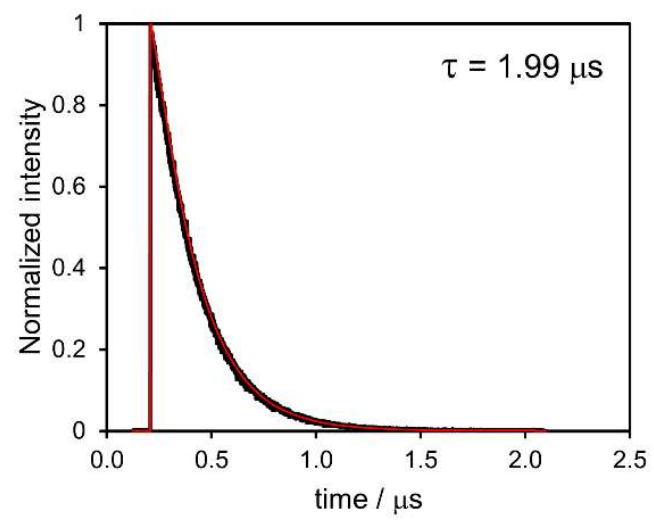

C

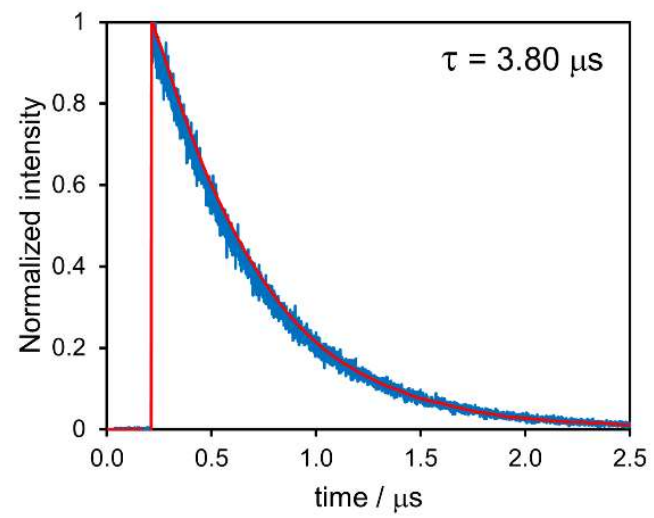

b

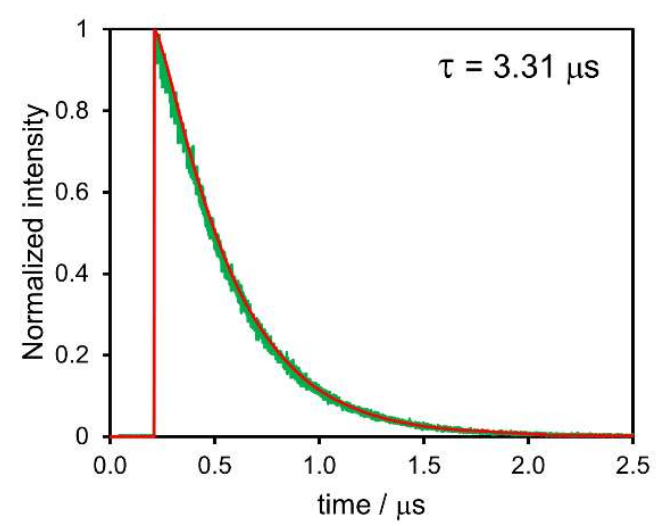

d

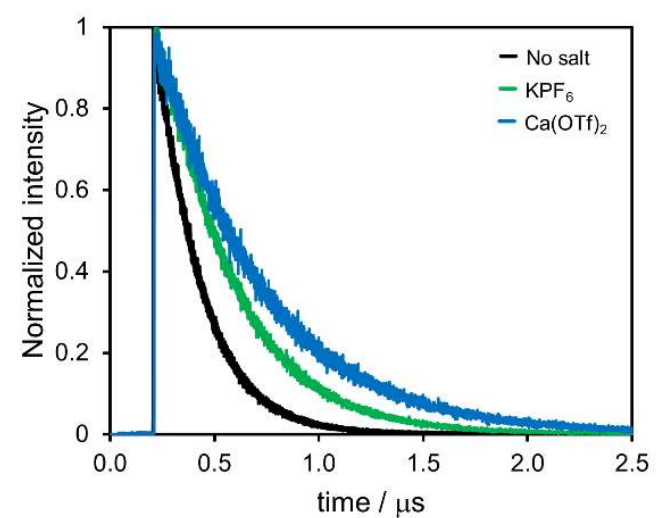

Figure S19. Luminescence decay plots of (a) 18C6-PtII, (b) 18C6-PtII $\supset \mathrm{K}^{+}$, and (c) 18C6-PtII $\supset \mathrm{Ca}^{2+}$. (d) Overlay of the three prepared systems. Fitting to a 2-exponential model is shown as a red line in Figures a-c. 


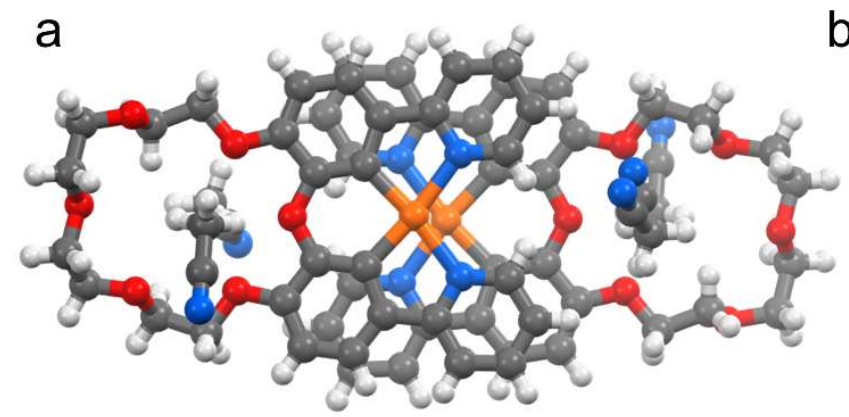

No salt $\bigcirc \cdots \circ 3.4318(7) \AA$

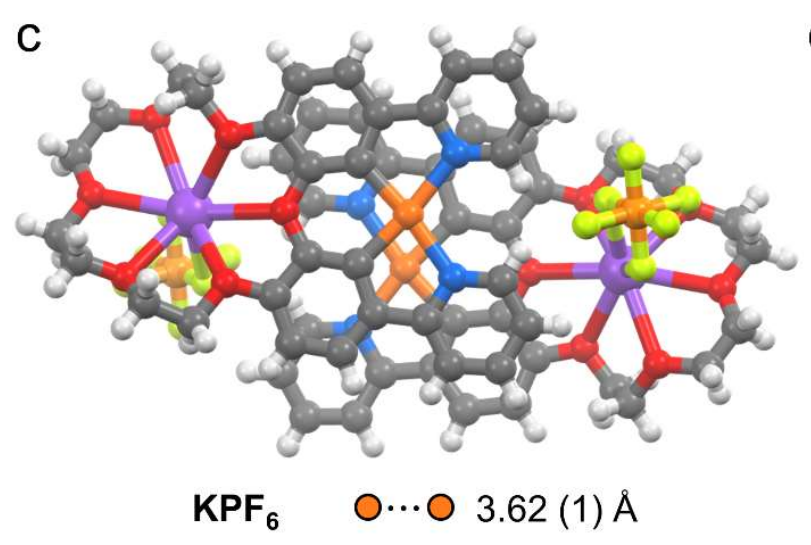

b

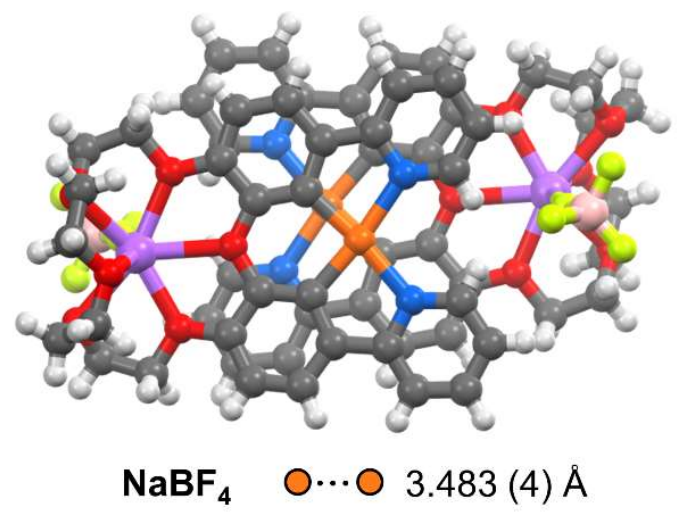

d

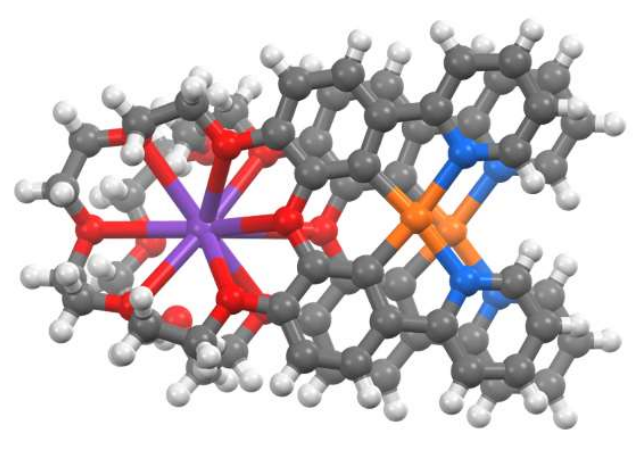

$\mathrm{RbBPh}_{4} \bigcirc \cdots \bigcirc 3.566(1) \AA$

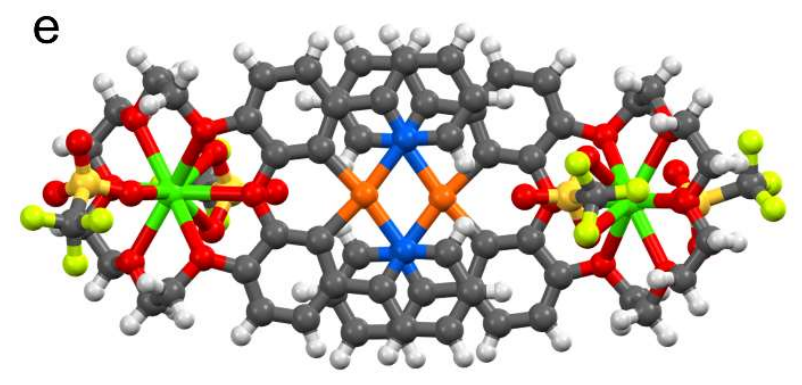

$\mathrm{Ca}(\mathrm{OTf})_{2} \mathrm{O} \cdots \bigcirc 4.049(2) \AA$

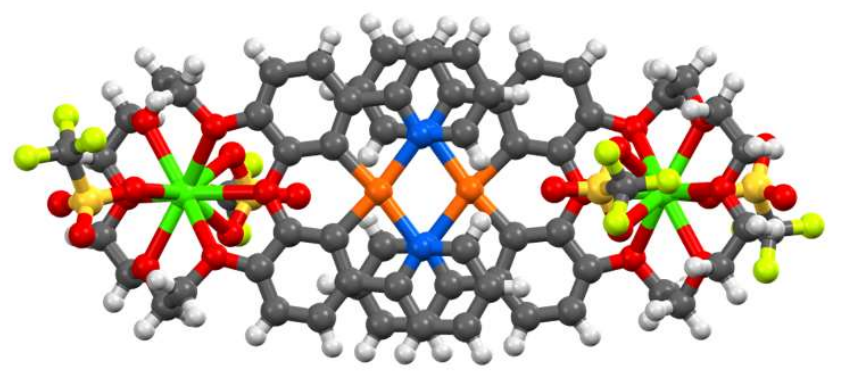

$\bigcirc \cdots \circ 4.378(2) \AA$

Figure S20. Top view of the dimeric structures observed for (a) 18C6-PtII, (b) 18C6-PtII $\supset \mathrm{NaBF}_{4}$ (c) 18C6-PtII $\supset$ KPF6, (d) 18C6- $\mathrm{Pt}^{\mathrm{II}} \supset \mathrm{RbBPh}_{4}$, and (e) 18C6-PtII $\supset \mathrm{Ca}(\mathrm{OTf})_{2}$. 


\section{Control experiments: cation effect on 1-PtII and 18C6-PtII}
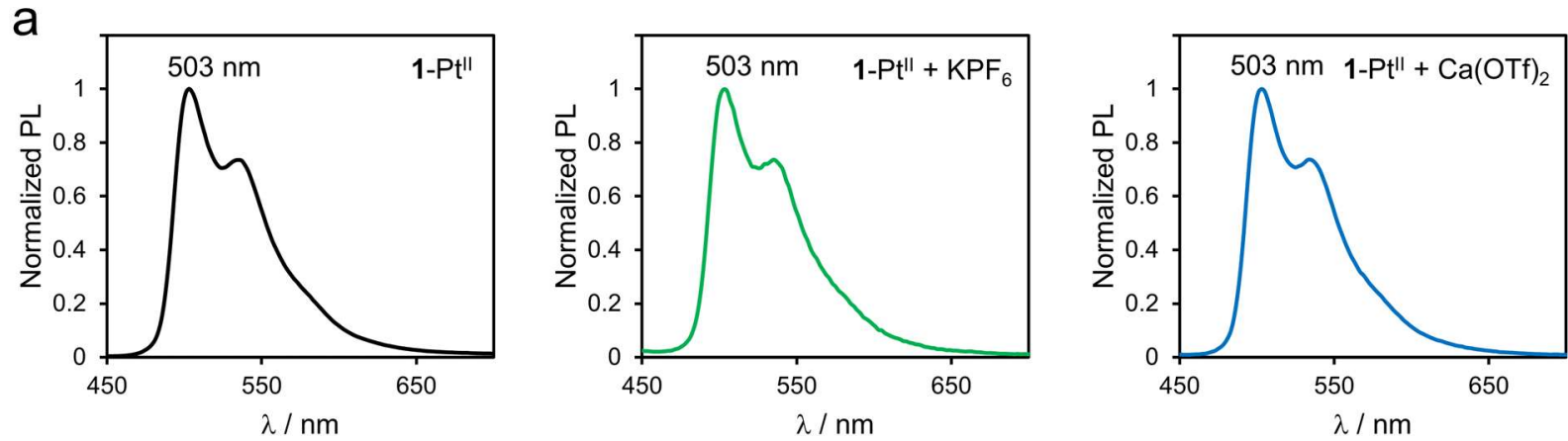

b
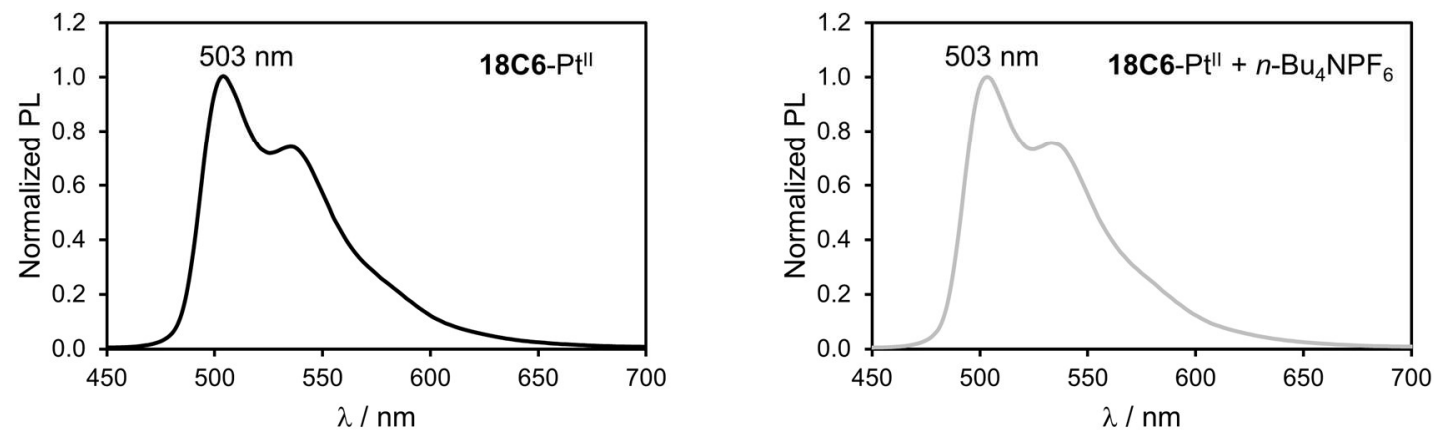

Figure S21. Photoluminescence spectra (MeCN) of (a) 1-PtII (left) and its mixture with 10 equiv of $\mathrm{KPF}_{6}$ (center) and $\mathrm{Ca}(\mathrm{OTf})_{2}$ (right), and (b) 18C6-PtII (left) mixed with 10 equiv of $n-\mathrm{Bu}_{4} \mathrm{NPF}_{6}$ (right). $\lambda_{\mathrm{ex}}=360 \mathrm{~nm}$. 


\section{Analysis of 18C6-Pt ${ }^{I I}$ solvates in the solid state}

A solution of 18C6-PtII in DCM was drop casted onto a glass slide. The corresponding emission spectrum was collected after the sample dried. The sample was stored inside a sealed chamber containing $\mathrm{H}_{2} \mathrm{O}$ for $3 \mathrm{~h}$ to obtain the parent purple solvate, which was analyzed by fluorescence spectroscopy (Figure S22).

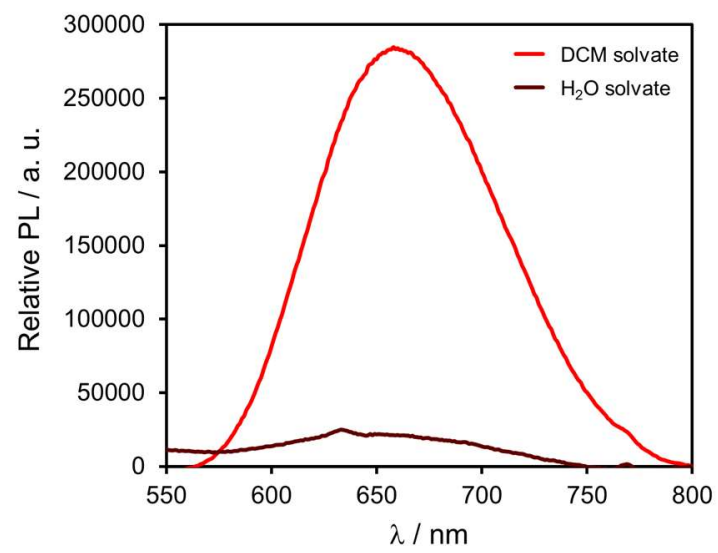

Figure S22. Photoluminescence spectra $\left(\lambda_{\mathrm{ex}}=450 \mathrm{~nm}\right.$ ) of 18C6-PtIl solvates: DCM (red) and $\mathrm{H}_{2} \mathrm{O}$ (purple).

Figure S23 and Figure S24 show the PXRD patterns and UV-vis spectra corresponding to the water and DCM solvates of 18C6-PtII. The samples were prepared as described above. 
a

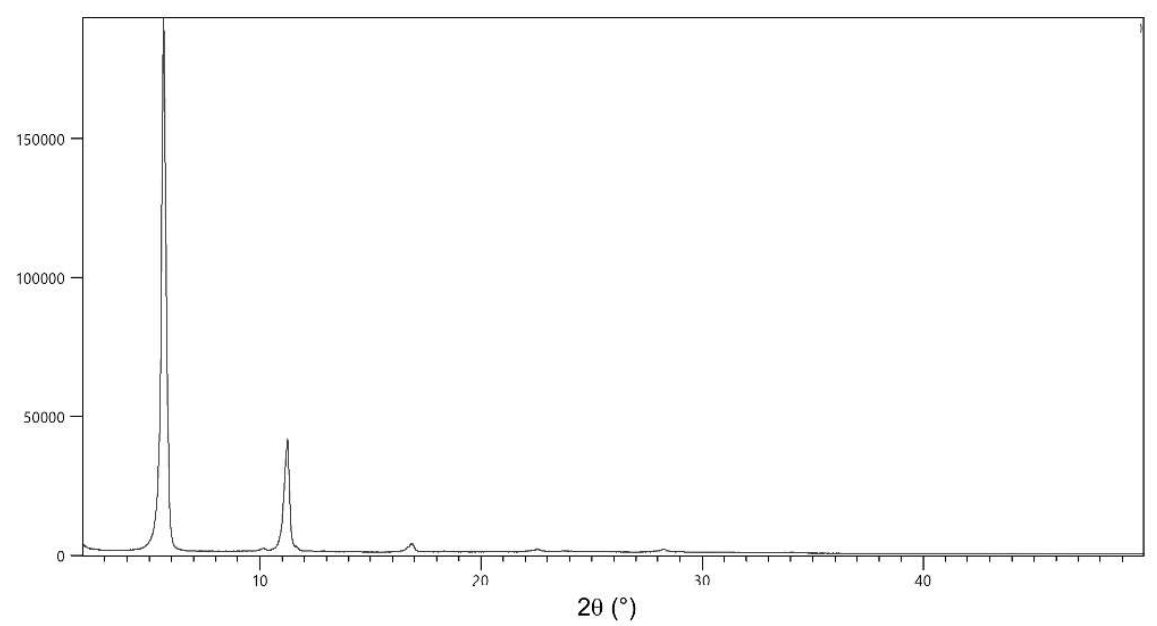

b

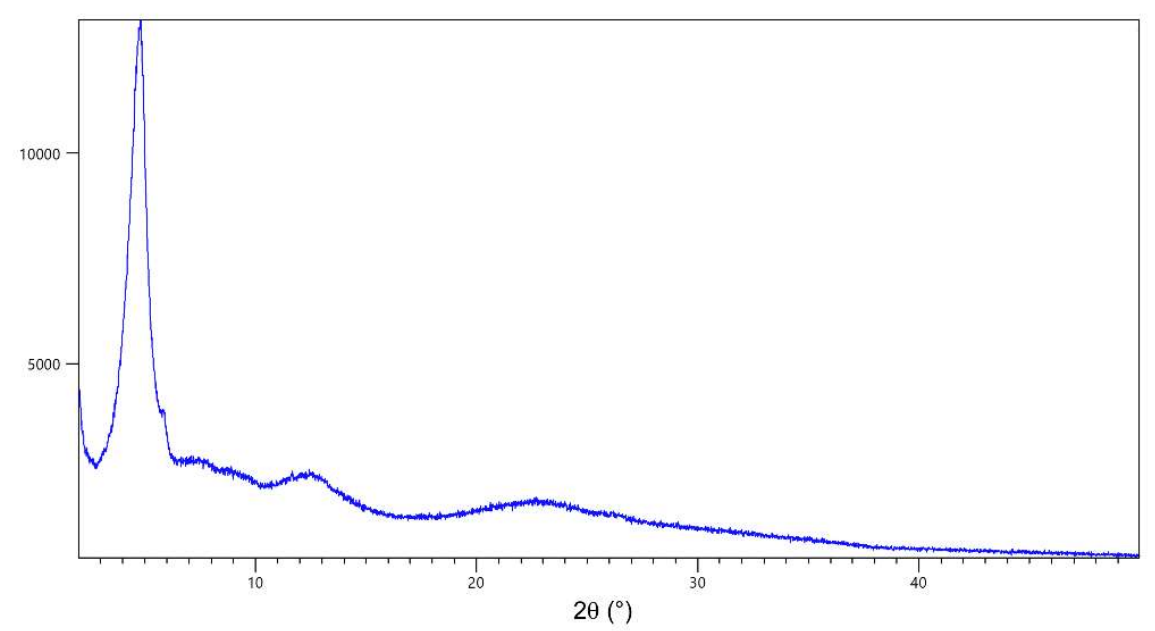

Figure S23. PXRD patterns for 18C6-PtII as (a) DCM and (b) $\mathrm{H}_{2} \mathrm{O}$ solvates.

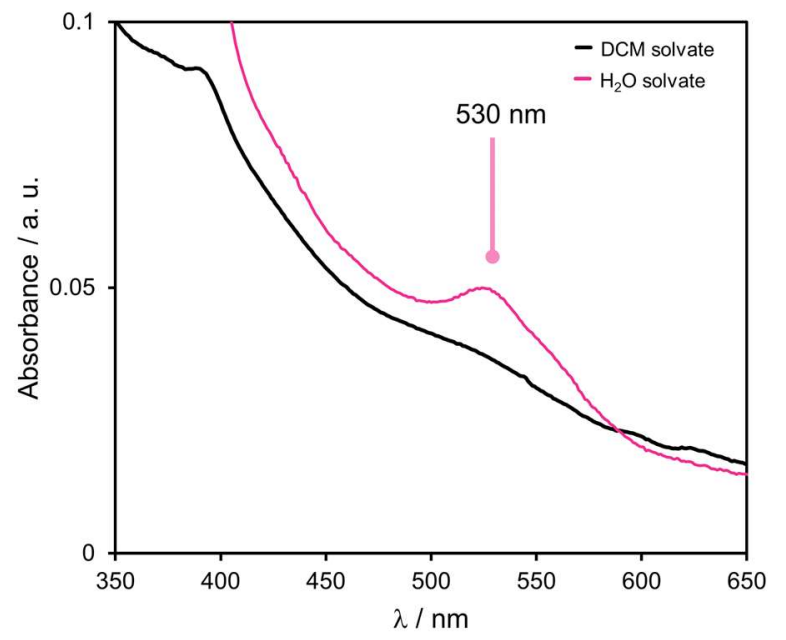

Figure S24. UV-vis spectra of 18C6-PtII in the solid state, as DCM and $\mathrm{H}_{2} \mathrm{O}$ solvates. The sample was drop casted onto a glass slide (from a DCM solution), measured, exposed to $\mathrm{H}_{2} \mathrm{O}$, and analyzed again in the spectrophotometer. 


\section{C6-PtII and its interaction with AcOH}

Figure S25 shows the ${ }^{1} \mathrm{H}$ NMR spectra of $18 \mathrm{C} 6-\mathrm{Pt}{ }^{I I}\left(1.5 \times 10^{-3} \mathrm{M}\right)$ in $\mathrm{MeCN}-d_{3} / \mathrm{D}_{2} \mathrm{O}(6: 4 \mathrm{v} / \mathrm{v})$ (top) and the same sample after adding $10 \% \mathrm{AcOH}\left(\mathrm{v} / \mathrm{v}\right.$ with respect to $\mathrm{D}_{2} \mathrm{O}$ ) (bottom). The subtle shift of protons $\alpha$ and $\beta$ suggest weak interaction between 18C6- $\mathrm{Pt}^{\mathrm{II}}$ and the added acid.
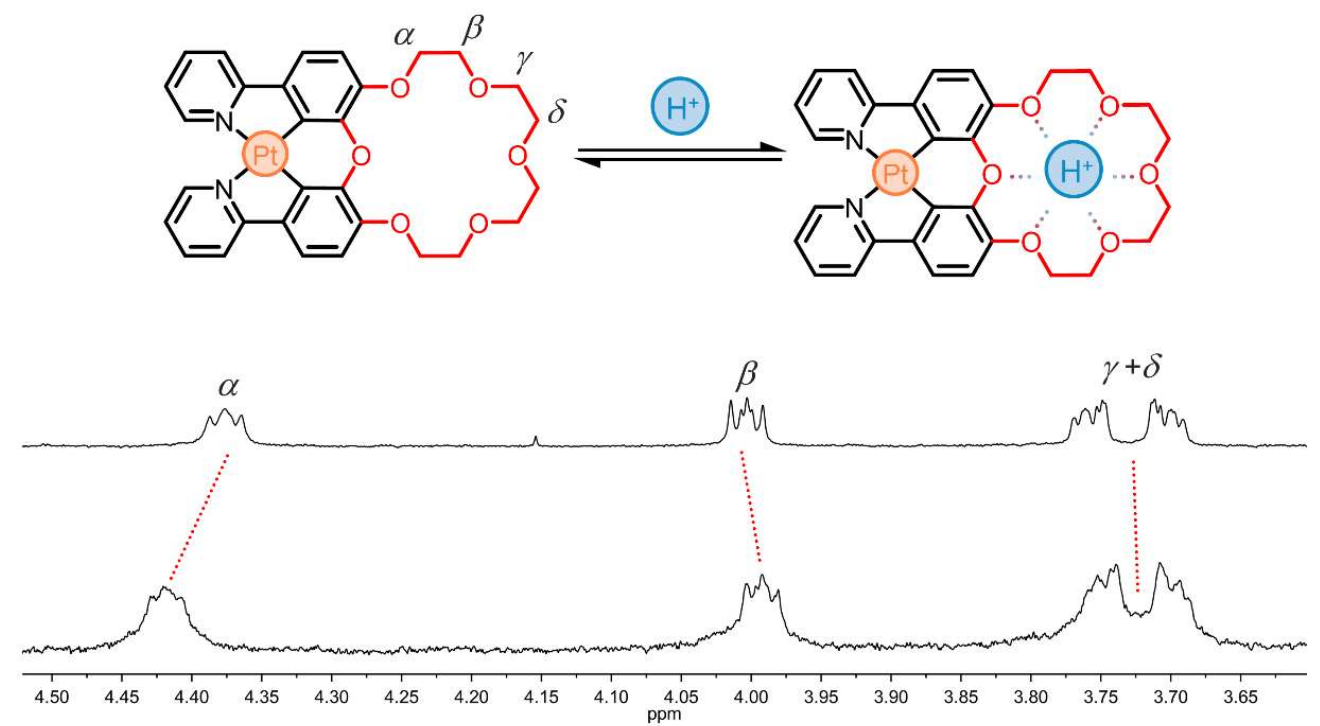

Figure S25. Partial ${ }^{1} \mathrm{H}$ NMR spectra (400 MHz) of 18C6-PtII $\left(1.5 \times 10^{-3} \mathrm{M}\right)$ in $\mathrm{MeCN}-d_{3} / \mathrm{D}_{2} \mathrm{O}(6: 4 \mathrm{v} / \mathrm{v})$ (top), and in MeCN$d_{3} / \mathrm{D}_{2} \mathrm{O}(6: 4 \mathrm{v} / \mathrm{v})\left(10 \% \mathrm{AcOH}, \mathrm{v} / \mathrm{v}\right.$, with respect to $\left.\mathrm{D}_{2} \mathrm{O}\right)$ (bottom).

\section{Aggregation-induced quenching}

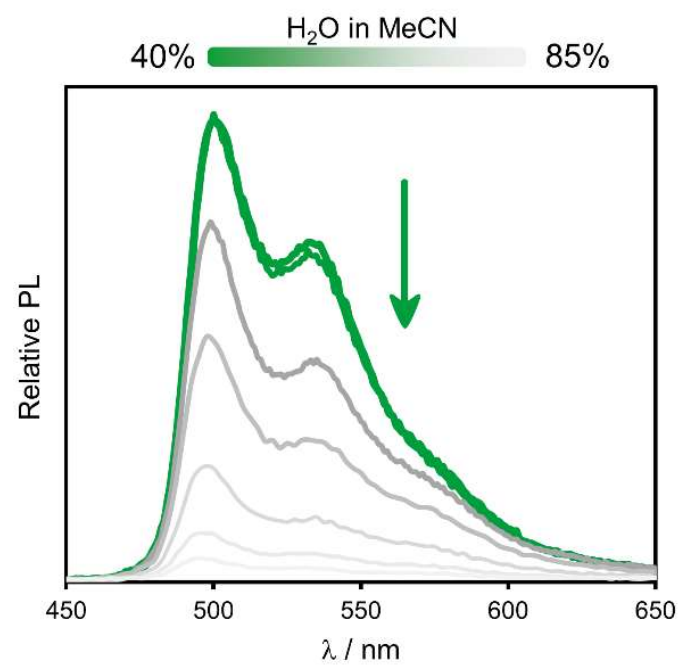

Figure S26. Photoluminescence spectra of 18C6-PtII $\left(7.5 \times 10^{-5} \mathrm{M}\right)$ at different ratios of solvent $(\mathrm{MeCN})$ and anti-solvent $\left(10 \% \mathrm{AcOH}\right.$ in $\left.\mathrm{H}_{2} \mathrm{O}, \mathrm{v} / \mathrm{v}\right) . \lambda_{\mathrm{ex}}=360 \mathrm{~nm}$. 


\section{Acetic acid (AcOH) as solution stabilizer}

Two solutions of 18C6-PtII $\left(7.5 \times 10^{-5} \mathrm{M}\right)$ were prepared in $\mathrm{MeCN} / \mathrm{H}_{2} \mathrm{O}(3: 7, \mathrm{v} / \mathrm{v})$; one of the samples contained $10 \% \mathrm{AcOH}(\mathrm{v} / \mathrm{v})$ with respect to $\mathrm{H}_{2} \mathrm{O}$. After $2 \mathrm{~h}$ at room temperature, precipitation of the Pt complex was evident in the system prepared without $\mathrm{AcOH}$, which was unveiled by the characteristic red emission of 18C6-PtII (Figure S27). The sample containing AcOH was stable for months at room temperature.

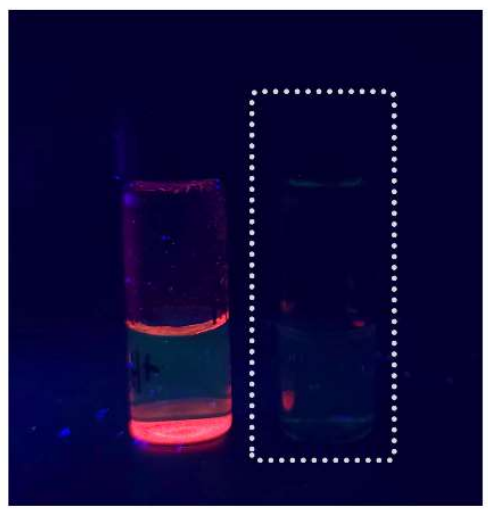

Figure S27. Solutions of 18C6-PtII $\left(7.5 \times 10^{-5} \mathrm{M}\right)$ irradiated at $365 \mathrm{~nm}$. The left vial has no AcOH, but the one on the right contains $\mathrm{AcOH}$ as stabilizer. 


\section{Solvent-induced aggregation: NMR study}

Solutions of $18 \mathrm{C} 6-\mathrm{Pt}^{\mathrm{II}}\left(5 \times 10^{-4} \mathrm{M}\right)$ were prepared in $\mathrm{MeCN}-d_{3} / 10 \% \mathrm{AcOH}$ in $\mathrm{D}_{2} \mathrm{O}(\mathrm{v} / \mathrm{v})$. The ratio of anti-solvent was set to $40 \%, 65 \%$ and $75 \%$. The resulting samples were stored for $2 \mathrm{~h}$ at room temperature and then analyzed by ${ }^{1} \mathrm{H}$ NMR spectroscopy; all collected spectra are shown in Figure S28.

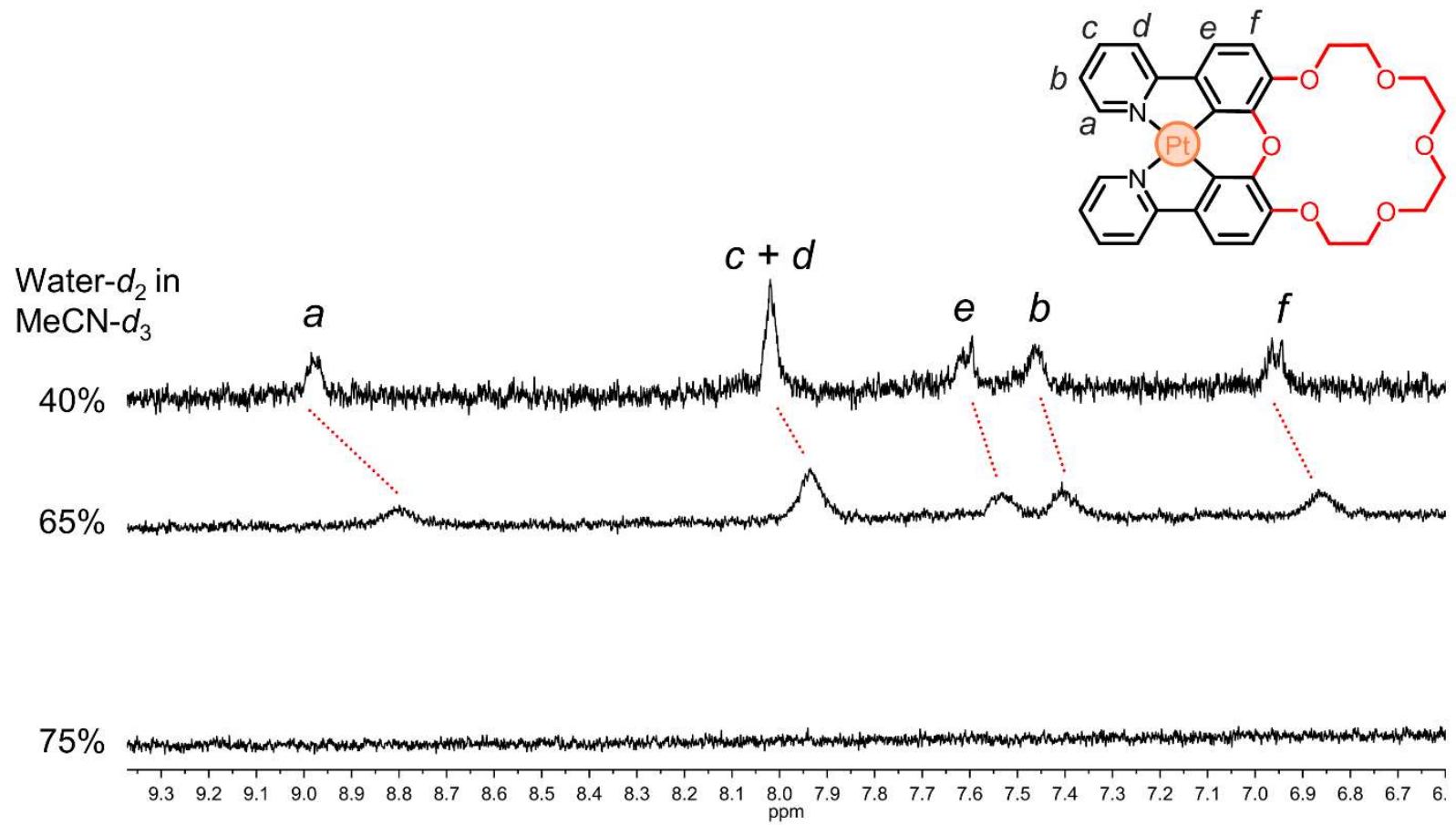

Figure S28. Partial ${ }^{1} \mathrm{H}$ NMR spectra $(400 \mathrm{MHz})$ of $18 \mathrm{C} 6-\mathrm{Pt}{ }^{\mathrm{II}}\left(5 \times 10^{-4} \mathrm{M}\right)$ in different ratios of solvent $\left(\mathrm{MeCN}-d_{3}\right)$ and antisolvent $\left(10 \% \mathrm{AcOH}\right.$ in $\left.\mathrm{D}_{2} \mathrm{O}, \mathrm{v} / \mathrm{v}\right)$. 


\section{Dimerization plots}

a

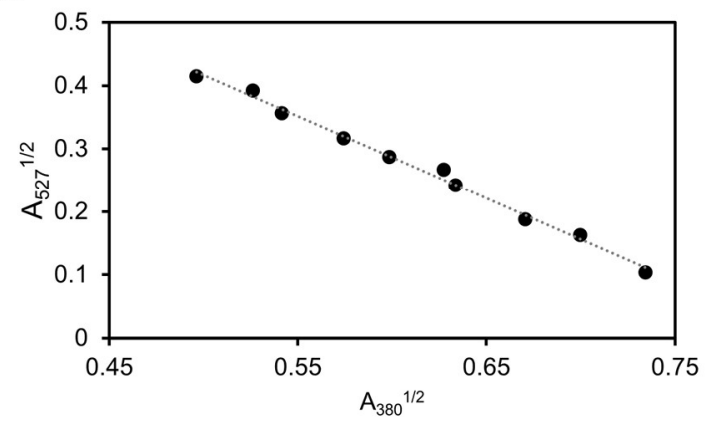

b

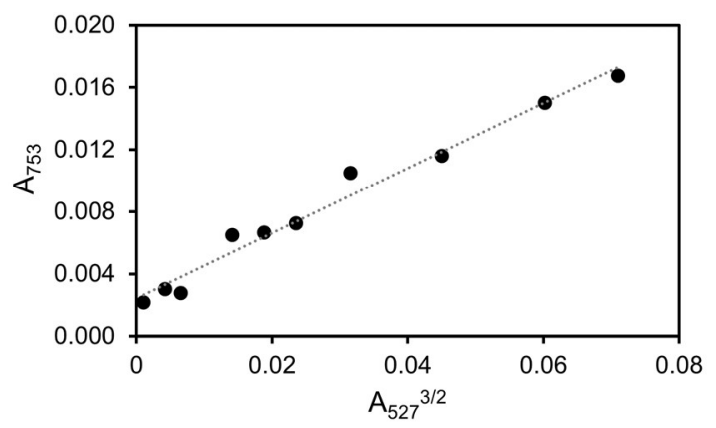

Figure S29. (a) Monomer-dimer and (b) dimer-trimer plots ${ }^{10}$ for 18C6- $\mathrm{Pt}{ }^{\mathrm{II}}$ solutions prepared in different ratios of solvent (MeCN) and antisolvent $\left(10 \% \mathrm{AcOH}\right.$ in $\mathrm{H}_{2} \mathrm{O}$, v/v); from $80 \%$ to $55 \%$ antisolvent. 


\section{Cation-prevented aggregation}

A solution of compound 18C6- $\mathrm{Pt}^{\mathrm{II}}\left(0.11 \mathrm{mg}, 1.5 \times 10^{-4} \mathrm{mmol}\right)$ in $600 \mathrm{~mL}$ of MeCN was prepared in duplicate. One of the samples was loaded with $\mathrm{KPF}_{6}$ (5 equiv.), and both systems were then diluted with $1.4 \mathrm{~mL}$ of $\mathrm{H}_{2} \mathrm{O}$. Figure $\mathrm{S} 30$ shows both samples after equilibration at room temperature and the corresponding UV-vis data.

a

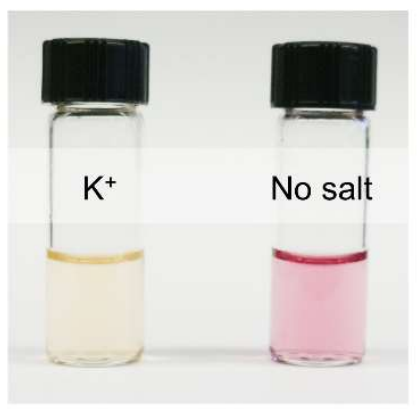

b

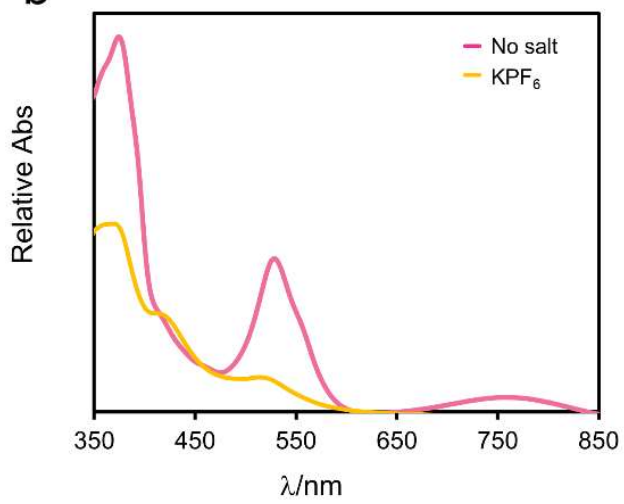

Figure S30. (a) Solutions of 18C6-PtII $\left(7.5 \times 10^{-5} \mathrm{M}\right)$ prepared in $\mathrm{MeCN} / \mathrm{H}_{2} \mathrm{O}(3: 7, \mathrm{v} / \mathrm{v})$ with and without $\mathrm{KPF}_{6}(\mathrm{left}$ and right, respectively). (b) UV-vis data recorded for both prepared samples. 


\section{Synthesis}

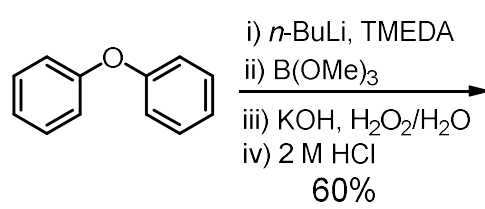<smiles>[B]c1ccc(O)c(Oc2cc(Br)ccc2Oc2ccccc2Oc2ccccc2O)c1</smiles>

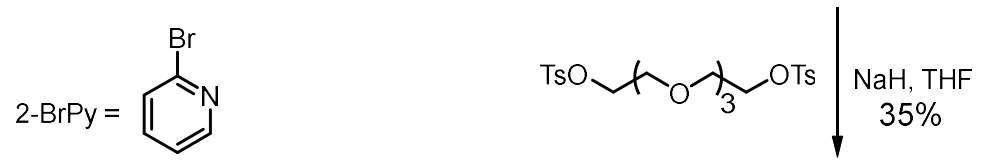

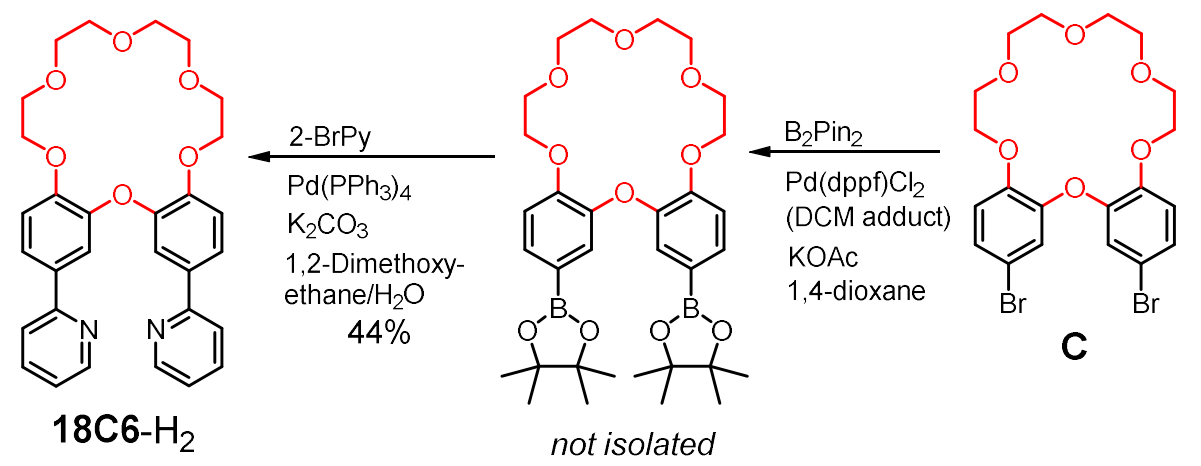

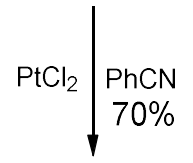<smiles></smiles>

18C6-Pt"

Scheme S2. Synthesis of the designed ligand and target complex 18C6-PtII. 


\section{Crown ether C}

Under the protection of a $\mathrm{N}_{2}$ atmosphere, a dry THF (240 mL) solution of tetraethylene glycol monotosylate ( $3.2 \mathrm{~g}, 6.4 \mathrm{mmol})$ and $\mathbf{B}(1.9 \mathrm{~g}, 5.4 \mathrm{mmol})$ was added dropwise (over $1 \mathrm{~d})$ to a refluxing suspension of $\mathrm{NaH}$ ( $4.1 \mathrm{~g}, 60 \%$ in mineral oil, $0.1 \mathrm{~mol}$ ) in dry THF (260 mL). Heating was continued for $2 \mathrm{~d}$ under $\mathrm{N}_{2}$, followed by cooling to room temperature. Unreacted $\mathrm{NaH}$ was then quenched with $\mathrm{MeOH}$ and all solvents were removed by rotary evaporation. The oily residue was partitioned between $\mathrm{CHCl}_{3}(150 \mathrm{~mL})$ and $\mathrm{H}_{2} \mathrm{O}(50 \mathrm{~mL})$, the aqueous layer was further extracted with $\mathrm{CHCl}_{3}(2 \times$ $150 \mathrm{~mL})$, and all combined organic layers were washed with $\mathrm{HCl}_{(a q)}(1 \mathrm{M}, 50 \mathrm{~mL})$, dried $\left(\mathrm{Na}_{2} \mathrm{SO}_{4}\right)$, and evaporated under vacuo. Flash column chromatography $\left(\mathrm{SiO}_{2}, 10 \% \mathrm{Et}_{2} \mathrm{O}\right.$ in $\mathrm{CHCl}_{3}, R_{f}=0.13$ yielded $\mathbf{C}$ as a white powder in 35\% yield (990 mg, $1.9 \mathrm{mmol}) .{ }^{1} \mathrm{H}$ NMR $(400 \mathrm{MHz}$, chloroform- $d$ ) $\delta 7.17$ (dd, $J=$ 8.6, 1.9 Hz, 2H), $6.96(\mathrm{~d}, J=1.8 \mathrm{~Hz}, 2 \mathrm{H}), 6.87(\mathrm{~d}, J=8.7 \mathrm{~Hz}, 2 \mathrm{H}), 4.16(\mathrm{t}, J=4.6 \mathrm{~Hz}, 4 \mathrm{H}), 3.79(\mathrm{t}, J=4.4$ $\mathrm{Hz}, 4 \mathrm{H}), 3.63$ (s, 8H). ${ }^{13} \mathrm{C}$ NMR (100 MHz, chloroform- $d$ ) $\delta 149.1,146.8,127.0,122.2,116.1,112.9$, 71.4, 71.0, 69.7, 69.4. ESI-HRMS, $m / z$ for $\left[\mathrm{C}+\mathrm{H}^{+}\right] 515.9790$ (found), 515.9783 (calculated), relative error $=1.23 \mathrm{ppm}$.

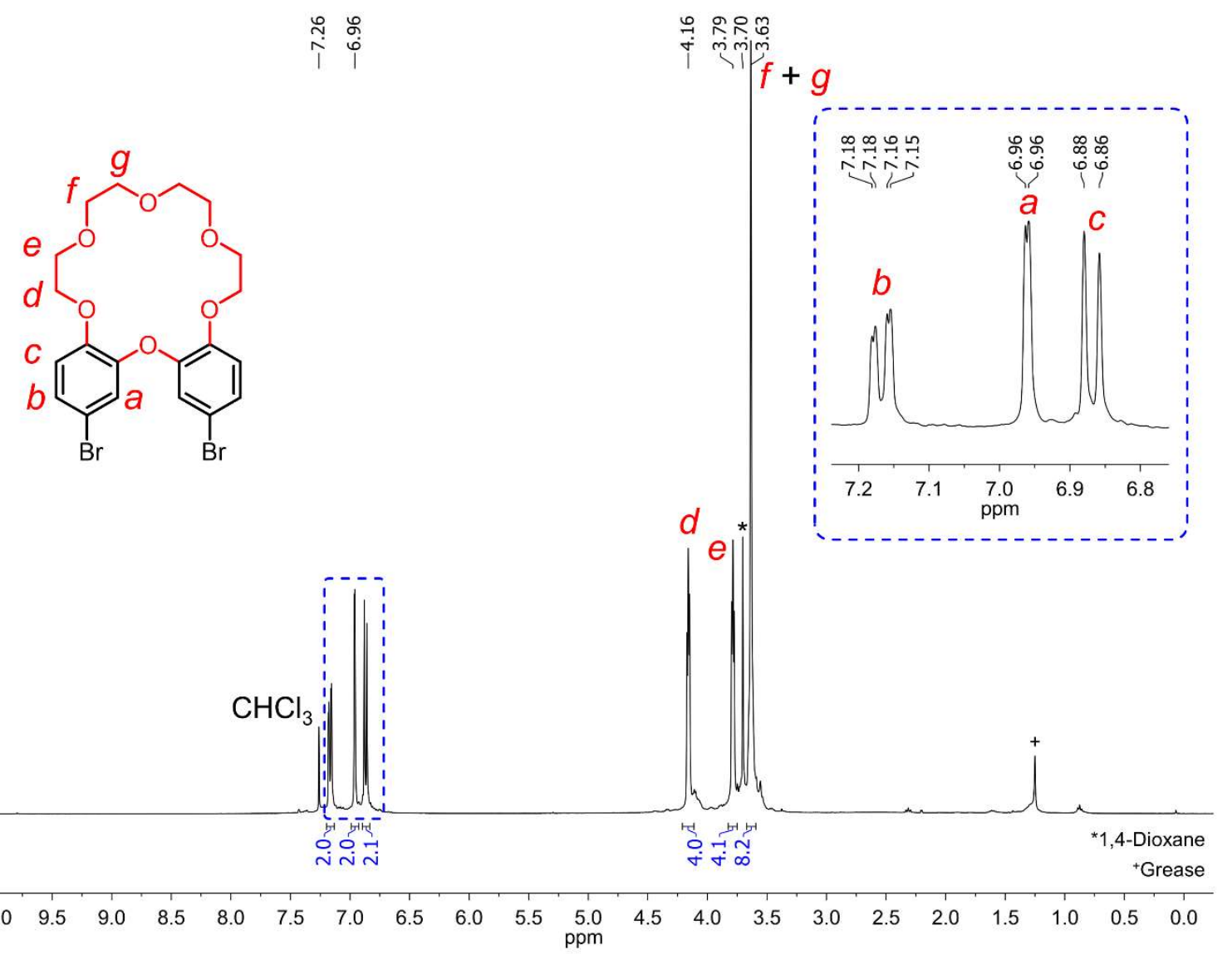

Figure S31. ${ }^{1} \mathrm{H}$ NMR spectrum (400 MHz, chloroform- $d$ ) of compound $\mathbf{C}$. 


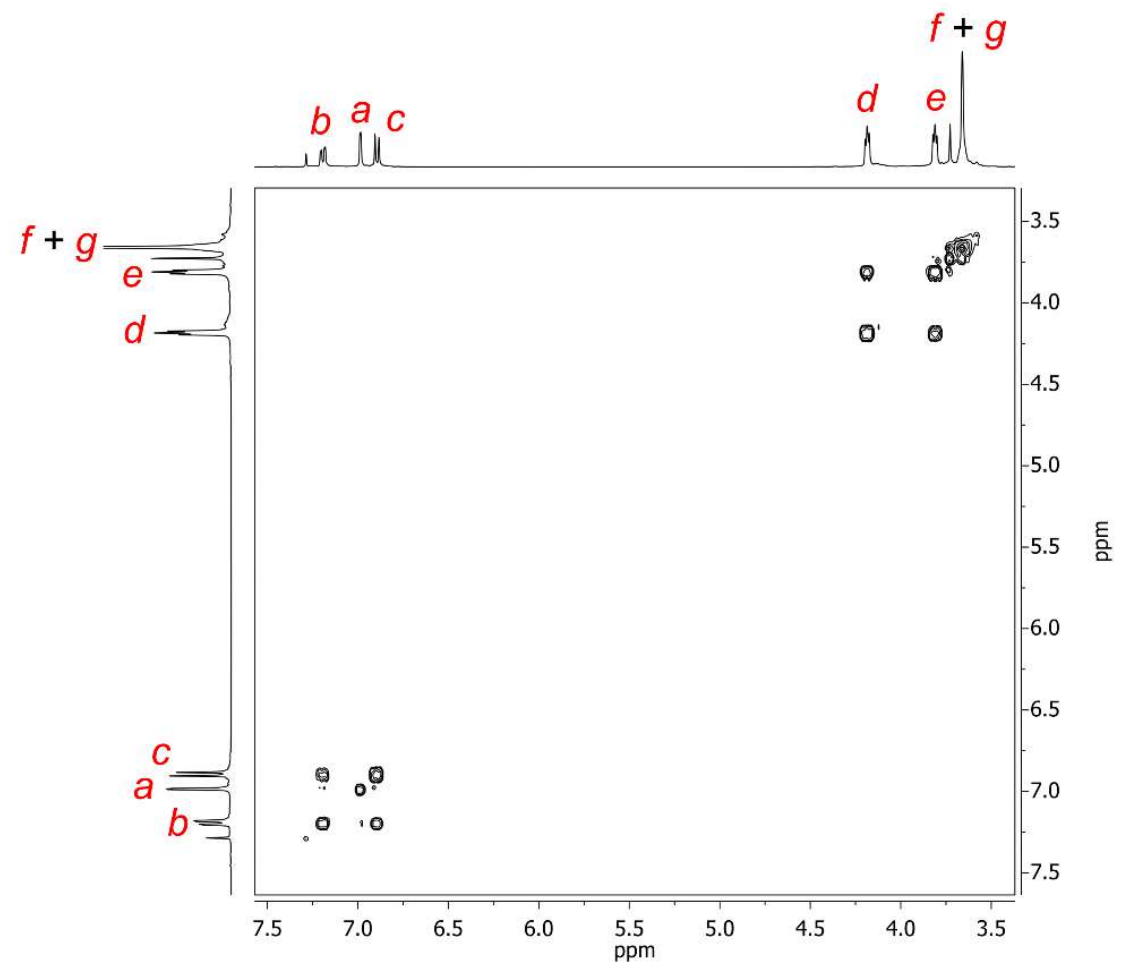

Figure S32. ${ }^{1} \mathrm{H}-1 \mathrm{H}$ COSY NMR spectrum (400 MHz, chloroform- $d$ ) of crown ether C.

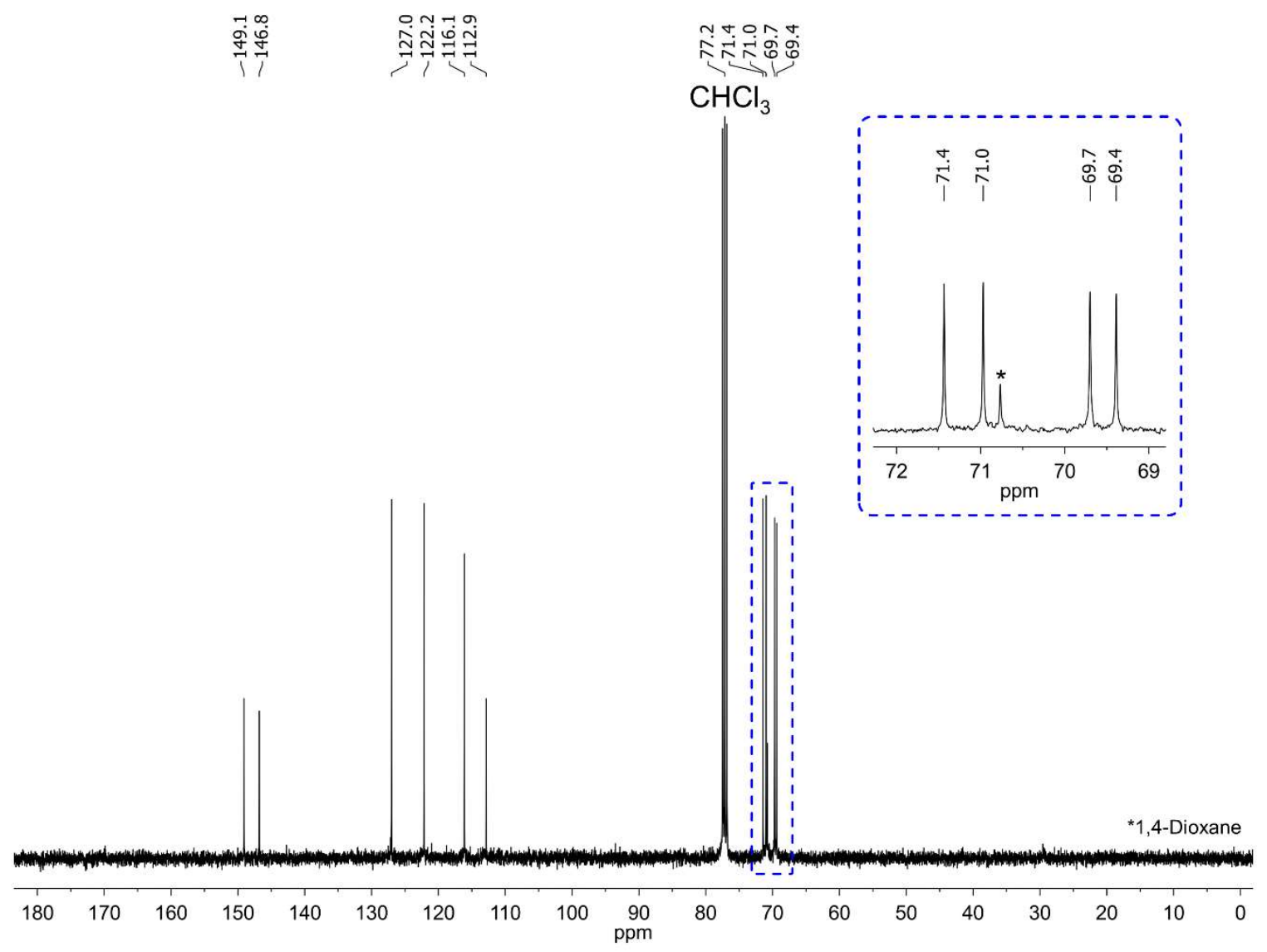

Figure S33. ${ }^{13} \mathrm{C}$ NMR spectrum $(100 \mathrm{MHz}$, chloroform- $d$ ) of the methylated compound $\mathbf{C}$. 


\section{Ligand 18C6- $\mathrm{H}_{2}$}

A mixture of compound C (854 mg, $1.7 \mathrm{mmol})$, bis(pinacolato)diboron (1.1 g, $4.1 \mathrm{mmol}),\left[1,1^{\prime}\right.$ Bis(diphenylphosphino)ferrocene]dichloropalladium(II) (DCM adduct, $134 \mathrm{mg}, 0.16 \mathrm{mmol}$ ), potassium acetate (432 mg, $4.4 \mathrm{mmol})$, and 1,4-dioxane $(30 \mathrm{~mL})$ was stirred at $80{ }^{\circ} \mathrm{C}$ for $1 \mathrm{~d}$ under $\mathrm{N}_{2}$. The solvent was then removed by rotatory evaporation. $\mathrm{H}_{2} \mathrm{O}(85 \mathrm{~mL})$ was added to the resulting black powder, and the mixture was extracted with benzene $(4 \times 35 \mathrm{~mL})$. The combined organic layers were washed with brine $(50 \mathrm{~mL})$ and then dried over anhydrous $\mathrm{MgSO}_{4}$. The solvent was removed under vacuum and the resulting brown oil was used without further purification ${ }^{1} \mathrm{H}$ NMR spectrum of the crude reaction mixture in Figure S34).

A flask containing the crude boronic ester, $\mathrm{K}_{2} \mathrm{CO}_{3}(2.1 \mathrm{~g}, 15.5 \mathrm{mmol})$ and $\mathrm{Pd}\left(\mathrm{PPh}_{3}\right)_{4}(266 \mathrm{mg}, 0.23$ mmol) was evacuated and backfilled with $\mathrm{N}_{2}$ three times, followed by the addition of a degassed (via freeze-pump-thaw) mixture of 1,2-dimethoxyethane ( $45 \mathrm{~mL})$ and $\mathrm{H}_{2} \mathrm{O}(15 \mathrm{~mL})$, and 2-bromopyridine ( $549 \mathrm{~mL}, 5.8 \mathrm{mmol}$ ). After heating the reaction under reflux for $1 \mathrm{~d}$ and under the protection of $\mathrm{N}_{2}$, the solvent was removed under vacuo to yield a brown oil, which was dissolved in DCM (80 mL) and washed with $\mathrm{H}_{2} \mathrm{O}(50 \mathrm{~mL})$. The aqueous layer was washed with DCM $(3 \times 80 \mathrm{~mL})$; all organic layers were combined, washed with brine $(50 \mathrm{~mL})$, dried $\left(\mathrm{MgSO}_{4}\right)$, and evaporated under vacuum. Following flash column purification $\left(\mathrm{SiO}_{2}, 30 \% \mathrm{Et}_{2} \mathrm{O}\right.$ in $\mathrm{CHCl}_{3}$ followed by $5 \% \mathrm{MeOH}$ in $\mathrm{CHCl}_{3}, R_{f}=$ 0.12 in the latter eluent), ligand 18C6-PtII was obtained in $44 \%$ yield (370 $\mathrm{mg}, 0.7 \mathrm{mmol}$ ) as a white solid. ${ }^{1} \mathrm{H}$ NMR (400 MHz, chloroform- $d$ ) $\delta 8.59(\mathrm{~d}, J=4.4 \mathrm{~Hz}, 2 \mathrm{H}), 7.77(d, J=8.4 \mathrm{~Hz}, 2 \mathrm{H}), 7.67(\mathrm{t}, J=$ $7.6 \mathrm{~Hz}, 2 \mathrm{H}), 7.60-7.50(\mathrm{~m}, 4 \mathrm{H}), 7.15(\mathrm{t}, J=5.9 \mathrm{~Hz}, 2 \mathrm{H}), 7.09(\mathrm{~d}, J=8.5 \mathrm{~Hz}, 2 \mathrm{H}), 4.26(\mathrm{t}, J=4.3 \mathrm{~Hz}, 4 \mathrm{H})$, $3.83(\mathrm{t}, J=4.2 \mathrm{~Hz}, 4 \mathrm{H}), 3.68(\mathrm{~s}, 8 \mathrm{H}) .{ }^{13} \mathrm{C}$ NMR $(100 \mathrm{MHz}$, chloroform- $d$ ) $\delta 156.4,150.7,149.3,146.5$, 137.2, 132.4, 122.7, 121.8, 120.3, 117.5, 114.5, 71.3, 70.8, 69.7, 69.0. ESI-HRMS, $m / z$ for $\left[18 C 6-\mathrm{H}_{2}+\right.$ $\mathrm{H}^{+}$] 515.2185 (found), 515.2177 (calculated), relative error $=-1.55 \mathrm{ppm}$. 


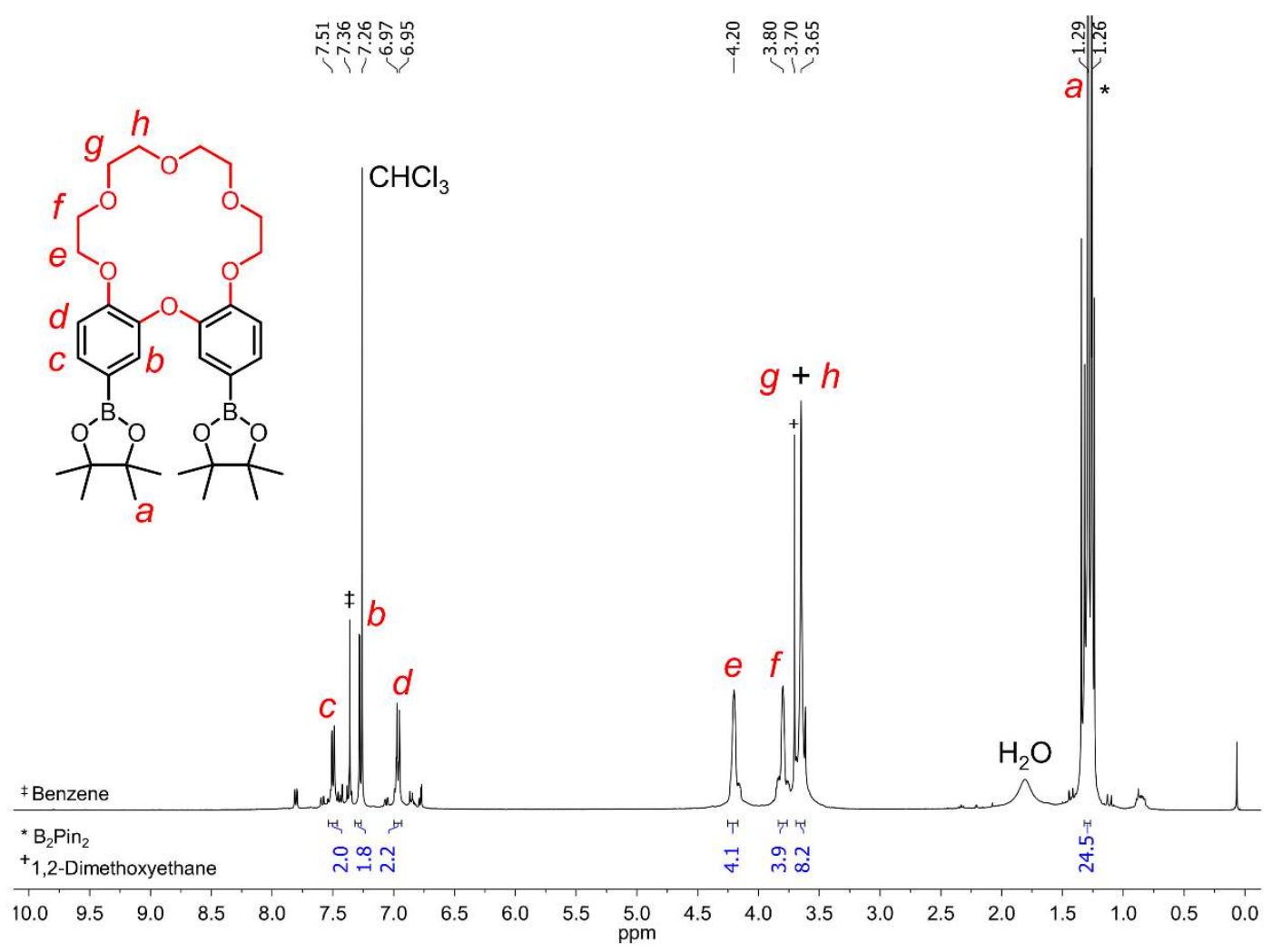

Figure S34. ${ }^{1} \mathrm{H}$ NMR spectrum (400 MHz, chloroform- $d$ ) of the obtained crude boronic ester.

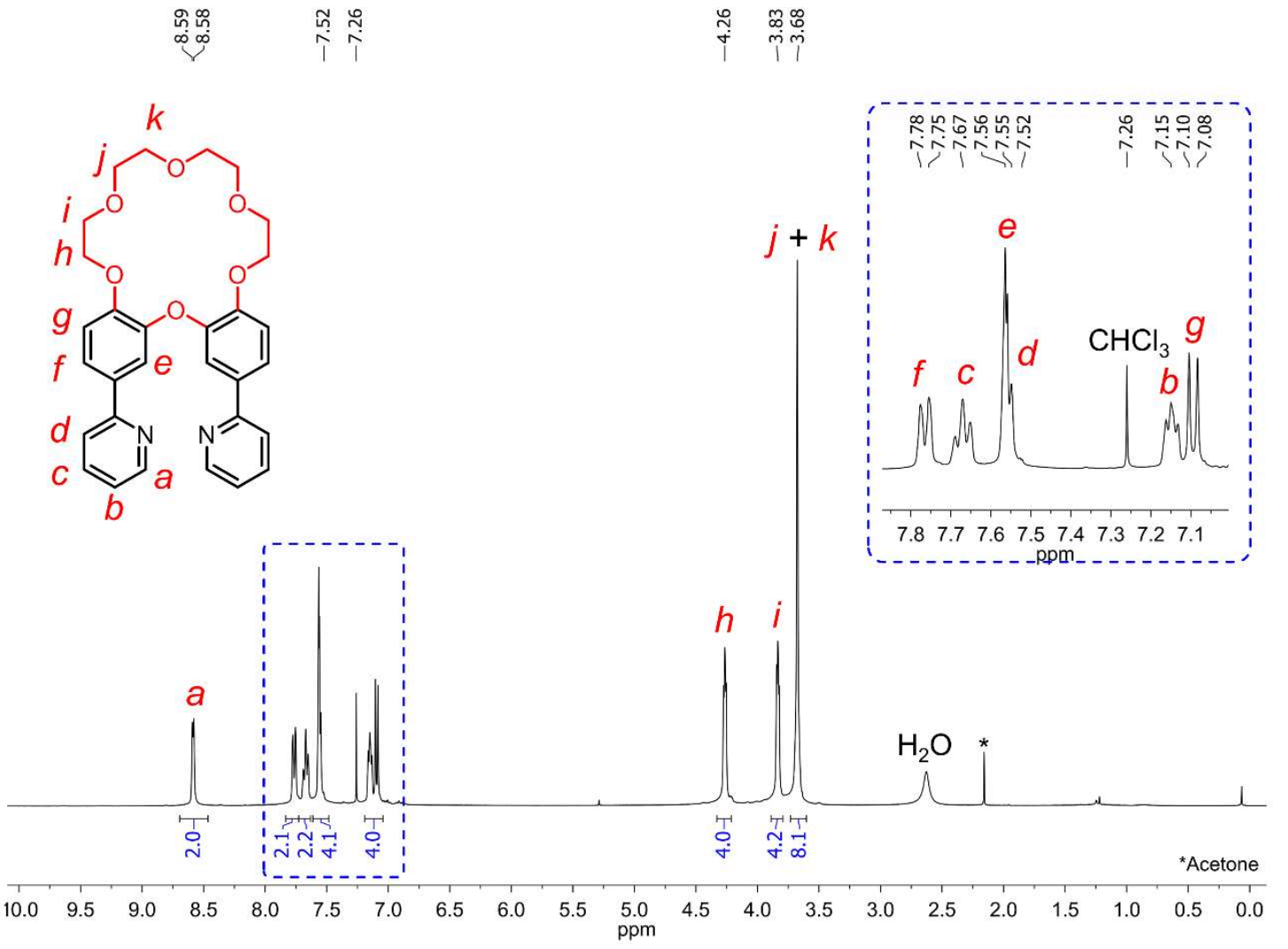

Figure S35. ${ }^{1 \mathrm{H}}$ NMR spectrum (400 MHz, chloroform- $d$ ) of ligand 18C6- $\mathrm{H}_{2}$. 


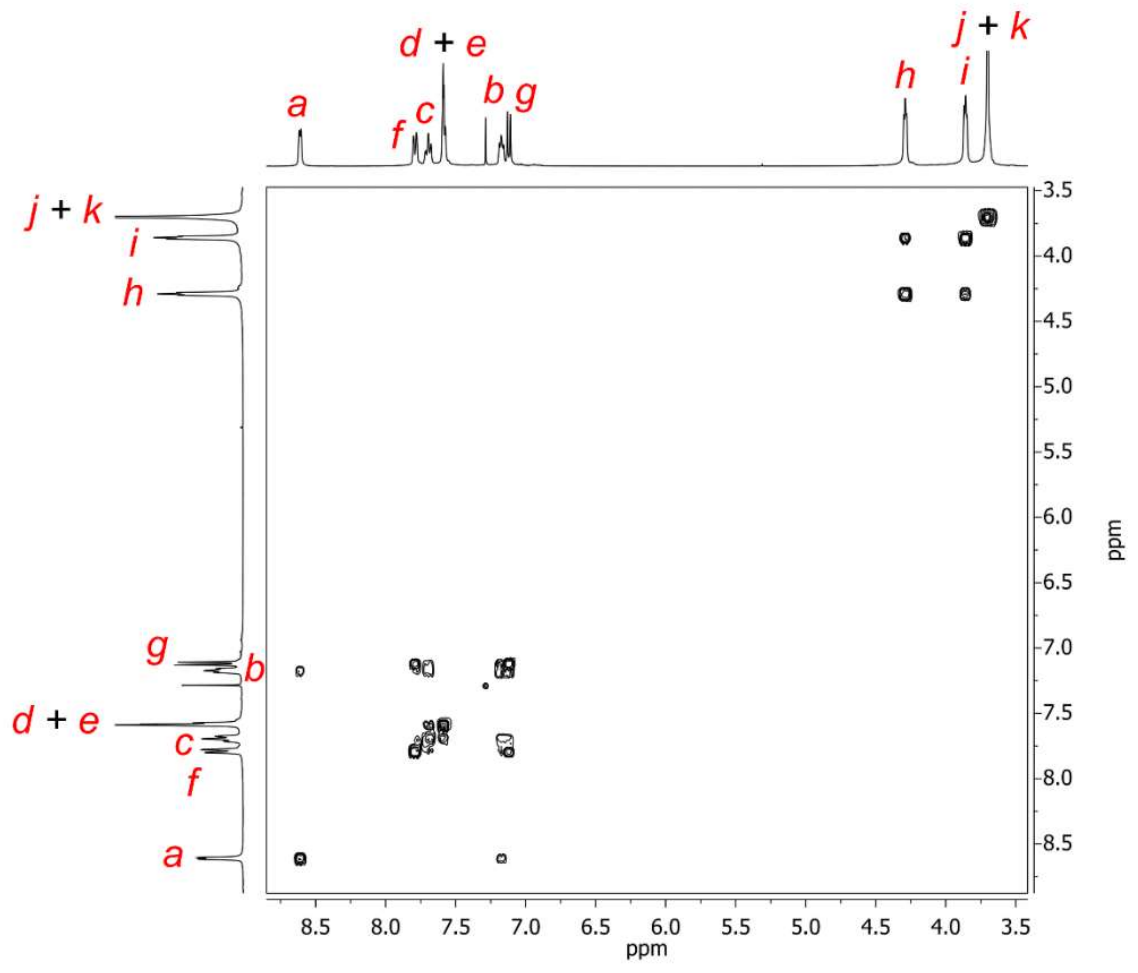

Figure S36. ${ }^{1 \mathrm{H}-1}{ }^{-1} \mathrm{C}$ COSY NMR spectrum ( $400 \mathrm{MHz}$, chloroform- $d$ ) of $\mathbf{1 8 C 6}-\mathrm{H}_{2}$.
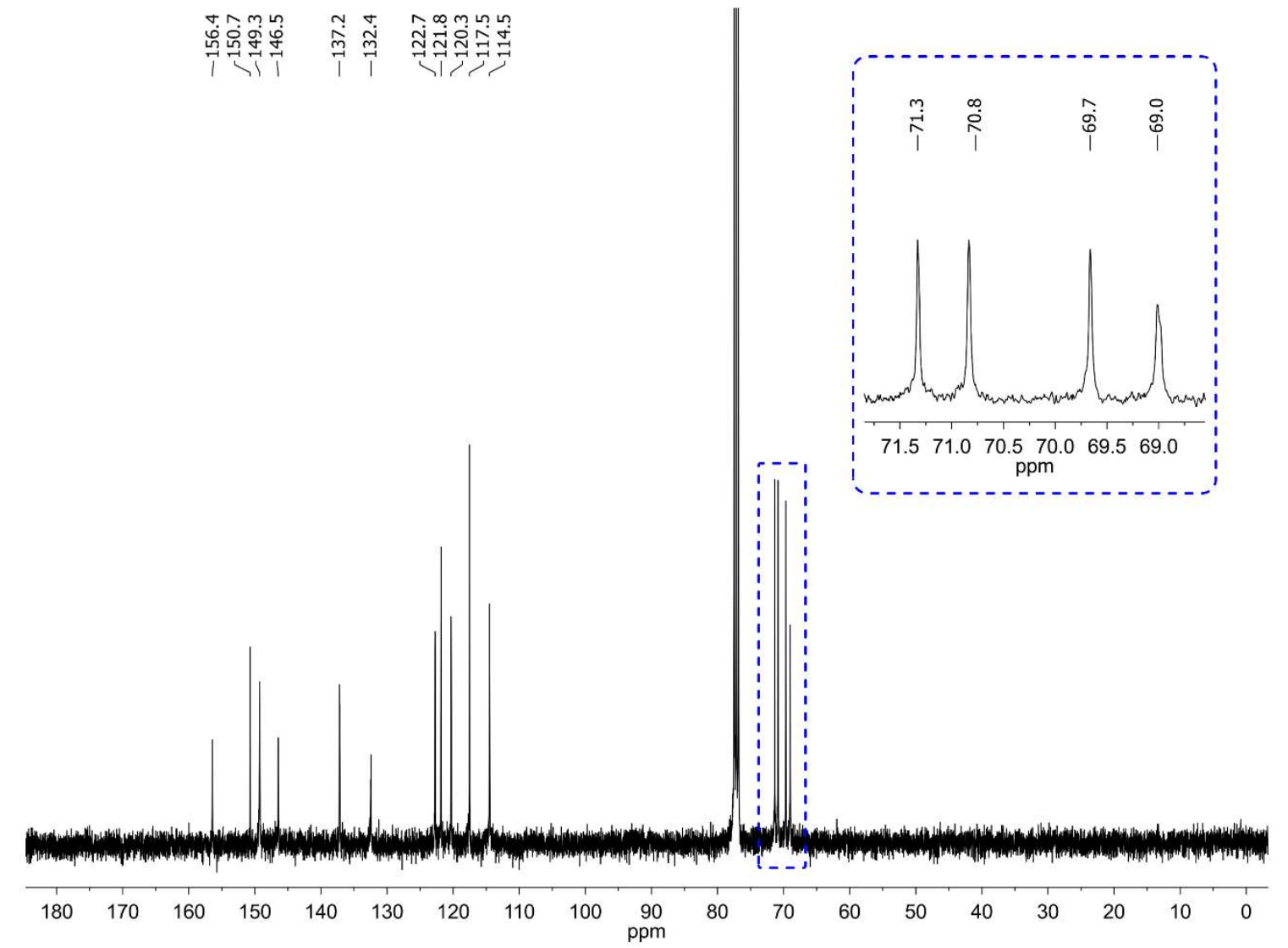

Figure S37. ${ }^{13} \mathrm{C}$ NMR spectrum (100 MHz, chloroform- $d$ ) of ligand $\mathbf{1 8 C 6}-\mathrm{H}_{2}$. 


\section{Square-planar Pt(II) complex 18C6-PtII}

A flask loaded with 18C6- $\mathrm{H}_{2}(50 \mathrm{mg}, 0.1 \mathrm{mmol})$ and $\mathrm{PtCl}_{2}(26.2 \mathrm{mg}, 0.1 \mathrm{mmol})$ was evacuated and backfilled with $\mathrm{N}_{2}$ three times, followed by the addition of degassed (via sparging with $\mathrm{Ar}$ ) PhCN. The obtained suspension was heated at $180{ }^{\circ} \mathrm{C}$ under $\mathrm{N}_{2}$ for $3 \mathrm{~d}$ and then cooled down to room temperature. PhCN was removed under vacuum and the residue was dissolved in DCM (20 mL) and washed $\mathrm{H}_{2} \mathrm{O}(30 \mathrm{~mL})$; the organic layer was repeatedly extracted with DCM $(3 \times 20 \mathrm{~mL})$ and all organic layers were combined, dried $\left(\mathrm{Na}_{2} \mathrm{SO}_{4}\right)$, and concentrated by rotary evaporation. The residue was subjected to column purification $\left(\mathrm{SiO}_{2}, 2.5 \%\right.$ triethylamine in $\left.\mathrm{DCM}, R_{f}=0.27\right)$ to obtain $18 \mathrm{C6}-\mathrm{Pt}^{\mathrm{II}}$ as a crystalline, bright orange solid in $70 \%$ yield ( $49 \mathrm{mg}, 0.07 \mathrm{mmol}$ ). A single crystal suitable for SCXRD analysis was grown by vapour diffusion of hexanes into a solution of 18C6-PtII in DCM. ${ }^{1} \mathrm{H}$ NMR (400 MHz, DCM- $d_{2}$ ) $\delta 8.85(\mathrm{~d}, \mathrm{~J}=5.5 \mathrm{~Hz}, 2 \mathrm{H}), 8.12-7.66(\mathrm{~m}, 4 \mathrm{H}), 7.49$ (d, J = 8.2 Hz, 2H), 7.31 $(\mathrm{td}, \mathrm{J}=5.7,2.9 \mathrm{~Hz}, 2 \mathrm{H}), 6.88(\mathrm{~d}, \mathrm{~J}=8.3 \mathrm{~Hz}, 2 \mathrm{H}), 4.35(\mathrm{t}, \mathrm{J}=5.0 \mathrm{~Hz}, 4 \mathrm{H}), 4.05(\mathrm{t}, \mathrm{J}=5.0 \mathrm{~Hz}, 4 \mathrm{H}), 3.90-$ 3.63 (m, 8H). ${ }^{13} \mathrm{C}$ NMR (100 MHz, DCM-d $) \delta 165.9,150.4,148.3,141.3,139.8,138.7,127.8,121.9$, 119.8, 119.6, 109.2, 71.6, 71.6, 70.7, 69.6. UV-vis $(\mathrm{MeCN}): \lambda_{\max }=291 \mathrm{~nm}\left(\varepsilon=2.5 \times 10^{4} \mathrm{M}^{-1} \mathrm{~cm}^{-1}\right) ; 313$ $\mathrm{nm}\left(\varepsilon=2.1 \times 10^{4} \mathrm{M}^{-1} \mathrm{~cm}^{-1}\right) ; 381 \mathrm{~nm}\left(\varepsilon=1.9 \times 10^{4} \mathrm{M}^{-1} \mathrm{~cm}^{-1}\right)$. 


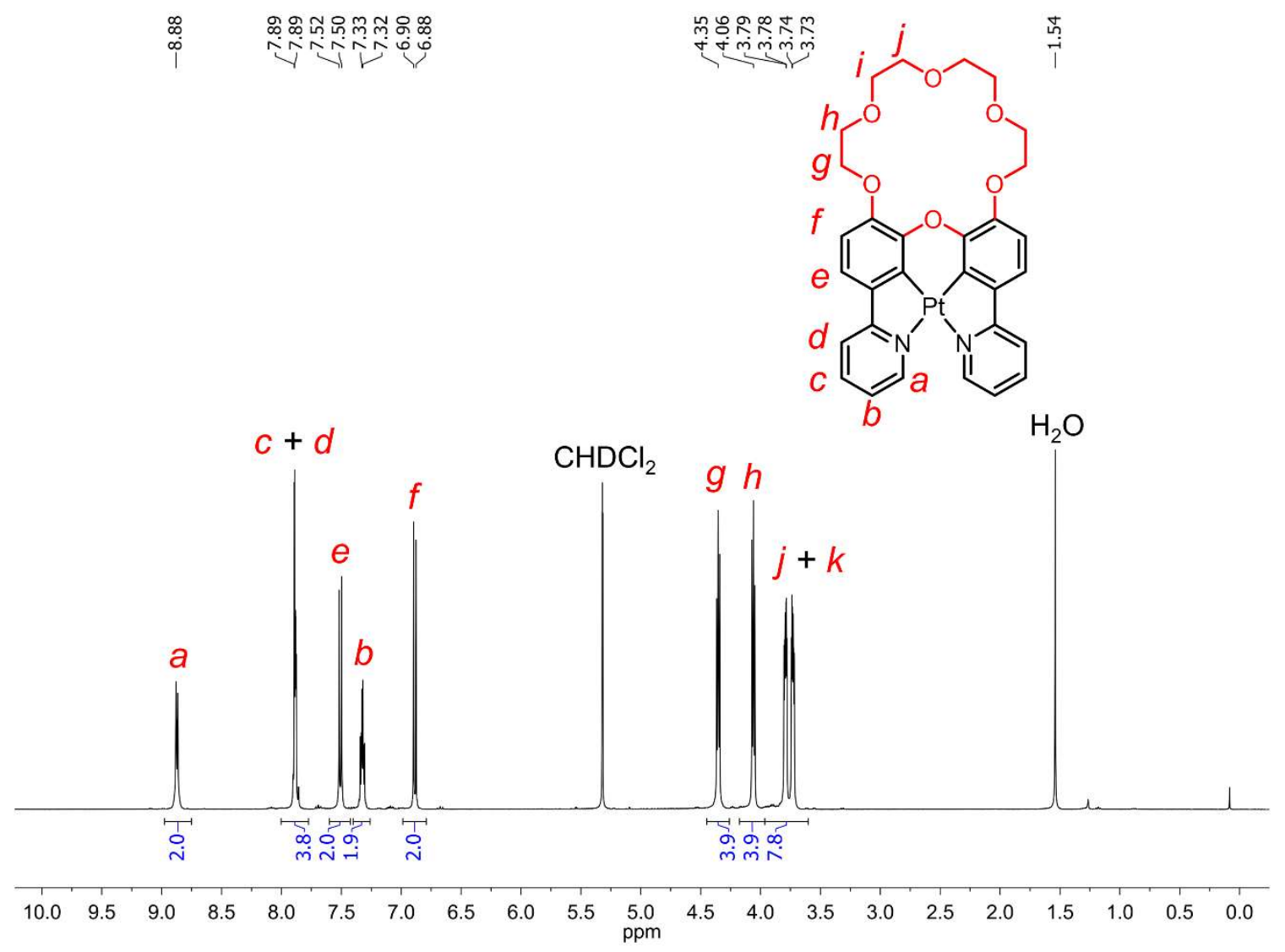

Figure S38. ${ }^{1} \mathrm{H}$ NMR spectrum $\left(400 \mathrm{MHz}\right.$, DCM- $\left.d_{2}\right)$ of complex 18C6-Pt'

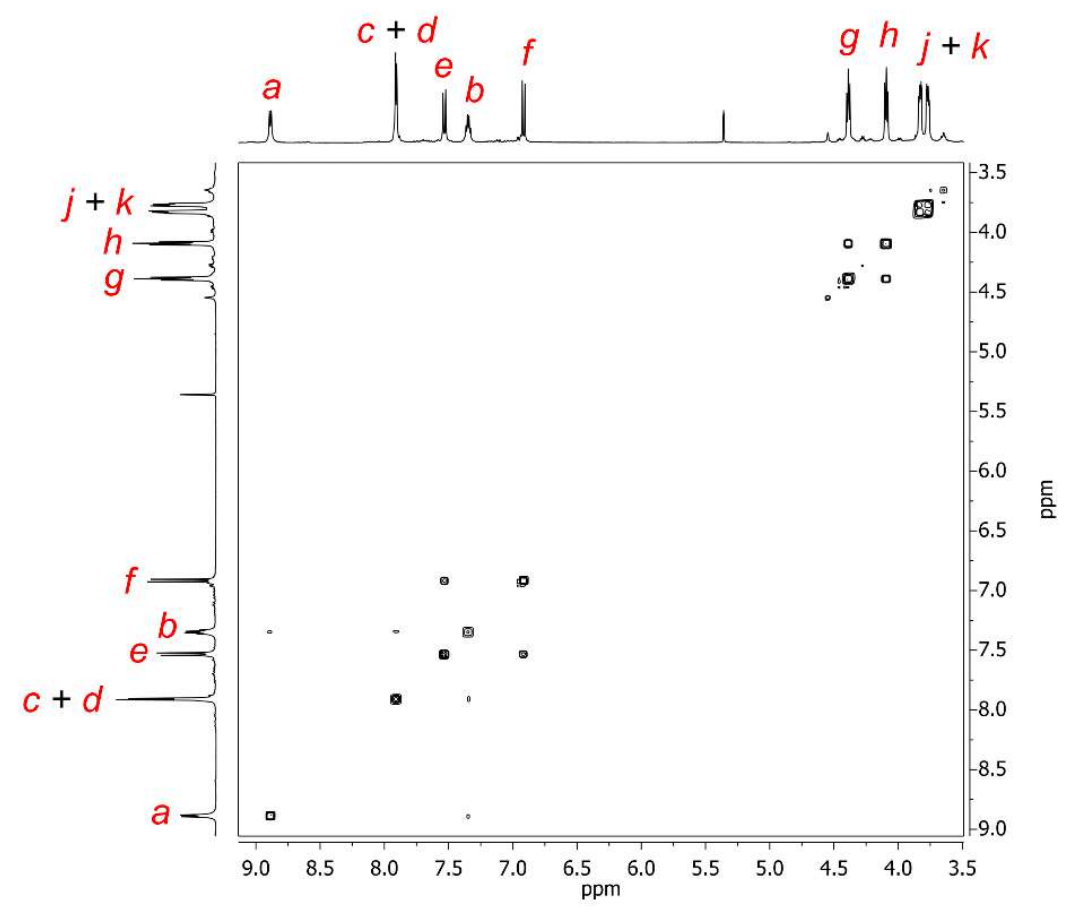

Figure S39. ${ }^{1} \mathrm{H}-1 \mathrm{H}$ COSY NMR spectrum (400 MHz, DCM- $\left.d_{2}\right)$ of 18C6-Pt ${ }^{\mathrm{II}}$. 


$$
\text { ll }
$$

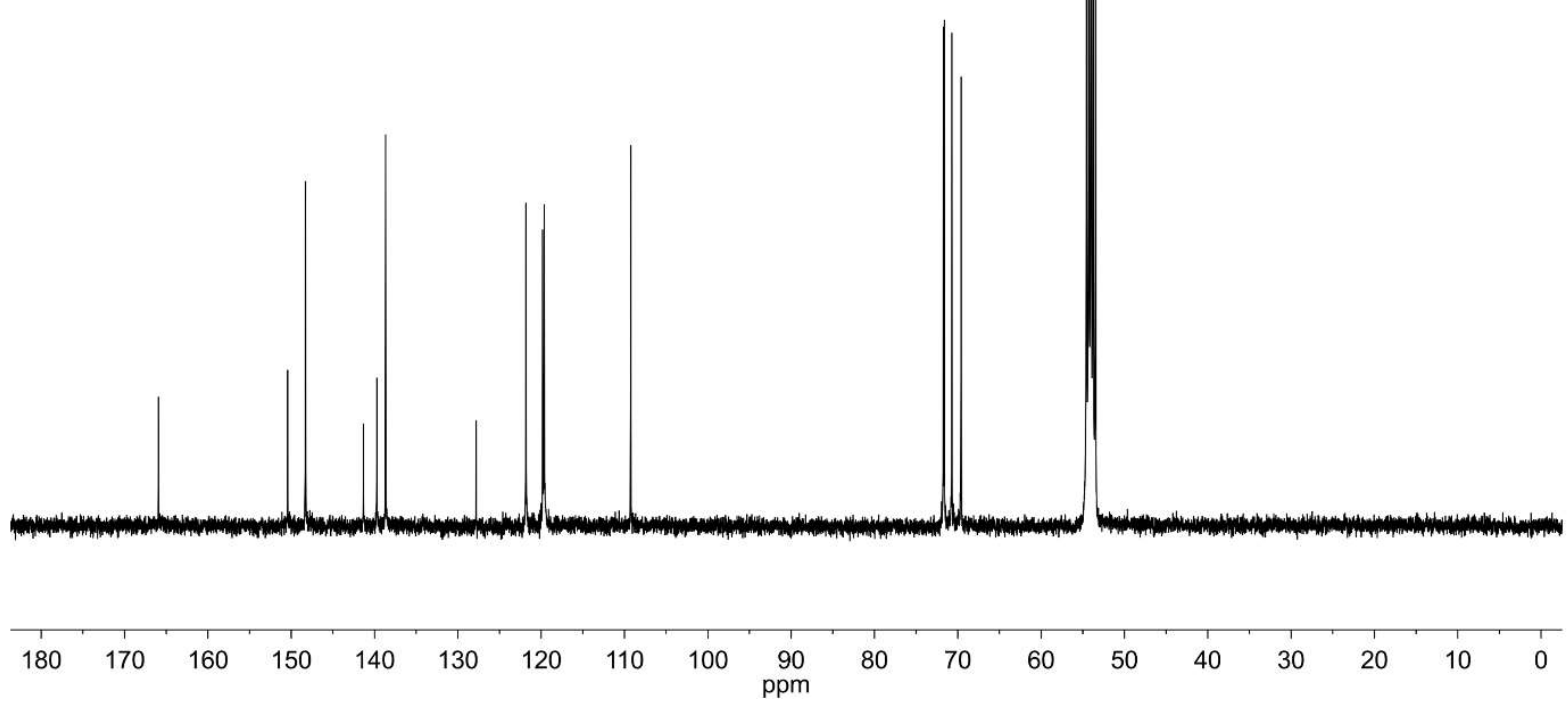

Figure S40. ${ }^{13} \mathrm{C}$ NMR spectrum (100 MHz, DCM- $\left.d_{2}\right)$ of ligand 18C6-PtII.

a

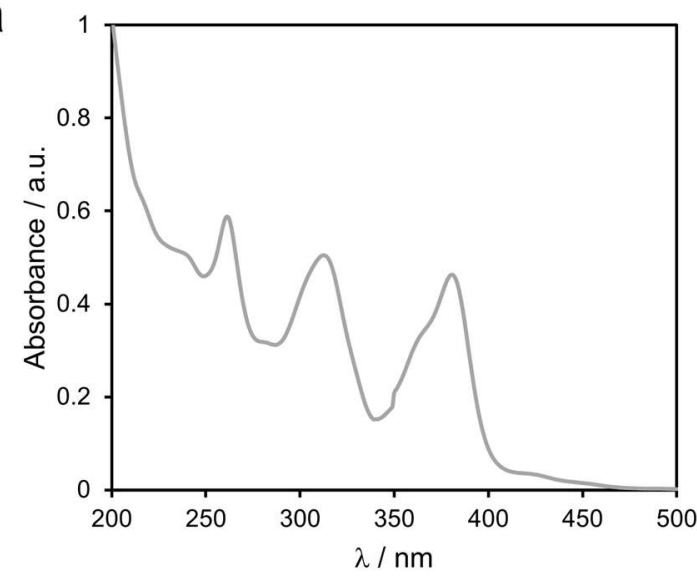

b

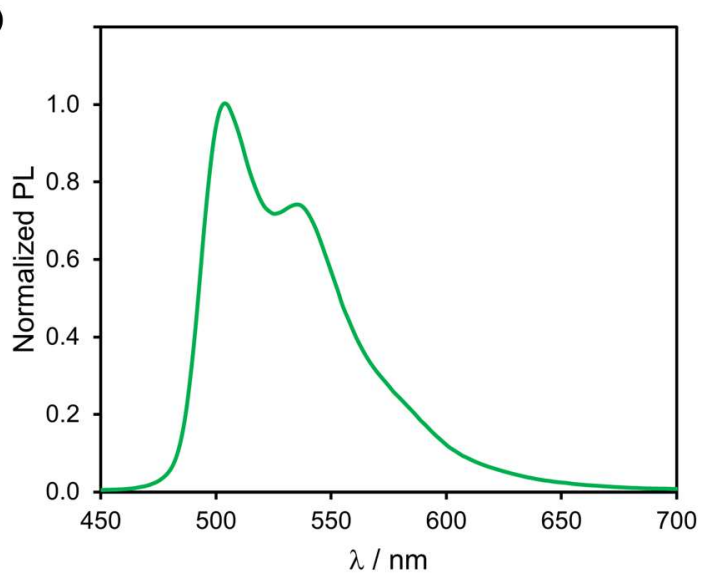

Figure S41. (a) UV-vis and (b) normalized emission spectra of 18C6-PtII in MeCN $\left(2.4 \times 10^{-5} \mathrm{M}\right)$. 


\section{Crystallographic data}

\section{C6-PtIV $(\mathbf{m m 4 2 8})$}

Data collection

A yellow crystal (plate, approximate dimensions $0.70 \times 0.23 \times 0.16 \mathrm{~mm}^{3}$ ) was placed on a mylar loop in oil and mounted on a Bruker APEX II area detector diffractometer at $100 \mathrm{~K}$. The data collection was carried out using $\mathrm{MoK}_{\alpha}$ radiation (TRIUMPH monochromator, sealed X-ray tube, 45kV, 30mA), with a frame time of 15 seconds and a detector distance of $40 \mathrm{~mm}$. A collection strategy was calculated and complete data to a resolution of $0.77 \AA$ aith a redundancy of 6.13 were collected. The frames were integrated with the Bruker SAINT ${ }^{3}$ software package using a narrow-frame algorithm. The integration of the data using an orthorhombic unit cell yielded a total of 38312 reflections to a maximum $\theta$ angle of $27.54^{\circ}$ (0.77 $\AA$ resolution), of which 6885 were independent (average redundancy 5.565, completeness $=99.1 \%$, Rint $=3.58 \%$, Rsig $=3.83 \%)$ and $6008(87.26 \%)$ were greater than $2 \sigma\left(F^{2}\right)$. The final cell constants of $a=26.395(5) \AA, b=8.1629(12) \AA, c=14.113(2) \AA$, volume $=3040.8(8) \AA^{3}$, are based upon the refinement of the XYZ-centroids of reflections above 20 $\sigma(I)$. Data were corrected for absorption effects using the Multi-Scan method (SADABS). ${ }^{4}$ The calculated minimum and maximum transmission coefficients (based on crystal size) are 0.5892 and 0.7456 .

\section{Structure solution and refinement}

The space group P n a 21 was determined based on intensity statistics and systematic absences. The structure was solved using the SHELX ${ }^{5,6}$ suite of programs and refined using full-matrix least-squares on $\mathrm{F}^{2}$ within the OLEX2 ${ }^{7}$ suite. An intrinsic phasing solution was calculated, which provided most non-hydrogen atoms from the E-map. Full-matrix least squares / difference Fourier cycles were performed, which located the remaining non-hydrogen atoms. All non-hydrogen atoms were refined with anisotropic displacement parameters. The hydrogen atoms were placed in ideal positions and refined as riding atoms with relative isotropic displacement parameters. The final full matrix least squares refinement converged to $\mathrm{R} 1=0.0332$ and $\mathrm{wR} 2=0.0764$ ( $\mathrm{F}^{2}$, all data). The goodness-of-fit was 1.070. On the basis of the final model, the calculated density was $1.886 \mathrm{~g} / \mathrm{cm}^{3}$ and $\mathrm{F}(000), 1696$ e- The compound was modelled s a 2-component inversion twin (merohedral, twin law -1 0 0, 0 -1 0, $00-1$, domain ratio $94: 6$ ). Disorder on the crown ether moiety was modelled by refining two parts with occupancies $0.744(14)$ and $0.256(14)$. Restraints on bond lengths, and constraints on atomic displacement parameters were employed. CCDC Deposition Number: 2087661 


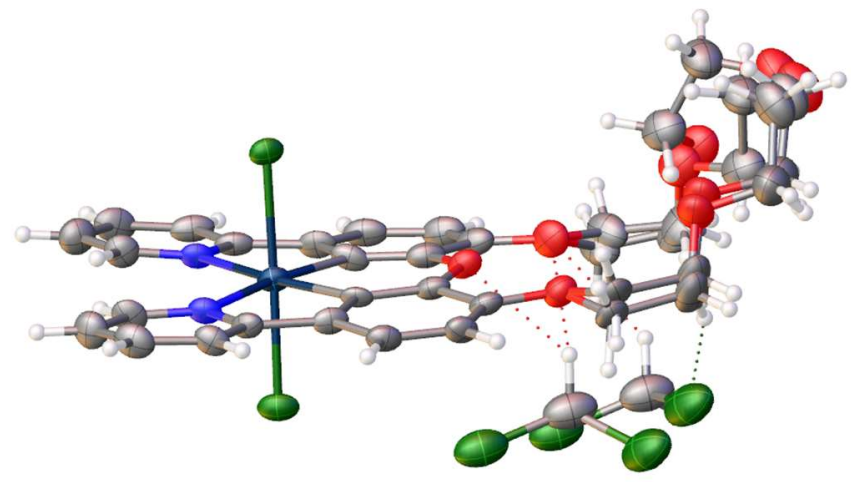

Figure S42. Molecular structure of 18C6- $\mathrm{Pt}^{\mathrm{IV}}$ as determined by SCXRD. Ellipsoids are plotted at 50\% probability level.

\section{C6- $\mathrm{H}_{2}(\mathrm{~mm} 393)$}

Data collection

A colourless crystal (plate, approximate dimensions $0.65 \times 0.42 \times 0.23 \mathrm{~mm} 3$ ) was placed on a mylar loop in oil and mounted on a Bruker APEX II area detector diffractometer at $100 \mathrm{~K}$. The data collection was carried out using $\mathrm{MoK}_{\alpha}$ radiation (TRIUMPH monochromator, sealed X-ray tube, 45kV, 30mA), with a frame time of 2 seconds and a detector distance of $40 \mathrm{~mm}$. A collection strategy was calculated and complete data to a resolution of $0.77 \AA$ with a redundancy of 3 were collected. frames were integrated with the Bruker SAINT $^{3}$ software package using a narrow-frame algorithm. The integration of the data using a monoclinic unit cell yielded a total of 31166 reflections to a maximum $\theta$ angle of $27.54^{\circ}(0.77 \AA$ resolution), of which 6023 were independent (average redundancy 5.174, completeness $=99.2 \%$, Rint $=3.65 \%$, Rsig $=2.96 \%)$ and $4947(82.14 \%)$ were greater than $2 \sigma\left(\mathrm{F}^{2}\right)$. The final cell constants of $a=7.3610(3) \AA, b=25.5081(9) \AA, c=14.0025(5) \AA, \beta=91.535(2)^{\circ}$, volume $=2628.24(17) \AA^{3}$, are based upon the refinement of the XYZ-centroids of reflections above $20 \sigma(\mathrm{I})$. Data were corrected for absorption effects using the Multi-Scan method (SADABS). ${ }^{4}$ The calculated minimum and maximum transmission coefficients (based on crystal size) are 0.9400 and 0.9780 .

\section{Structure solution and refinement}

The space group P 1 2 1 /n 1 was determined based on intensity statistics and systematic absences. The structure was solved using the SHELX ${ }^{5,6}$ suite of programs and refined using full-matrix leastsquares on F2 within the OLEX27 suite. An intrinsic phasing solution was calculated, which provided most non-hydrogen atoms from the E-map. Full-matrix least squares / difference Fourier cycles were performed, which located the remaining non-hydrogen atoms. All non-hydrogen atoms were refined 
with anisotropic displacement parameters. The hydrogen atoms were placed in ideal positions and refined as riding atoms with relative isotropic displacement parameters. The final full matrix least squares refinement converged to $\mathrm{R} 1=0.0392$ and $\mathrm{wR} 2=0.0989$ (F2, all data). The goodness-of-fit was 1.022 . On the basis of the final model, the calculated density was $1.346 \mathrm{~g} / \mathrm{cm} 3$ and $F(000), 1128$ e-. CCDC Deposition Number: 2090452.

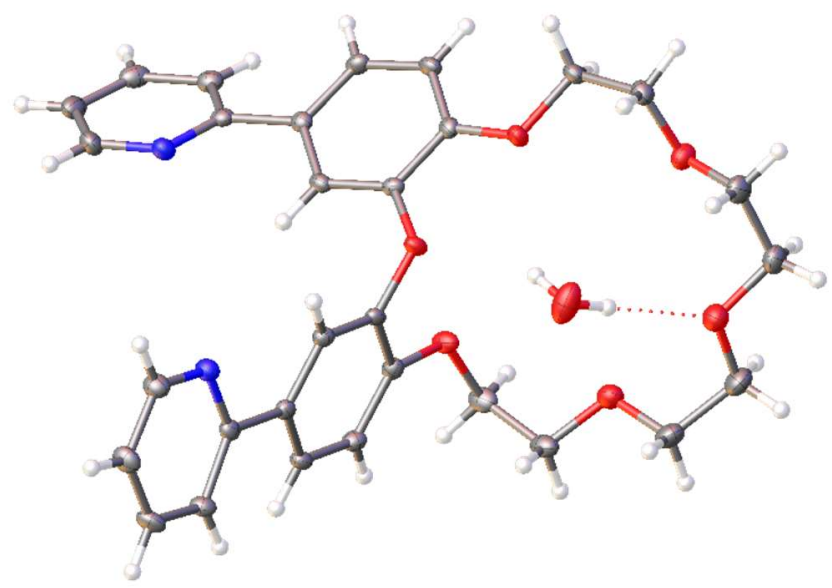

Figure S43. Molecular structure of $\mathbf{1 8 C 6}-\mathrm{H}_{2}$ as determined by SCXRD. Ellipsoids are plotted at 50\% probability level.

\section{C6-PtII (DCM solvate, mm429)}

\section{Data collection}

An orange crystal (plate, approximate dimensions $0.13 \times 0.07 \times 0.06 \mathrm{~mm}^{3}$ ) was placed on a mylar loop in oil and mounted on a Bruker APEX II area detector diffractometer at $100 \mathrm{~K}$. The data collection was carried out using $\mathrm{MoK}_{\alpha}$ radiation (TRIUMPH monochromator, sealed X-ray tube, 45kV, 30mA), with a frame time of 60 seconds and a detector distance of $40 \mathrm{~mm}$. A collection strategy was calculated and complete data to a resolution of $0.77 \AA$ with a redundancy of 4.2 were collected. The frames were integrated with the Bruker SAINT ${ }^{3}$ software package using a narrow-frame algorithm. The integration of the data using a monoclinic unit cell yielded a total of 19800 reflections to a maximum $\theta$ angle of $27.50^{\circ}(0.77 \AA$ resolution), of which 6488 were independent (average redundancy 3.052, completeness $=99.6 \%$, Rint $=7.28 \%$, Rsig $=9.45 \%)$ and $4393(67.71 \%)$ were greater than $2 \sigma\left(F^{2}\right)$. The final cell constants of $a=18.024(4) \AA, b=9.985(2) \AA, c=16.307(3) \AA, \beta=$ $104.715(6)^{\circ}$, volume $=2838.5(10) \AA^{3}$, are based upon the refinement of the XYZ-centroids of reflections above $20 \sigma(\mathrm{I})$. Data were corrected for absorption effects using the Multi-Scan method (SADABS). ${ }^{4}$ The calculated minimum and maximum transmission coefficients (based on crystal size) are 0.5984 and 0.7456 


\section{Structure solution and refinement}

The space group P 1 21/c 1 was determined based on intensity statistics and systematic absences. The structure was solved using the SHELX suite of programs ${ }^{5,6}$ and refined using full-matrix leastsquares on $\mathrm{F}^{2}$ within the OLEX $2^{7}$ suite. An intrinsic phasing solution was calculated, which provided most non-hydrogen atoms from the E-map. Full-matrix least squares / difference Fourier cycles were performed, which located the remaining non-hydrogen atoms. All non-hydrogen atoms were refined with anisotropic displacement parameters. The hydrogen atoms were placed in ideal positions and refined as riding atoms with relative isotropic displacement parameters. The final full matrix least squares refinement converged to $\mathrm{R} 1=0.0410$ and $\mathrm{wR} 2=0.0928$ (F2, all data). The goodness-of-fit was 0.98 . On the basis of the final model, the calculated density was $1.855 \mathrm{~g} / \mathrm{cm}^{3}$ and $\mathrm{F}(000), 1560 \mathrm{e}^{-}$ . Disordered dichloromethane solvent forms hydrogen bonds with the crown ether moiety. CCDC Deposition Number: 2087658

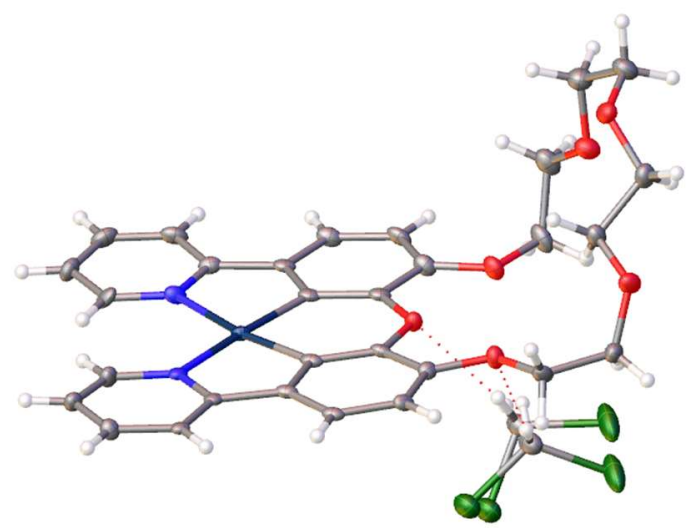

Figure S44. Molecular structure of 18C6-PtII (DCM solvate) as determined by SCXRD. Ellipsoids are plotted at 50\% probability level.

\section{C6-PtII $つ \mathrm{KPF}_{6}(\mathrm{~mm} 434)$}

Data collection

An orange crystal (plate, approximate dimensions $0.36 \times 0.13 \times 0.12 \mathrm{~mm}^{3}$ ) was placed on a mylar loop in oil and mounted on a Bruker APEX II area detector diffractometer at $100 \mathrm{~K}$. The data collection was carried out using $\mathrm{MoK}_{\alpha}$ radiation (TRIUMPH monochromator, sealed X-ray tube, 45kV, 30mA), with a frame time of 2 seconds and a detector distance of $40 \mathrm{~mm}$. A collection strategy was calculated 
and complete data to a resolution of $0.65 \AA$ with a redundancy of 5 were collected. The frames were integrated with the Bruker SAINT $^{3}$ software package using a narrow-frame algorithm. The integration of the data using a monoclinic unit cell yielded a total of 61516 reflections to a maximum $\theta$ angle of $33.18^{\circ}$ (0.65 Å resolution), of which 12283 were independent (average redundancy 5.008, completeness $=99.8 \%$, Rint $=7.04 \%$, Rsig $=5.59 \%)$ and $9268(75.45 \%)$ were greater than $2 \sigma(F 2)$.

The final cell constants of $a=19.161(8) \AA, b=8.604(3) \AA, c=19.566(8) \AA, \beta=93.660(11)^{\circ}$, volume $=$ 3219.(2) $\AA^{3}$, are based upon the refinement of the XYZ-centroids of reflections above $20 \sigma(\mathrm{I})$. Data were corrected for absorption effects using the Multi-Scan method (SADABS). ${ }^{4}$ The calculated minimum and maximum transmission coefficients (based on crystal size) are 0.5767 and 0.7465 .

\section{Structure solution and refinement}

The space group P 1 2 1 / c 1 was determined based on intensity statistics and systematic absences. The structure was solved using the SHELX ${ }^{5,6}$ suite of programs and refined using full-matrix leastsquares on $\mathrm{F}^{2}$ within the OLEX $2^{7}$ suite. An intrinsic phasing solution was calculated, which provided most non-hydrogen atoms from the E-map. Full-matrix least squares / difference Fourier cycles were performed, which located the remaining non-hydrogen atoms. All non-hydrogen atoms were refined with anisotropic displacement parameters. The hydrogen atoms were placed in ideal positions and refined as riding atoms with relative isotropic displacement parameters. The final full matrix least squares refinement converged to $\mathrm{R} 1=0.0319$ and $\mathrm{wR} 2=0.0652$ (F2, all data). The goodness-of-fit was 1.009. On the basis of the final model, the calculated density was $1.925 \mathrm{~g} / \mathrm{cm}^{3}$ and $\mathrm{F}(000), 1832$ e- Disorder was modelled on the crown ether and on a pyridine ring, by modelling two parts with occupancies $0.549(3)$ and $0.451(3)$. Restraints on bond lengths, and constraints on atomic displacement parameters were employed. CCDC Deposition Number: 2087659 


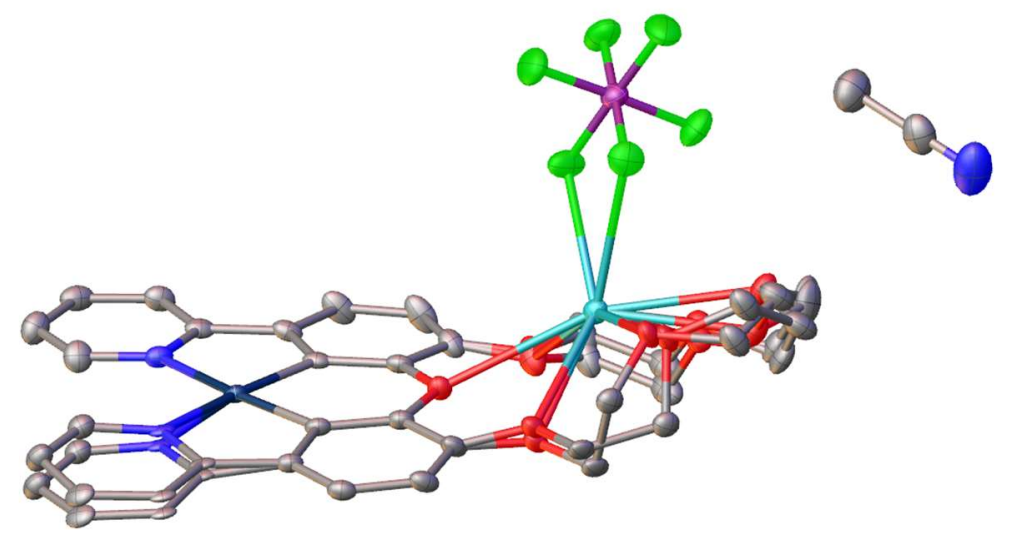

Figure S45. Molecular structure of 18C6-PtII $\supset \mathrm{KPF}_{6}$ as determined by SCXRD. Ellipsoids are plotted at 50\% probability level. Hydrogen atoms omitted for clarity.

\section{C6-PtII $\supset \mathrm{NaBF}_{4}(\mathrm{~mm} 435)$}

\section{Data collection}

An orange crystal (plate, approximate dimensions $0.27 \times 0.10 \times 0.09 \mathrm{~mm}^{3}$ ) was placed on a mylar loop in oil and mounted on a Bruker APEX II area detector diffractometer at $100 \mathrm{~K}$. The data collection was carried out using $\mathrm{MoK}_{\alpha}$ radiation (TRIUMPH monochromator, sealed X-ray tube, 45kV, 30mA), with a frame time of 10 seconds and a detector distance of $40 \mathrm{~mm}$. A collection strategy was calculated and complete data to a resolution of $0.77 \AA ̊$ with a redundancy of 3.4 were collected. The frames were integrated with the Bruker SAINT ${ }^{3}$ software package using a narrow-frame algorithm. The integration of the data using a monoclinic unit cell yielded a total of 21072 reflections to a maximum $\theta$ angle of $27.58^{\circ}(0.77 \AA$ resolution), of which 6258 were independent (average redundancy 3.367, completeness $=99.2 \%$, Rint $=8.86 \%$, Rsig $=10.01 \%)$ and $4249(67.90 \%)$ were greater than $2 \sigma\left(F^{2}\right)$. The final cell constants of $a=17.807(3) \AA, b=8.8703(16) \AA, c=17.810(3) \AA, \beta=$ $104.666(5)^{\circ}$, volume $=2721.5(8) \AA^{3}$, are based upon the refinement of the XYZ-centroids of reflections above $20 \sigma(\mathrm{I})$. Data were corrected for absorption effects using the Multi-Scan method (SADABS). ${ }^{4}$ The calculated minimum and maximum transmission coefficients (based on crystal size) are 0.5751 and 0.7456 .

\section{Structure solution and refinement}

The space group P 1 2 1 /c 1 was determined based on intensity statistics and systematic absences. The structure was solved using the SHELX ${ }^{5,6}$ suite of programs and refined using full-matrix leastsquares on $\mathrm{F}^{2}$ within the OLEX2 ${ }^{7}$ suite. An intrinsic phasing solution was calculated, which provided 
most non-hydrogen atoms from the E-map. Full-matrix least squares / difference Fourier cycles were performed, which located the remaining non-hydrogen atoms. All non-hydrogen atoms were refined with anisotropic displacement parameters. The hydrogen atoms were placed in ideal positions and refined as riding atoms with relative isotropic displacement parameters. The final full matrix least squares refinement converged to $\mathrm{R} 1=0.0456$ and $w R 2=0.1070\left(\mathrm{~F}^{2}\right.$, all data). The goodness-of-fit was 0.998 . On the basis of the final model, the calculated density was $1.995 \mathrm{~g} / \mathrm{cm}^{3}$ and $\mathrm{F}(000), 1600$ e-. CCDC Deposition Number: 2087660

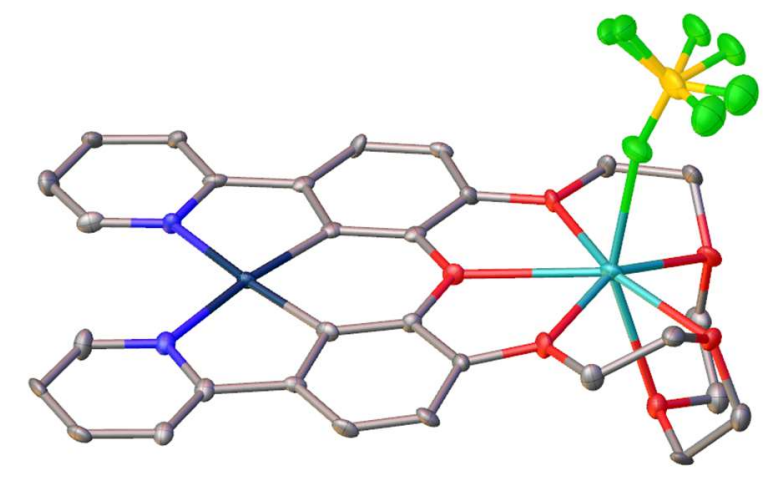

Figure S46. Molecular structure of 18C6- $\mathrm{Pt}^{\mathrm{II}} \supset \mathrm{NaBF}_{4}$ as determined by SCXRD. Ellipsoids are plotted at 50\% probability level. Hydrogen atoms omitted for clarity.

\section{C6-PtII $\supset \mathrm{Ca}(\mathrm{OTf})_{2}(\mathrm{~mm} 532)$}

\section{Data Collection}

A yellow needle-shaped crystal with dimensions $0.27 \times 0.08 \times 0.03 \mathrm{~mm}^{3}$ was mounted on a mylar loop in oil. Data were collected using a Bruker APEX II area detector diffractometer equipped with an Oxford Cryosystems low-temperature device operating at $T=110(2) \mathrm{K}$. Data were measured using $\omega$ and $\phi$ scans of $0.5^{\circ}$ per frame for $30 \mathrm{~s}$ using $\mathrm{MoK}_{\alpha}$ radiation (TRIUMPH monochromator, sealed X-ray tube, $45 \mathrm{kV}, 30 \mathrm{~mA}$ ). The total number of runs and images was based on the strategy calculation from the program APEX3. The maximum resolution that was achieved was $\Theta=26.383^{\circ}$ $(0.80 \AA ̊)$. The unit cell was refined using SAINT³ (Bruker, V8.40B, after 2013) on 9942 reflections, 9\% of the observed reflections. Data reduction, scaling and absorption corrections were performed using SAINT ${ }^{3}$ (Bruker, V8.40B, after 2013). The final completeness is $99.90 \%$ out to $26.383^{\circ}$ in $\Theta$. A multi-scan absorption correction was performed using SADABS-2016/24 (Bruker, 2016/2) was used for absorption correction. $w R_{2}$ (int) was 0.0556 before and 0.0485 after correction. The ratio of minimum to maximum transmission is 0.7581 . The $\lambda / 2$ correction factor is not present. The 
absorption coefficient $\mu$ of this material is $4.024 \mathrm{~mm}^{-1}$ at this wavelength $(\lambda=0.71073 \AA)$ and the minimum and maximum transmissions are 0.672 and 0.886.

\section{Structure Solution and Refinement}

The structure was solved and the space group P-1 (\# 2) determined by the $\mathbf{X T}^{5}$ (Sheldrick, 2015) structure solution program using Intrinsic Phasing methods and by using 0lex $2^{7}$ as the graphical interface. The model was refined by full matrix least squares minimisation on $\boldsymbol{F}^{2}$ using version 2018/3 of $\mathbf{X L}^{8}$ (Sheldrick, 2015). The material crystallizes with four Pt complexes in the asymmetric unit, in addition to 3.6 molecules of solvent ACN. One solvent molecule site is only partially occupied. Finally, one triflate anion, coordinated to $\mathrm{Ca}(3)$, is disordered and was modeled in two orientations. RIGU and DELU commands were used with each complex to maintain reasonable ADPs for all atoms. All non-hydrogen atoms were refined anisotropically. Hydrogen atom positions were calculated geometrically and refined using the riding model. The value of $\mathrm{Z}^{\prime}$ is 4. CCDC Deposition Number:

\section{2.}

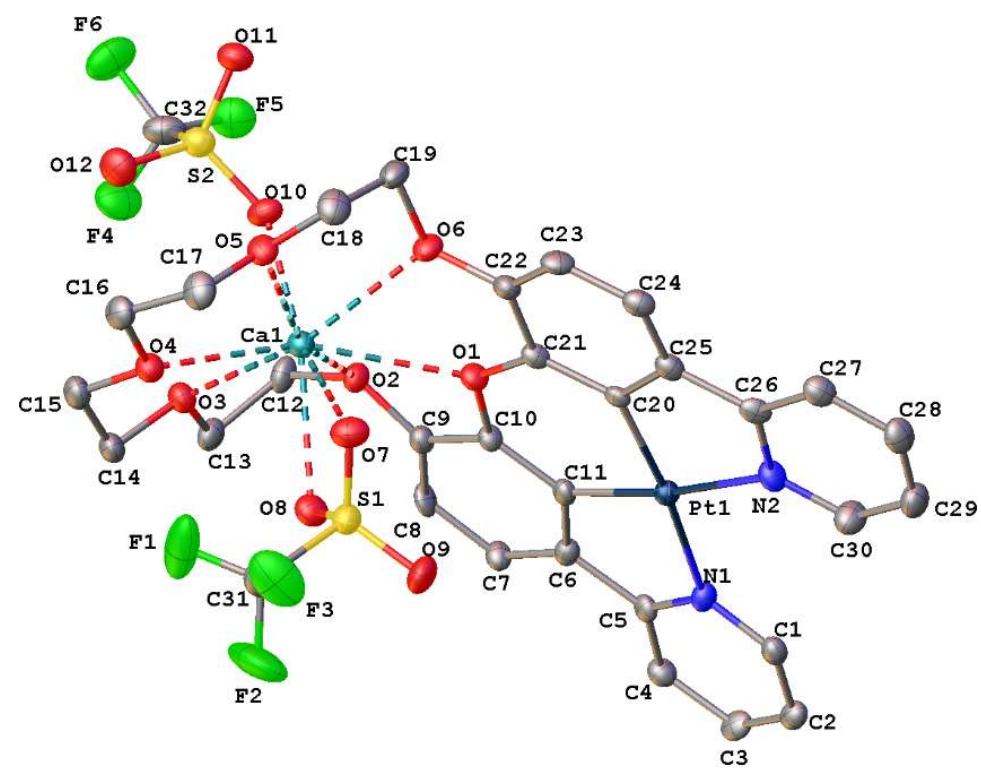

Figure S47. ORTEP-style image of the first Pt complex. Solvent and hydrogen atoms removed for clarity. 


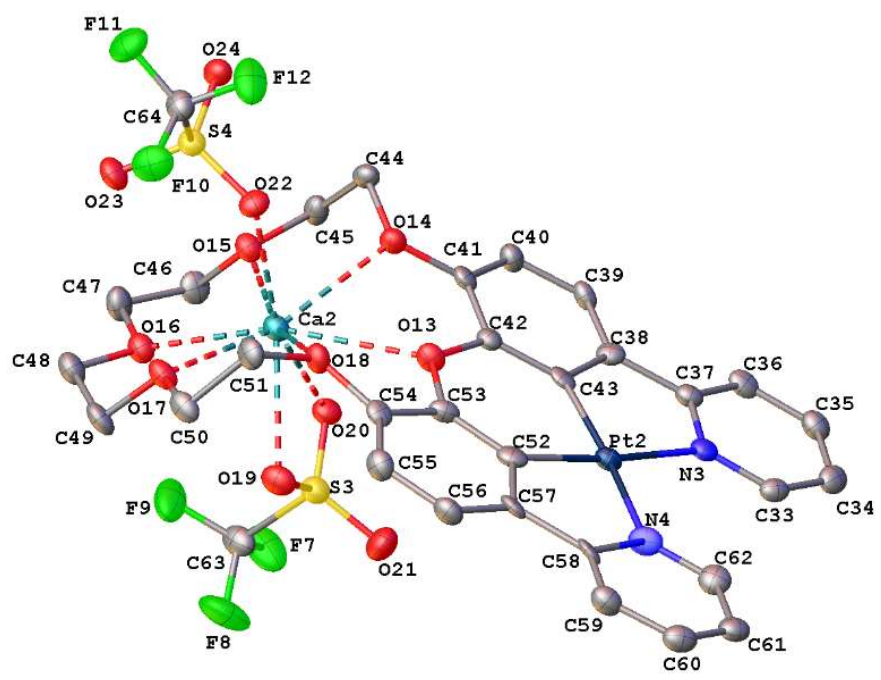

Figure S48. ORTEP-style image of the second Pt complex. Solvent and hydrogen atoms removed for clarity.

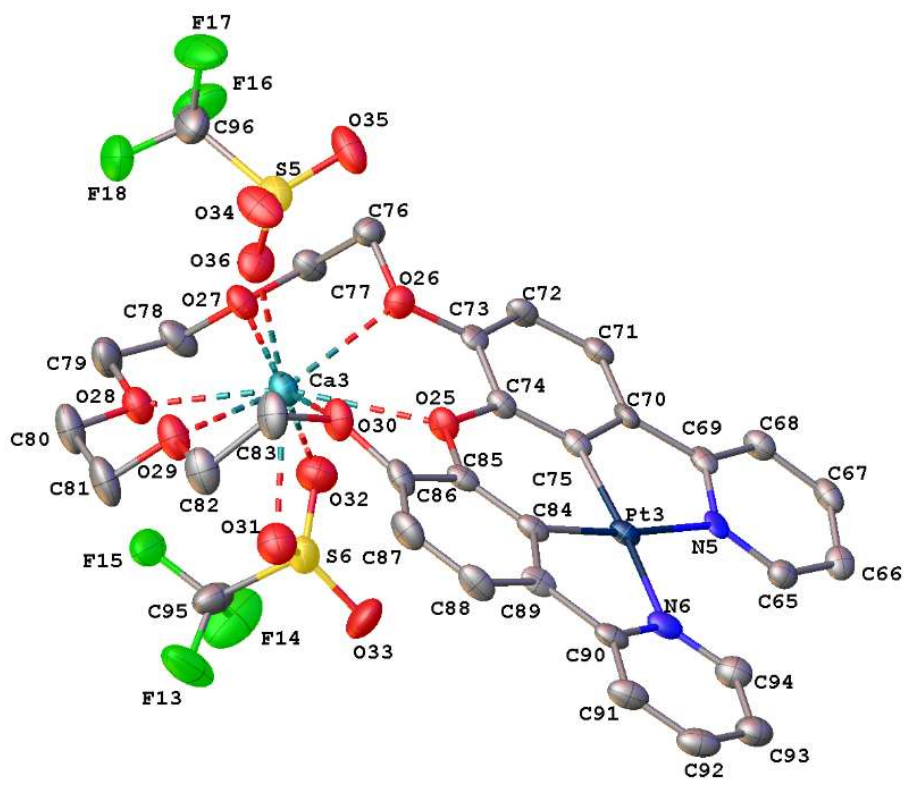

Figure S49. ORTEP-style image of the third Pt complex. Solvent and hydrogen atoms removed for clarity. 


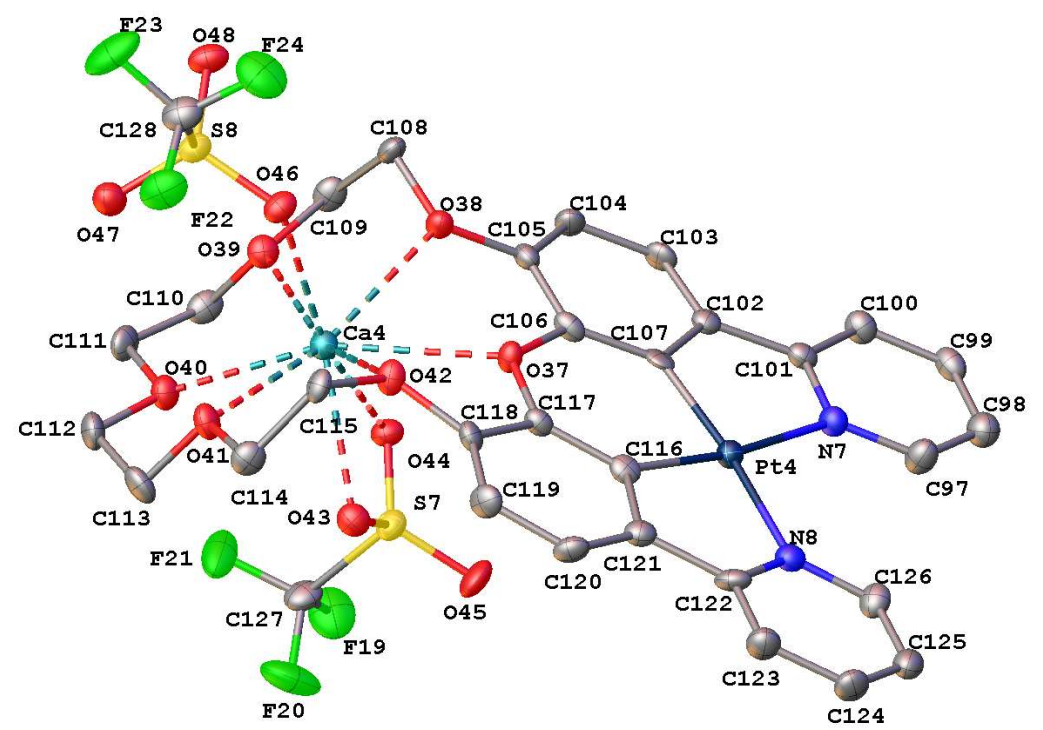

Figure S50. ORTEP-style image of the fourth Pt complex. Solvent and hydrogen atoms removed for clarity.

\section{C6-PtII $\supset \mathrm{RbBPh}_{4}$ (mo_mm496_0m)}

\section{Data Collection}

An orange plate-shaped crystal with dimensions $0.10 \times 0.07 \times 0.02 \mathrm{~mm}^{3}$ was mounted on a mylar loop in oil. Data were collected using a Bruker APEX II area detector diffractometer equipped with an Oxford Cryosystems low-temperature device operating at $T=90(2) \mathrm{K}$. Data were measured using $\omega$ and $\phi$ scans of $0.5^{\circ}$ per frame for $60 \mathrm{~s}$ using $\mathrm{MoK}_{\alpha}$ radiation (TRIUMPH monochromator, sealed Xray tube, $45 \mathrm{kV}, 30 \mathrm{~mA}$ ). The total number of runs and images was based on the strategy calculation from the program APEX3. The maximum resolution that was achieved was $\Theta=25.420^{\circ}(0.83 \AA)$. The unit cell was refined using SAINT ${ }^{3}$ (Bruker, V8.40A, after 2013) on 9786 reflections, 23\% of the observed reflections. Data reduction, scaling and absorption corrections were performed using SAINT $^{3}$ (Bruker, V8.40A, after 2013). The final completeness is $100.00 \%$ out to $25.420^{\circ}$ in $\Theta$. A multiscan absorption correction was performed using SADABS-2016/24 (Bruker, 2016/2) was used for absorption correction. $w R_{2}$ (int) was 0.0750 before and 0.0584 after correction. The ratio of minimum to maximum transmission is 0.8773 . The $\lambda / 2$ correction factor is not present. The absorption coefficient $\mu$ of this material is $4.334 \mathrm{~mm}^{-1}$ at this wavelength $(\lambda=0.71073 \AA)$ and the minimum and maximum transmissions are 0.804 and 0.917 . 


\section{Structure Refinement and Solution}

The structure was solved and the space group $C 2$ (\# 5) determined by the $\mathbf{X T}^{5}$ (Sheldrick, 2015) structure solution program using Intrinsic Phasing methods and by using Olex2 ${ }^{7}$ as the graphical interface. The model was refined by full matrix least squares minimisation on $\boldsymbol{F}^{2}$ using version 2018/3 of $\mathbf{X L}^{8}$ (Sheldrick, 2015). One of the heterocyclic rings is disordered and was modeled in two orientations. Additionally, there are two half-occupied tetraphenylborate anions in the asymmetric unit. Both of these are disordered about different 2 -fold rotation axes in the unit cell. This disorder allows for the presence of solvent acetonitrile in the lattice. In total there appear to be three complete ACN molecules in the asymmetric unit. All non-hydrogen atoms were refined anisotropically. Hydrogen atom positions were calculated geometrically and refined using the riding model. The Flack parameter was refined to $-0.008(4)$ (Parsons, 2013). ${ }^{9}$ Determination of absolute structure using Bayesian statistics on Bijvoet differences using the Olex2 results in -0.006(4). CCDC Deposition Number: 2087664.

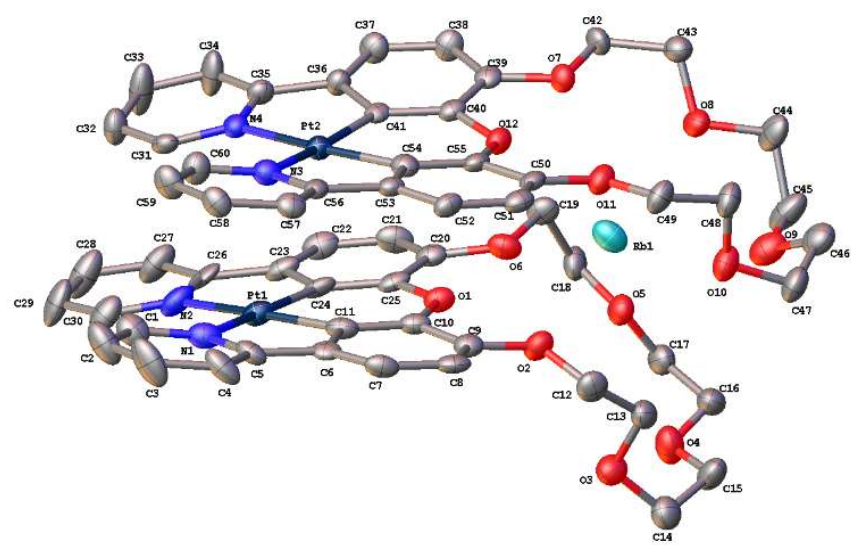

Figure S51. Molecular Structure of 18C6-PtII $\supset$ RbBPh4 as determined by SCXRD. Ellipsoids are plotted at 50\% probability level. Hydrogen atoms are omitted for clarity.

\section{C6-PtII (MeCN solvate, mm524)}

\section{Data Collection}

An orange irregular-shaped crystal with dimensions $0.12 \times 0.11 \times 0.02 \mathrm{~mm}^{3}$ was mounted on a mylar loop in oil. Data were collected using a Bruker APEX II area detector diffractometer equipped with an Oxford Cryosystems low-temperature device operating at $T=110(2) \mathrm{K}$. Data were measured using $\omega$ and $\phi$ scans of $0.5^{\circ}$ per frame for $20 \mathrm{~s}$ using $\mathrm{MoK}_{\alpha}$ radiation (TRIUMPH monochromator, sealed X-ray tube, $45 \mathrm{kV}, 30 \mathrm{~mA}$ ). The total number of runs and images was based on the strategy 
calculation from the program APEX3. The maximum resolution that was achieved was $\Theta=26.448^{\circ}$ $(0.80 \AA ̊)$. The unit cell was refined using SAINT ${ }^{3}$ (Bruker, V8.40B, after 2013) on 9977 reflections, $31 \%$ of the observed reflections. Data reduction, scaling and absorption corrections were performed using SAINT ${ }^{3}$ (Bruker, V8.40B, after 2013). The final completeness is $100.00 \%$ out to $26.448^{\circ}$ in $\Theta$. A multi-scan absorption correction was performed using SADABS-2016/24 (Bruker, 2016/2) was used for absorption correction. $w R_{2}$ (int) was 0.0712 before and 0.0466 after correction. The ratio of minimum to maximum transmission is 0.7746 . The $\lambda / 2$ correction factor is not present. The absorption coefficient $\mu$ of this material is $4.643 \mathrm{~mm}^{-1}$ at this wavelength $(\lambda=0.71073 \AA)$ and the minimum and maximum transmissions are 0.706 and 0.911.

\section{Structure Refinement and Solution}

The structure was solved and the space group $P 2_{1}$ /c (\# 14) determined by the $\mathbf{X T}^{5}$ 2018/2 (Sheldrick, 2015) structure solution program using Intrinsic Phasing methods and by using Olex $2^{7}$ as the graphical interface. The model was refined by full matrix least squares minimisation on $\boldsymbol{F}^{2}$ using version 2018/3 of $\mathbf{X L}^{8}$ (Sheldrick, 2015). The material crystallizes with two molecules of solvent acetonitrile in the asymmetric unit. One ACN molecule is disordered and is modeled in two orientations. All non-hydrogen atoms were refined anisotropically. Hydrogen atom positions were calculated geometrically and refined using the riding model. CCDC Deposition Number: 2087663.

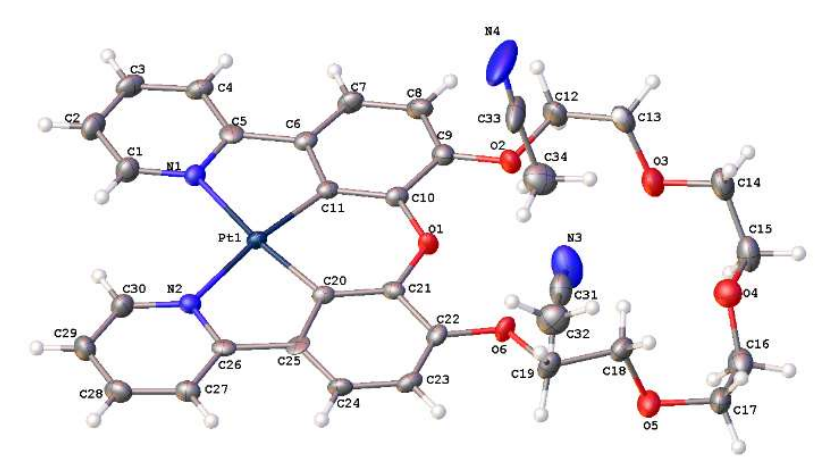

Figure S52. Molecular structure of 18C6-PtII (MeCN solvate) as determined by SCXRD. Ellipsoids are plotted at 50\% probability level. 
Table S2. Crystal data and structure refinement for 18C6-PtIV , 18C6-PtII (DCM solvate), 18C6-PtII つ KPF6, and 18C6$\mathrm{Pt} I \mathrm{II} \supset \mathrm{NaBF}_{4}$.

\begin{tabular}{|c|c|c|c|c|}
\hline Compound & $18 \mathrm{C} 6-\mathrm{Pt} \mathrm{t}^{\mathrm{IV}}$ & $\begin{array}{l}\text { 18C6-PtII } \\
\text { (DCM solvate) }\end{array}$ & 18C6-PtII د $\mathrm{KPF}_{6}$ & 18C6-PtII $\supset \mathrm{NaBF}_{4}$ \\
\hline Formula & $\mathrm{C}_{31} \mathrm{H}_{30} \mathrm{Cl}_{4} \mathrm{~N}_{2} \mathrm{OPt}$ & $\mathrm{C}_{31} \mathrm{H}_{30} \mathrm{Cl}_{2} \mathrm{~N}_{2} \mathrm{O}_{6} \mathrm{Pt}$ & $\mathrm{C}_{32} \mathrm{H}_{31} \mathrm{~F}_{6} \mathrm{KN}_{3} \mathrm{O}_{6} \mathrm{PPt}$ & $\begin{array}{l}\mathrm{C}_{30} \mathrm{H}_{28} \mathrm{BF}_{4} \mathrm{~N}_{2} \mathrm{NaO}_{6} \\
\mathrm{Pt}\end{array}$ \\
\hline$D_{\text {calc. }} / \mathrm{g} \mathrm{cm}^{-3}$ & 1.886 & 1.855 & 1.925 & 1.995 \\
\hline$\mu / \mathrm{mm}^{-1}$ & 5.015 & 5.181 & 4.624 & 5.251 \\
\hline Formula Weight & 863.46 & 792.56 & 932.76 & 817.43 \\
\hline Colour & Yellow & Orange & Orange & Orange \\
\hline Shape & Plate & Plate & Plate & Plate \\
\hline Size $/ \mathrm{mm}^{3}$ & $0.70 \times 0.23 \times 0.16$ & $0.14 \times 0.07 \times 0.06$ & $0.36 \times 0.13 \times 0.12$ & $0.27 \times 0.10 \times 0.09$ \\
\hline$T / \mathrm{K}$ & $100 \mathrm{~K}$ & $100 \mathrm{~K}$ & $100 \mathrm{~K}$ & $100 \mathrm{~K}$ \\
\hline Crystal System & Orthorhombic & Monoclinic & Monoclinic & Monoclinic \\
\hline Space Group & $\operatorname{Pna}_{1}$ & $P 2_{1} / c$ & $P 2_{1} / c$ & $P 2_{1} / c$ \\
\hline$a / \AA$ & $26.395(5)$ & $18.024(4)$ & $19.161(8)$ & $17.807(3)$ \\
\hline$b / \AA$ & $8.1629(12)$ & $9.985(2)$ & $8.604(3)$ & $8.8703(16)$ \\
\hline$c / \AA$ & $14.113(2)$ & $16.307(3)$ & $19.566(8)$ & $17.810(3)$ \\
\hline$\alpha /^{\circ}$ & 90 & 90 & 90 & 90 \\
\hline$\beta /^{\circ}$ & 90 & $104.715(6)$ & $93.660(11)$ & $104.666(5)$ \\
\hline$\gamma /^{\circ}$ & 90 & 90 & 90 & 90 \\
\hline $\mathrm{V} / \AA^{3}$ & $3040.8(8)$ & $2838.6(10)$ & $3219(2)$ & $2721.5(8)$ \\
\hline$Z$ & 4 & 4 & 4 & 4 \\
\hline$Z^{\prime}$ & 1 & 1 & 1 & 1 \\
\hline Wavelength/Å & 0.71073 & 0.71073 & 0.71073 & 0.71073 \\
\hline Radiation type & $\operatorname{MoK}_{\alpha}$ & $\mathrm{MoK}_{\alpha}$ & $\operatorname{MoK}_{\alpha}$ & $\mathrm{MoK}_{\alpha}$ \\
\hline$\Theta_{\min } /^{\circ}$ & 1.543 & 2.337 & 2.086 & 1.182 \\
\hline$\Theta_{\max } /^{\circ}$ & 27.544 & 27.504 & 33.176 & 27.580 \\
\hline Measured Refl's. & 38312 & 19800 & 61516 & 21072 \\
\hline Indep't Refl's & 6885 & 6488 & 12283 & 6258 \\
\hline
\end{tabular}




$\begin{array}{lllll}\text { Refl's I } \geq 2 \sigma(\mathrm{I}) & 6008 & 4393 & 9268 & 4249 \\ R_{\text {int }} & 0.0358 & 0.0728 & 0.0704 & 0.0886 \\ \text { Parameters } & 436 & 353 & 498 & 386 \\ \text { Restraints } & 27 & 377 & 48 & 3 \\ \text { Largest Peak } & 1.712 & 2.238 & 2.261 & 3.383 \\ \text { Deepest Hole } & -2.008 & -1.432 & -1.044 & -1.445 \\ \text { GooF } & 1.070 & 0.980 & 1.009 & 0.998 \\ w R_{2} \text { (all data) } & 0.0764 & 0.0928 & 0.0652 & 0.1070 \\ w R_{2} & 0.0728 & 0.0797 & 0.0585 & 0.0903 \\ R_{1} \text { (all data) } & 0.0419 & 0.0842 & 0.0552 & 0.0895 \\ R_{1} & 0.0332 & 0.0410 & 0.0319 & 0.0456\end{array}$


Table S3. Crystal data and structure refinement for 18C6-PtII $\supset$ Ca(OTf) $2,18 C 6-\mathrm{Pt}^{\mathrm{II}} \supset \mathrm{RbBPh}_{4}, 18 \mathrm{C} 6-\mathrm{Pt}^{\mathrm{II}}(\mathrm{MeCN}$ solvate).

\begin{tabular}{|c|c|c|c|c|}
\hline Compound & $18 \mathrm{C} 6-\mathrm{H}_{2}$ & 18C6-PtII $\supset \mathrm{Ca}(\mathrm{OTf})_{2}$ & 18C6-PtII $\supset \mathrm{RbBPh}_{4}$ & $\begin{array}{l}\text { 18C6-PtII } \\
\text { (MeCN solvate) }\end{array}$ \\
\hline Formula & $\mathrm{C}_{30} \mathrm{H}_{32} \mathrm{~N}_{2} \mathrm{O}_{7}$ & $\mathrm{C}_{33.8} \mathrm{H}_{30.7} \mathrm{CaF}_{6} \mathrm{~N}_{2.9} \mathrm{O}_{12} \mathrm{PtS}_{2}$ & $\mathrm{C}_{90} \mathrm{H}_{85} \mathrm{BN}_{7} \mathrm{O}_{12} \mathrm{Pt}_{2} \mathrm{Rb}$ & $\mathrm{C}_{34} \mathrm{H}_{34} \mathrm{~N}_{4} \mathrm{O}_{6} \mathrm{Pt}$ \\
\hline$D_{\text {calc. }} / \mathrm{g} \mathrm{cm}^{-3}$ & 1.346 & 1.888 & 1.678 & 1.716 \\
\hline$\mu / \mathrm{mm}^{-1}$ & 0.096 & 4.024 & 4.334 & 4.643 \\
\hline Formula Weight & 532.57 & 1082.80 & 1943.10 & 789.74 \\
\hline Colour & colourless & yellow & orange & orange \\
\hline Shape & plate & needle & plate & irregular \\
\hline $\mathrm{Size} / \mathrm{mm}^{3}$ & $0.65 \times 0.42 \times 0.23$ & $0.27 \times 0.08 \times 0.03$ & $0.10 \times 0.07 \times 0.02$ & $0.12 \times 0.11 \times 0.02$ \\
\hline$T / \mathrm{K}$ & 100 & $110(2)$ & $90(2)$ & $110(2)$ \\
\hline Crystal System & monoclinic & triclinic & monoclinic & monoclinic \\
\hline Flack Parameter & n.a. & n.a. & $-0.008(4)$ & n.a. \\
\hline Hooft Parameter & n.a. & n.a. & $-0.006(4)$ & n.a. \\
\hline Space Group & $P 2_{1} / n$ & $P-1$ & $C 2$ & $P 2_{1} / c$ \\
\hline$a / \AA$ & $7.3610(3)$ & $9.9279(6)$ & $44.823(12)$ & $18.9441(4)$ \\
\hline$b / \AA$ & $25.5081(9)$ & $17.7918(11)$ & $15.826(4)$ & $9.4065(2)$ \\
\hline$c / \AA$ & $14.0025(5)$ & $43.409(3)$ & $11.145(2)$ & $17.1603(4)$ \\
\hline$\alpha /^{\circ}$ & 90 & $85.6500(10)$ & 90 & 90 \\
\hline$\beta 1^{\circ}$ & $91.535(2)$ & $86.2330(10)$ & 103.399(9) & $91.4000(10)$ \\
\hline$\gamma /^{\circ}$ & 90 & $86.6070(10)$ & 90 & 90 \\
\hline $\mathrm{V} / \AA^{3}$ & $2628.24(17)$ & $7617.7(8)$ & 7691(3) & $3057.01(12)$ \\
\hline$Z$ & 4 & 8 & 4 & 4 \\
\hline$Z^{\prime}$ & 1 & 4 & 1 & 1 \\
\hline Wavelength/Å & 0.71073 & 0.71073 & 0.71073 & 0.71073 \\
\hline Radiation type & $\operatorname{MoK}_{\alpha}$ & $\mathrm{MoK}_{\alpha}$ & $\mathrm{MoK}_{\alpha}$ & $\mathrm{MoK}_{\alpha}$ \\
\hline$\Theta_{\min } /^{\circ}$ & 2.160 & 1.886 & 1.369 & 2.151 \\
\hline$\Theta_{\max } /^{\circ}$ & 27.541 & 26.383 & 25.420 & 26.448 \\
\hline Measured Refl's. & 31166 & 109986 & 42063 & 32092 \\
\hline Indep't Refl's & 6023 & 30012 & 14096 & 6286 \\
\hline
\end{tabular}




$\begin{array}{lllll}\text { Refl's I } \geq 2 \sigma(\mathrm{I}) & 4947 & 21997 & 11904 & 4735 \\ R_{\text {int }} & 0.0365 & 0.0671 & 0.0551 & 0.0541 \\ \text { Parameters } & 355 & 2188 & 1333 & 421 \\ \text { Restraints } & 0 & 3381 & 2881 & 44 \\ \text { Largest Peak } & 0.286 & 1.438 & 1.031 & 0.918 \\ \text { Deepest Hole } & -0.237 & -2.282 & -0.697 & -0.847 \\ \text { GooF } & 1.022 & 1.048 & 1.005 & 1.011 \\ w R_{2} \text { (all data) } & 0.0989 & 0.0753 & 0.0688 & 0.0473 \\ w R_{2} & 0.0926 & 0.0683 & 0.0643 & 0.0424 \\ R_{1} \text { (all data) } & 0.0499 & 0.0789 & 0.0547 & 0.0431 \\ R_{1} & 0.0392 & 0.0466 & 0.0385 & 0.0232\end{array}$

\section{References}

(1) Soto, M. A.; Carta, V.; Andrews, R. J.; Chaudhry, M. T.; MacLachlan, M. J. Structural Elucidation of Selective Solvatochromism in a Responsive-at-Metal Cyclometalated Platinum(II) Complex. Angew. Chem. Int. Ed. 2020, 59, 10348-10352.

(2) Shirude, P. S.; Kumar, V. A.; Ganesh, K. N. BisPNA Targeting to DNA: Effect of Neutral Loop on DNA Duplex Strand Invasion by AepPNA-N7G/AepPNA-C Substituted Peptide Nucleic Acids. Eur. J. Org. Chem. 2005, 2005, 5207-5215.

(3) SAINT. Bruker Analytical X-Ray Systems: Madison, WI.

(4) SADABS. Bruker Analytical X-Ray Systems: Madison, WI.

(5) Sheldrick, G. M. SHELXT - Integrated Space-Group and Crystal-Structure Determination. Acta Crystallogr. Sect. A Found. Crystallogr. 2015, 71, 3-8.

(6) Sheldrick, G. M. A Short History of SHELX. Acta Crystallogr. Sect. A Found. Crystallogr. 2008, 64, 112-122.

(7) Dolomanov, O. V.; Bourhis, L. J.; Gildea, R. J.; Howard, J. A. K.; Puschmann, H. OLEX2: A Complete Structure Solution, Refinement and Analysis Program. J. Appl. Crystallogr. 2009, 42, 339-341.

(8) Sheldrick, G. M. Crystal Structure Refinement with SHELXL. Acta Crystallogr. Sect. C Struct. Chem. 2015, 71, 3-8.

(9) Parsons, S.; Flack, H. D.; Wagner, T. Use of Intensity Quotients and Differences in Absolute Structure Refinement. Acta Crystallogr. Sect. B Struct. Sci. Cryst. Eng. Mater. 2013, 69, 249-259.

(10) Chan, A. K.-W.; Ng, M.; Low, K. H.; Yam, V. W.-W. Versatile Control of Directed Supramolecular Assembly via Subtle Changes of the Rhodium(I) Pincer Building Blocks. J. Am. Chem. Soc. 2018, 140, 8321-8329 